Florida International University FIU Digital Commons

FIU Electronic Theses and Dissertations

University Graduate School

3-28-1997

\title{
Feature geometry, underspecification and child substitutions
}

Cynthia Williams Core

Florida International University

DOI: $10.25148 /$ etd.FI14061514

Follow this and additional works at: https://digitalcommons.fiu.edu/etd

Part of the Linguistics Commons

\section{Recommended Citation}

Core, Cynthia Williams, "Feature geometry, underspecification and child substitutions" (1997). FIU Electronic Theses and Dissertations. 2517.

https://digitalcommons.fiu.edu/etd/2517

This work is brought to you for free and open access by the University Graduate School at FIU Digital Commons. It has been accepted for inclusion in FIU Electronic Theses and Dissertations by an authorized administrator of FIU Digital Commons. For more information, please contact dcc@fiu.edu. 
FLORIDA INTERNATIONAL UNIVERSITY

Miami, Florida

\title{
FEATURE GEOMETRY, UNDERSPECIFICATION AND CHILD SUBSTITUTIONS
}

\author{
A thesis submitted in partial satisfaction of the \\ requirements for the degree of \\ MASTER OF ARTS \\ IN \\ LINGUISTICS \\ by \\ Cynthia Williams Core
}


To: $\quad$ Arthur W. Herriott

College of Arts and Sciences

This thesis, written by Cynthia Williams Core, and entitled "Feature Geometry, Underspecification and Child Substitutions," having been approved in respect to style and intellectual content, is referred to you for judgement.

We have read this thesis and recommend that it be approved.

Feryal Yavas

Kemp Williams

Mehmet Yavas, Major Professor

Date of Defense: March 28, 1997

The thesis of Cynthia Williams Core is approved.

Dean Arthur W. Herriott

College of Arts and Sciences

Dr. Richard L. Campbell

Dean of Graduate Studies

Florida International University, 1997 
CCOPYRIGHT 1997 by Cynthia Williams Core All rights reserved 


\section{ACKNOWLEDGEMENTS}

I would like to express my most sincere gratitude to my advisor, Dr. Mehmet Yavas, for his help and support with this thesis. Without his encouragement, guidance and inspiration, this project would not have been possible.

Special thanks also go to the other two member of my thesis committee, Dr. Kemp Williams and Dr. Feryal Yavas who cheerfully helped oversee this project.

All three of my committee members graciously and generously gave their time and assistance in this project, providing an excellent example of leadership. I am thankful to have had the opportunity to have been their student. 
ABSTRACT OF THE THESIS

FEATURE GEOMETRY, UNDERSPECIFICATION

AND CHILD SUBSTITUTIONS

by

Cynthia Williams Core

Florida International University, 1997

Miami, Florida

Professor Mehmet Yavas, Major Professor

This thesis looks at two recent developments in phonology, feature geometry and underspecification. Three models for feature geometry (Bernhardt, Halle-Sagey and Clements-Hume) and principles of radical underspecification are studied using previously collected data from child substitutions which reflect normal and unusual substitution processes. The goal of the thesis is to determine the ability of the feature geometry models and underspecification to account for the differences between normal and unusual processes in a principled manner. The findings are that neither feature geometry nor underspecification when used alone provides a complete explanation for the difference between normal and unusual substitution processes. However, by incorporating principles of underspecification into the feature geometry models, the normal and unusual substitutions can be distinguished. Modifications to the feature geometries are recommended based on the findings. 


\section{TABLE OF CONTENTS}

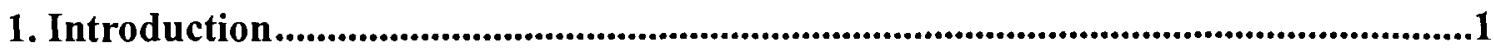

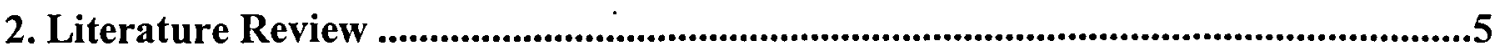

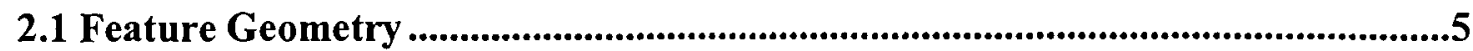

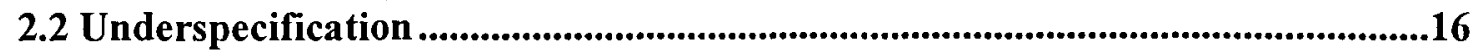

2.3 Phonological Development ......................................................................................22

2.4 Acquisition, Feature Geometry and Underspecification......................................28

2.5 Goal of the Thesis .....................................................................................................................31

3. Analysis of Feature Geometry Models and Substitutions ........................................34

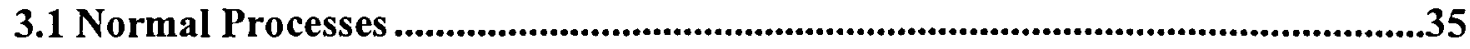

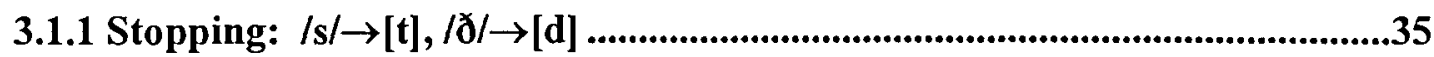

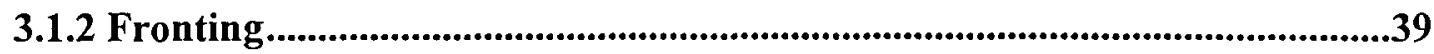

3.1.3 Liquid Gliding: $/ \mathrm{r} / \rightarrow[\mathrm{w}], / \mathrm{V} \rightarrow[\mathrm{j}]$.................................................................44

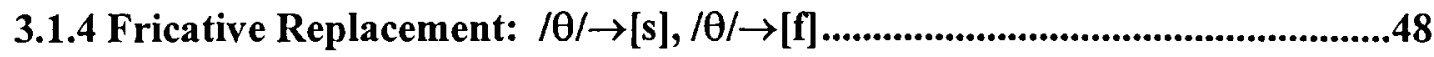

3.1.5 Summary of Normal Processes............................................................................52

3.2 Less Common Substitutions ....................................................................................53

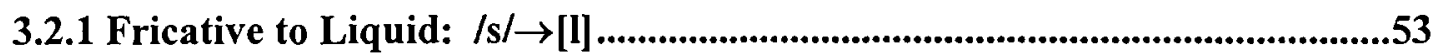

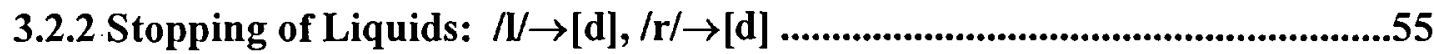

3.2.3 Summary of Less Common Processes ..............................................................59

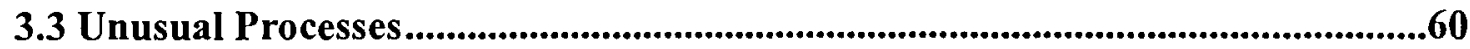

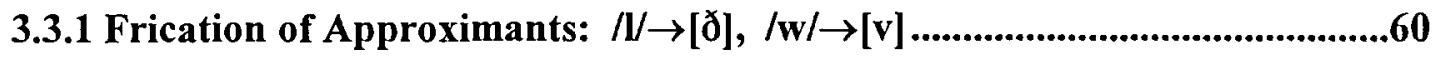

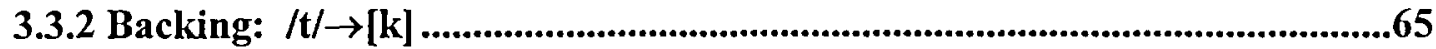

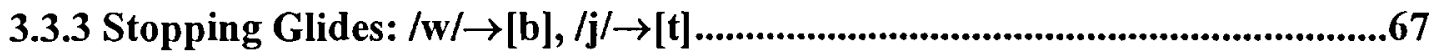

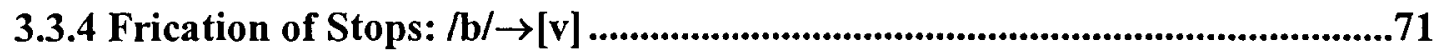

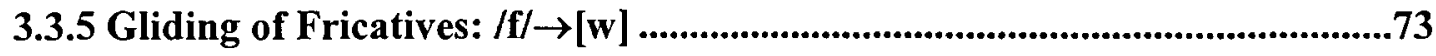

3.3.6 Summary of Unusual Processes ........................................................................75

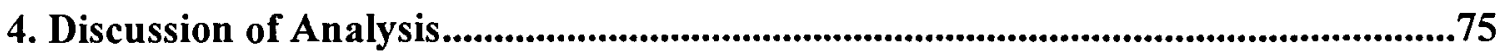

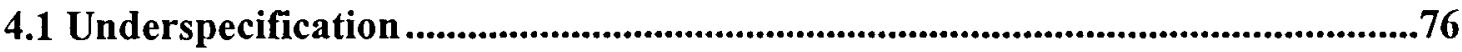

4.2 Feature Geometry Trees .........................................................................................78

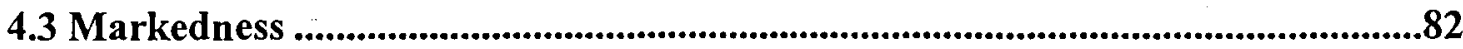

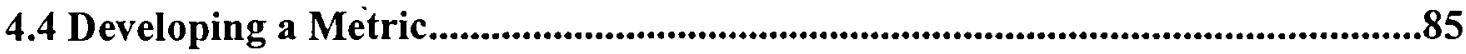

4.5 Data from Normal Phonological Development .......................................................87

4.6 Relationship of Findings to Other Studies ................................................................90

4.7 Redefining the Tree Structure.....................................................................................94

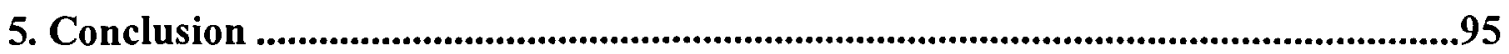




\section{LIST OF TABLES}

Table 1 Underspecification of Adult English Consonants .............................................22

Table 2 Order of Acquisition of Phonemes.......................................................................24

Table 3 Customary Age of Production and Mastery of Consonantal Phonemes......24

Table 4 Age of Disappearance of Processes ...................................................................26

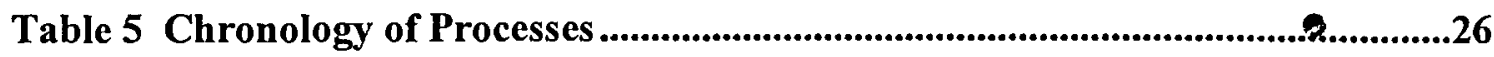




\section{LIST OF FIGURES}

Figure 2.1.a The Halle-Sagey Model of Feature Geometry ...........................................13

Figure 2.1.b The Clements-Hume Model of Feature Geometry ......................................14

Figure 2.1.c The Bernhardt Model of Feature Geometry ................................................16

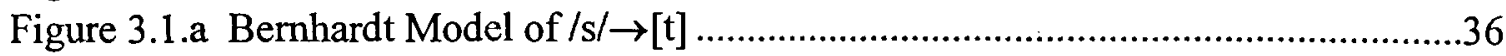

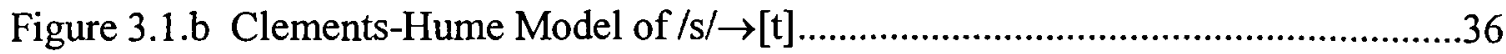

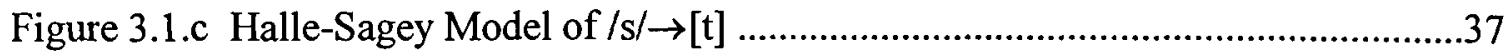

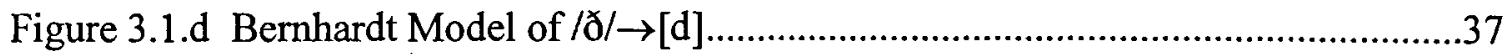

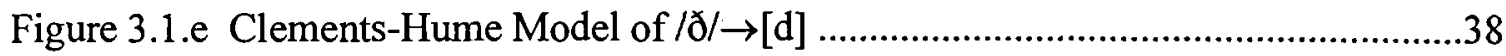

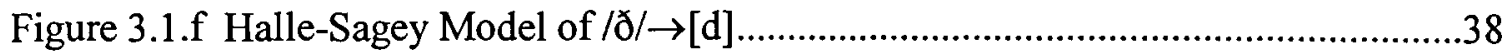

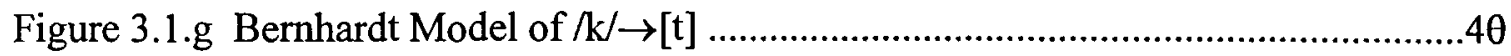

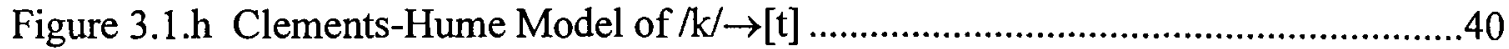

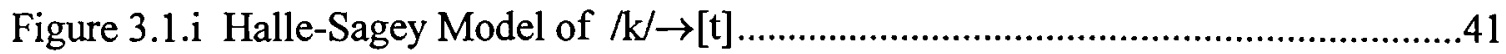

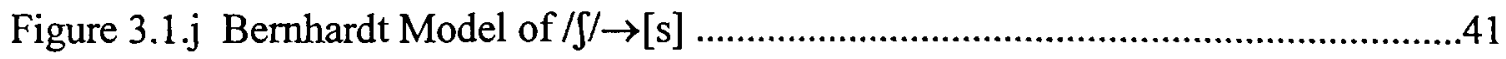

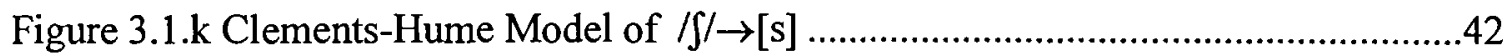

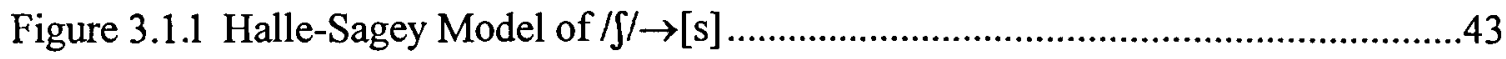

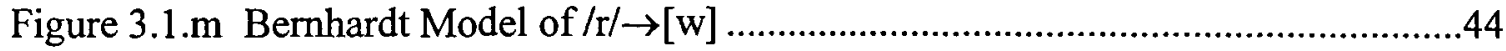

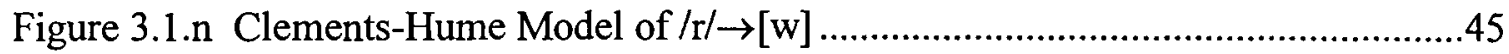

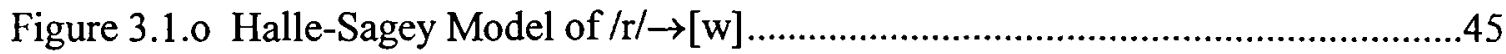

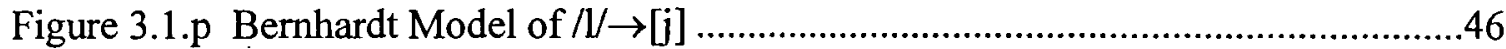

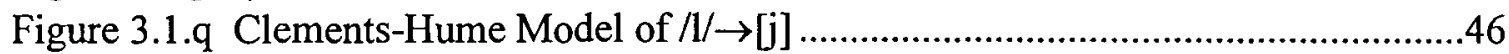

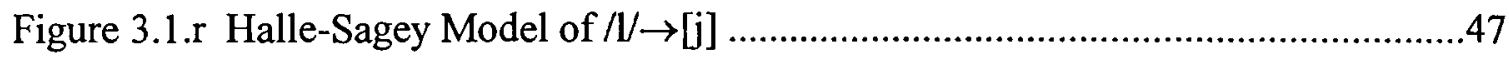

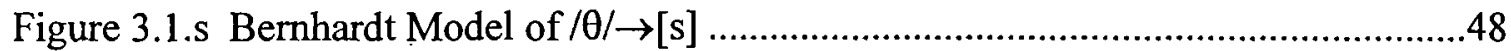

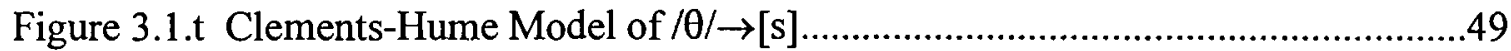

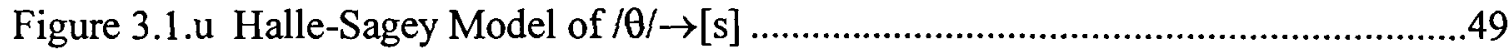

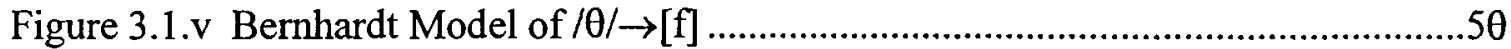

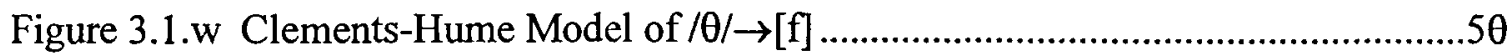

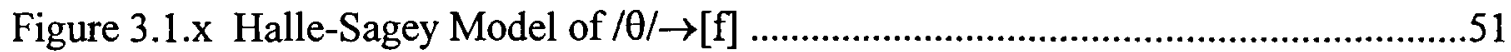

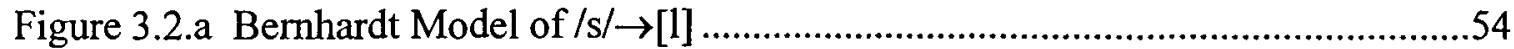

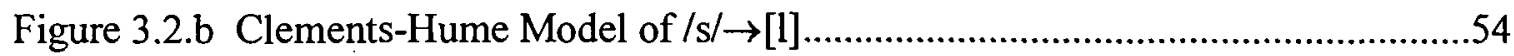

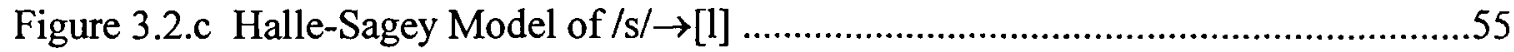

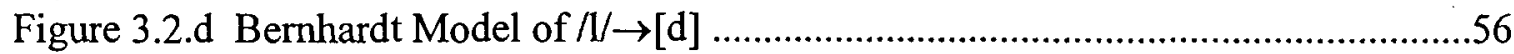

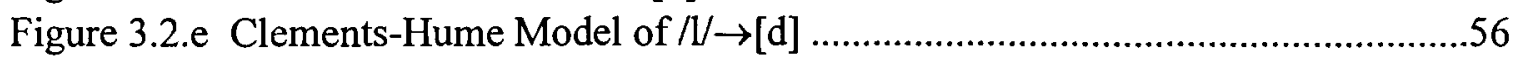

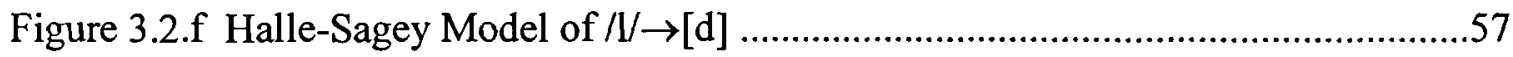

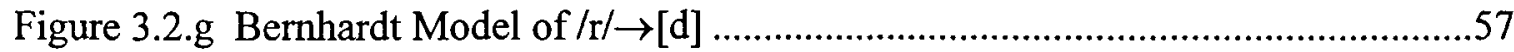

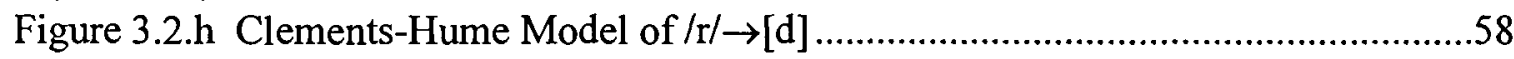

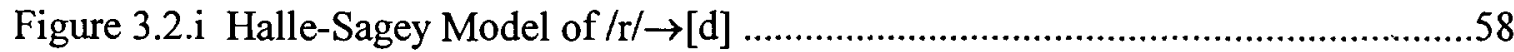

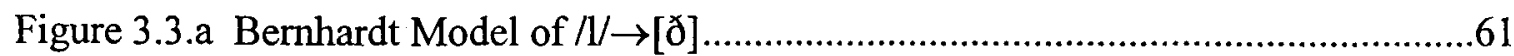

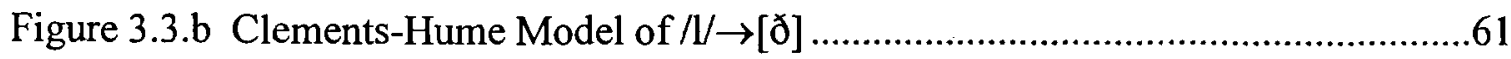




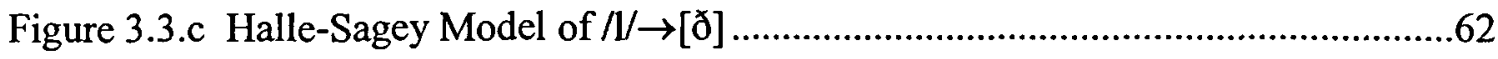

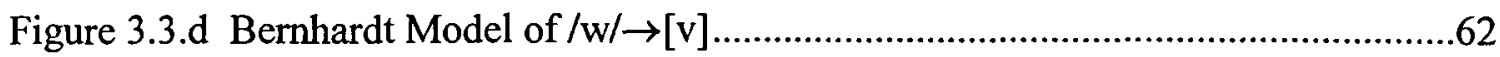

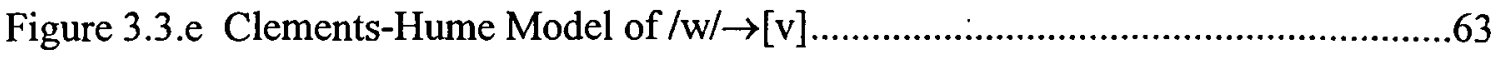

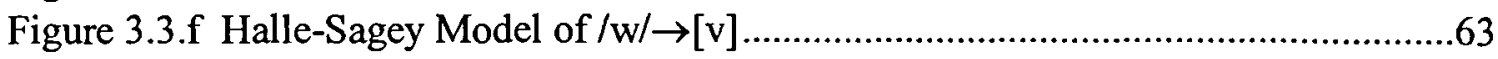

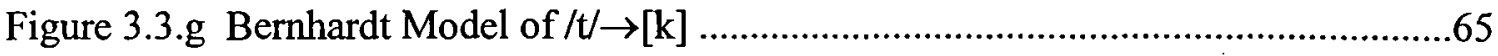

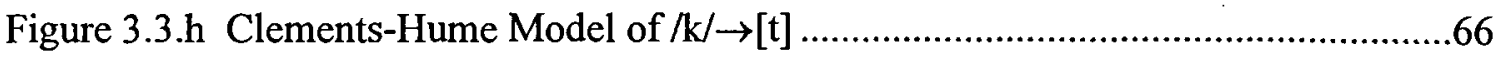

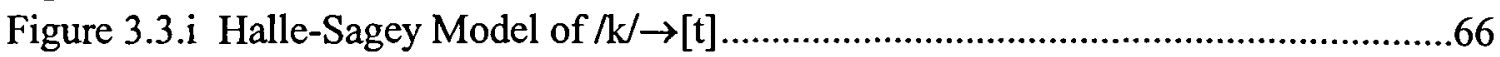

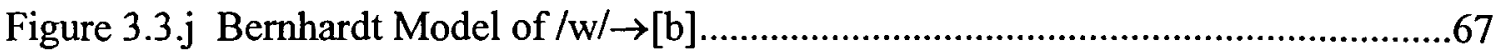

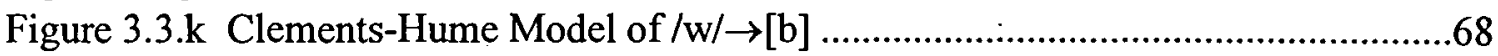

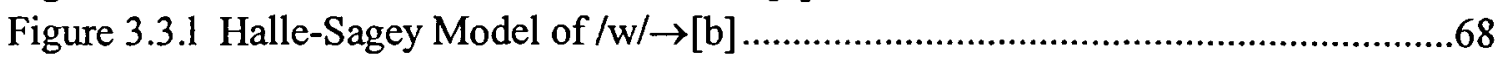

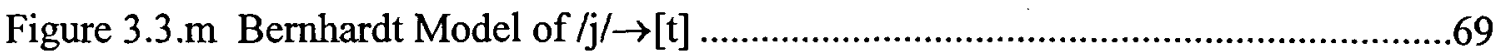

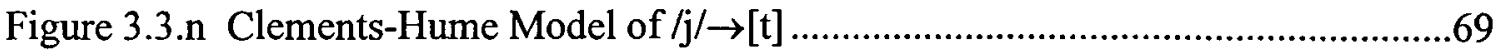

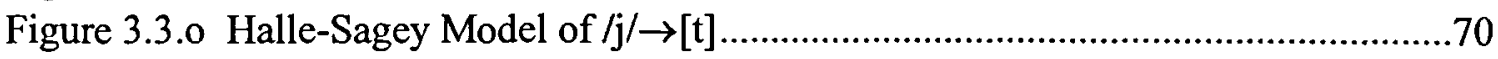

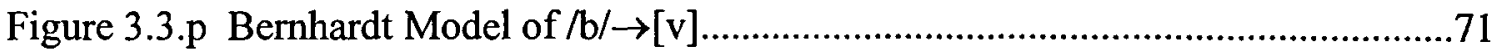

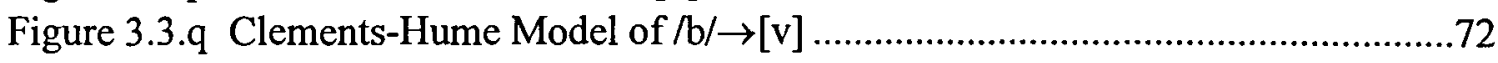

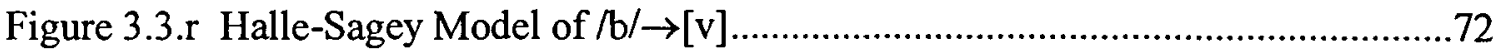

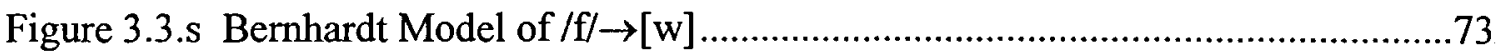

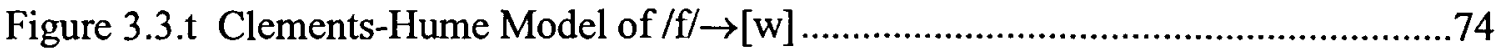

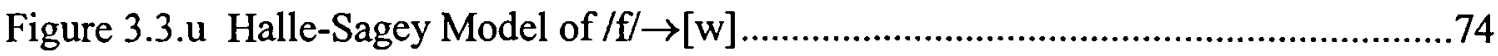




\section{LIST OF SYMBOLS}

SYMBOL

I]
$\rightarrow$
$\mathrm{C}$
$\mathrm{V}$
$\mathrm{N}$
I
$\theta, \partial$
$\int, 3$
$\mathrm{t} \int, \mathrm{d} 3$
$\mathrm{i}$
$\mathrm{I}$
$\mathrm{y}$
$\varnothing$
$\mathrm{y}$
×
$\mathrm{u}$
$\mathrm{u}$

\section{DESCRIPTION}

Indicates Phoneme

Indicates Phonetic Representation

Becomes

Consonant

Vowel

Nasal

In the environment of

Voiceless, Voiced Interdental Fricatives

Voiceless, Voiced Palatal Fricatives

Voiceless, Voiced Alveo-palatal Affricates

High Front Tense Vowel

High Front Lax Vowel

High Front Round Vowel

Mid Front Round Vowel

Velar Nasal

Low Front Lax Vowel

High Back Lax Vowel

High Back Unrounded Vowel 


\section{Introduction}

Linguistic study and knowledge have contributed to the development of speech pathology clinical practice for more than two decades now. Natural Phonology (Stampe 1969) and Generative Phonology (Chomsky \& Halle 1968) were both revolutionary in their effect on phonological remediation (Ingram 1997). As a result of successful application of linguistic theory and research to clinical settings, clinical linguistics is emerging as a field. New developments in linguistic theory must continually be tested and explored for their relevance in application to clinical linguistics and speech pathology.

In spite of the great advances made in phonological intervention as a result of generative phonology and natural phonology, these two theories did not solve all of the problems of dealing with normal and disordered phonological acquisition. Currently, there is no principled way to account for the differences between substitutions that occur in normally-developing children, and the unusual substitutions that occur among the disordered population. In order to find ways to account for normal and disordered patterns in both description and explanation, it is important to continue applying linguistic findings to clinical data and settings.

In recent years, much data on both normal phonological development and phonologically impaired children has been acquired. We have seen that similar to normally-developing children, there is great systematicity in the development of phonologically impaired children. Linguistic models should be able to account for the patterns of development that exist in both normal and disordered phonological systems. 
Two recent developments in the study of phonology are feature geometry and underspecification. These proposals have been applied to phonological remediation and studied by-Bernhardt (1992) and Bernhardt and Gilbert (1992) for their ability to aid in clinical practice. They found that when autosegmental theories of phonology that focus on syllable structure were combined with principles of feature geometry, treatment was successful and efficient. This finding gives an indication that feature geometry and radical underspecification may provide a way to account for differences between normal and disordered phonologies.

Feature geometry is a way of organizing features in a hierarchical dependency relationship that reflects the configuration of the vocal tract and articulators represented by a tree diagram. It allows for broad groupings which have been used in phonetics and phonology such as place, manner and voice, to be associated with individual features such as [coronal] and [sonorant]. Feature geometry rose out of autosegmental phonology, so the representation of a segment can be linked though a series of tiered relationships to the syllable. Currently, there is no one preferred model of feature geometry, though several models have been proposed (Sagey 1986, Clements-Hume 1995, Halle 1992, Bernhardt 1992). All models share some basic features, such as a root node that dominates manner and place nodes. Details of the organization of features and nodes varies from model to model.

Underspecification, particularly radical underspecification proposed by Archangeli (1988), has been proposed to account for the way that children acquire the sounds of a language. In radical underspecification, only those features which are 
responsible for distinguishing one segment for another are present in the underlying representation. Language universals and language-specific default rules fill in features which are not present in the underlying representation. It has been proposed that children acquire language by first learning the default features, then gradually acquiring more features of a specification, until the most specified segments are acquired (Bernhardt 1992).

Incorporated into the concept of both feature geometry and radical underspecification is the principle of markedness. In a feature geometry representation, more marked features should be located at lower nodes of the tree, and less marked features should be located at higher nodes. Similarly, with radical underspecification, segments whose underlying representation contains fewer features should be less marked than features with a greater number of features specified in the underlying representation.

Proposals have been made for the ability of feature geometry and radical underspecification to account for normal phonological acquisition (Beers 1996, Rice and Avery 1995). According to feature geometry, features located closer to the root (higher) are acquired before lower (more embedded) features. Acquisition proceeds with children acquiring nodes or features from the root down to the terminal nodes of the geometry models. Similarly, in radical underspecification it is proposed that children acquire a phonological system beginning with the least specified segments. Acquisition proceeds gradually with children acquiring more specifications until the most specified segments are acquired. 
Since patterns of acquisition differ between normally-developing and phonologically-disordered children, feature geometry and underspecification proposals may be useful in determining how the patterns differ. Patterns of normal phonological development are outlined by Grunwell (1987) and Stoel-Gammon and Dunn (1985), and these serve as a source for common child substitutions. Normal substitutions are the result of simplification processes that are common among most children. Grunwell (1987) also identifies several less common substitutions which exist to a limited degree among normally developing children, but are more common among disordered children. There is also an identified class of unusual substitutions which never appear among normally developing children. The less common and unusual substitutions are also given labels as processes, though they are not processes outlined in natural phonology. Since there are three distinct and systematic groups of processes, our linguistic models should be able to account for differences among all three groups.

I would like to examine how the models of underspecification and feature geometry interact in their ability to account for data of normal and disordered child substitutions. To accomplish this goal, I will study already-published normal, less common and unusual child substitutions. I will outline the specification of target and substitute segments according to radical underspecification for English phonemes. I will determine which features differ between the target and substitute, and I mark them on thre different feature geometry models proposed by Bernhardt, Clements-Hume and HalleSagey. 
After examining the underspecification and feature geometry trees for each substitution, I will draw some generalizations about the substitutions in each type of process: normal, less common and unusual. From this analysis, I will discuss the ability of the models to account for the characteristics of the different groups. If the models account for some common traits within each group, then it should be possible to develop a metric to assess substitutions. It may be necessary to make alterations to the tree models may be necessary to account for all of the data since there is not an agreed-upon feature geometry model.

\section{Literature Review}

\subsection{Feature Geometry}

Feature Geometry is a recent development in nonlinear phonology which attempts to classify and describe sounds in terms of their distinctive features. In order to assess feature geometry, it is important to consider the development of the theory. Distinctive feature theory and generative phonology are the precursors to feature geometry. In distinctive feature theory, developed by Jakobson, Fant and Halle (1952), several acoustically-based features were identified and assigned binary $(+/-)$ values.

Combinations of the features were used to describe sounds contrastively. Important aspects of the theory were the binary values assigned features, and the universality of the features. Chomsky and Halle (1968) further developed on these ideas with The Sound Pattern of English (hereafter SPE) and generative phonology. 
In Chomsky and Halle's model, features are articulator-based rather than acoustically-based. They group together to form segments into natural classes for phonological processes. By using distinctive features for the description, the regularities of the sound change are revealed. In SPE, Chomsky and Halle introduce the concept of an underlying phonological representation that is mapped onto a surface representation through a set of rules. Most of the sound changes considered are context-sensitive, which means that they occur in a particular environment. So, for any sound which undergoes change, there is an underlying representation, a set of phonological rules which alter the segment in a given environment, and a surface form. While this system can reveal many of the regularities of sound change and sound patterns in languages, and it considers the feature rather than the phoneme as the primitive phonological unit, it has several shortcomings. In order to overcome some of the problems of previous theories, feature geometry has been proposed. Feature Geometry retains some of the standard feature theory's use of distinctive features and binary values, and it is able to resolve some of the problems of standard feature theory and generative phonology (Ingram 1997).

A problem with standard theory is that it fails to account for the very common phonological processes that occur among groups of features rather than independent features. An example of how the SPE and feature theory lack the power to account for a process is with assimilation (Spencer 1996). In the homorganic assimilation of a nasal to the adjacent consonant, as in the assimilation of the prefix /in-/ to the first consonant of the adjoining morpheme, SPE requires listing the role of each feature in the process as if each feature is acting independently (McCarthy 1988). 


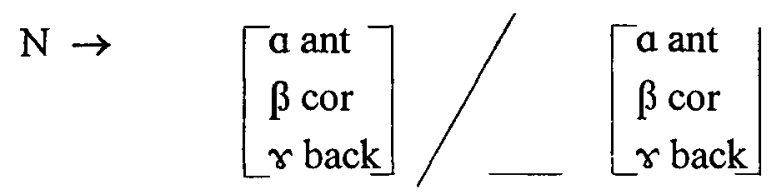

However, there is evidence that the features act together in a dependency

relationship to perform the assimilation process, as well as other processes. Feature

theory fails to capture the linguistically significant generalization about the nature of the phonological processes. It also fails to account for the naturalness of processes. Under traditional feature theory, groupings of features that act together in a phonological process are no more valued than arbitrary groupings of features. Thus, there is no way under the theory to distinguish the natural processes from the impossible ones (Clements \& Hume 1995).

For example, there is a rule that describes nasalization of vowels before nasal consonants which is a common assimilatory process:

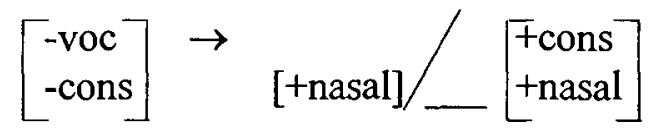

However, a rule which denasalizes nasal consonants before vowels could also be written, although it is at least rare, if not unheard of in the world's languages:

$$
\left[\begin{array}{l}
+ \text { cons } \\
+ \text { nas }
\end{array}\right] \rightarrow[\text {-nasal }] /\left[\begin{array}{l}
+ \text { voc } \\
- \text { cons }
\end{array}\right]
$$

A theory of phonology should be able to indicate that the first process is a very common and natural process, while the second one is not. Similarly, grouping features into natural classes should be possible, and it should be possible to see which features never group to form a natural class of features that act together in a phonological event. 
For example, there are vowel assimilations that group [high], [back] and [low], but it would be unusual or impossible to find an assimilation involving [high], [nasal] and [ATR] (Yavas, in preparation). Another problem that standard feature theory cannot address is the fact that features may spread over more than one segment, as in vowel or nasal harmony, and features may occupy only part of one segment, as in pre- or postnasalization (Spencer 1996). Under feature theory, features can apply only to entire segments. There is also no way to capture the temporal relationships that occur in phonological processes because the features are described in a linear fashion.

To overcome this view of features as separate and unorganized bundles, several theories of feature geometry have been introduced (Clements and Hume 1995, McCarthy 1988; Rice and Avery 1995, Sagey 1986, Bernhardt 1992). Feature Geometry rose out of autosegmental phonology which proposed that prosodic features such as tone and segmental features exist on separate tiers which can act independently of one another (Goldsmith 1995). In autosegmental phonology there are tiers that represent word level, foot, syllable, onset-rhyme, CV and segment (Katamba 1989). Under feature geometry, segments are represented by features which are organized in a hierarchy of tiers. A segment is represented by a hierarchy of features which are organized into a tree. An important aspect of feature geometry is that it is capable of relating the segmental tier to the prosodic tier, though that is not a topic of discussion in this thesis.

These theories of feature geometry express the organization of features in terms of a hierarchical tree in keeping with linguistic tradition. The geometries try to express the dependent nature of the features as they act in groups to perform phonological processes. 
Under this theory, segments are "geometrically organized features, each with some autonomy, but also with some dominance relationship with other features" (Bernhardt and Gilbert, 128). Features group together in phonological processes because of their location in the hierarchy. In describing the assimilation process mentioned above, a theory of feature geometry would attempt to account for the changes in relevant features in one group rather than individually. The result is that a large quantity of data can be explicated in an efficient and principled manner.

The organization of the features is related to the organization of the articulators that produce speech. Speech is produced by using the articulators, which include the lips, tongue front, tongue body, tongue root, soft palate and larynx. These articulators function independently and may act together to make one restriction or may combine to produce several constrictions (Clements \& Hume 1995). Traditional phonetic features include descriptions of broad categories, such as place, manner and voicing of articulation. Feature geometry also places emphasis on these broad categories in describing features, and organizes the tiers based on that. Under feature geometry, there are some differences in the features that are used in generative phonology. For example, the distinctive feature [velar], which is not based on an articulator, is captured by [dorsal] under feature geometry, reflecting the use of the tongue body in creating the sound (Ingram 1997).

Under feature geometry, a sound is regarded as a set of features arranged hierarchically, represented through a tree diagram. Many of the features are assigned binary values, as under the Chomsky-Halle system. There is debate among the different theories for organization of the trees, but the theories agree that there is a root node, and 
separate class nodes. Most features correspond to a single articulator, and are called articulator-bound features. An example of an articulator-bound feature is [+labial] which corresponds only to the lips. Other features relate to more than one articulator and are called articulator-free features. These are the major class features [consonantal] and [sonorant], and the manner features [continuant], [strident] and [lateral]. Presence of a feature located lower in the hierarchy implies presence of its corresponding articulator at all higher nodes. The dependency and dominance relationships among features are thus represented in feature geometry (Yavas, in preparation).

Although the majority of features are bivalent, there are some features which operate only on a positive value, such as [+coronal, +dorsal, +labial]. There do not appear to be any rules that function with the negative value of these features, so they are thought to be privative, or having only one value, not a binary $+/$ - distinction (Clements \& Hume 1995). Such monovalent nodes include the root node, the laryngeal node and the place node (Bernhardt \& Gilbert 1992). The monovalent nodes dominate a set of terminal nodes which do have a binary distinction, such as [ $+/$ - rounded].

Although different models represent the tree organization differently, the following basic configurations are constant for all of the models. First, the basic organization of the trees begins with the root node, which links the segment to other tiers, such as the prosodic tier. The root node dominates the manner nodes, which also have a dominance relationship over the place and laryngeal nodes. The laryngeal node corresponds to the glottis. The place node identifies the oral cavity configuration of the segment. It dominates other place nodes, such as labial, coronal and dorsal. Labial refers 
to lip articulations, and dorsal refers to articulations made with the dorsum of the tongue. The coronal place node refers to articulations made with the tongue tip or blade. If the coronal node does not dominate any terminal features, it is assumed to be a default place (Bernhardt \& Gilbert 1992).

Organization of the nodes and tiers accounts for the grouping of features or articulators in phonological processes. Spreading of the root node results in total assimilation (McCarthy 1988). Class nodes can spread independently of one another to account for various processes. By representing processes in spreading of class nodes, the temporal aspect of the process is accurately represented. That is, assimilation involves several features which act together simultaneously rather than in any particular order (Spencer 1996). Features which are represented higher in the hierarchy are less capable of spreading than those that are lower in the hierarchy. For example, a place feature, which is on the lowest level of the hierarchy, would be much more likely to spread than the feature [sonorant] which is located higher in the hierarchy.

Tiers are joined by association lines that indicate the relationships between them. Tiers may link to add phonological information to a segment, or delink to delete features. Under the theory, all phonological processes can be expressed as a result of these two operations, linking and delinking. Now, rather than describing phonological rules or processes, the theory focuses on the representation of the phonological event via tree structures and the linking or delinking of nodes (McCarthy 1988).

The theory operates under the following principles: 1) phonological rules perform single operations only, so that only sets that form constituents may function together in 
phonological rules, and 2) Feature organization is universal (Clements \& Hume 1995).

To date, several models of a feature hierarchy have been introduced. They share many common features and the principle of representation remains the same, but the models differ in their organization. I will consider three of them: (1) Halle-Sagey; (2) ClementsHume; and (3) Bernhardt's model which is based on the 1988 model of McCarthy.

The Halle-Sagey model (Figure 2.1.a), which was developed by Halle based on the model presented by Sagey (1988), is based on the idea that features are organized around the articulators (Halle 1992). Articulator-free features form two groups: the major class features [consonantal] and [sonorant], and the stricture features, [continuant], [strident] and [lateral]. This model places [consonantal] and [sonorant] at the root of the tree. The author argues for these features as the root node because 1) spreading of these features does not usually occur except in cases of complete assimilation; 2) the vowelconsonant or sonorant-obstruent opposition in languages is universal; 3) higher level features in the tree should represent a basic contrast; 4) these features play a prominent role in syllabification that establishes prosodic structure over the segments, and as such, they share a special status (Kenstowicz 1994).

The root features can combine to form three major segment classes: obstruents [+consonantal] [-sonorant], sonorant consonants (liquids and nasals) [+consonantal] [+sonorant], and vocoids (vowels and glides) [-consonantal][+sonorant]. Root features are somewhat restricted in the way they combine with the articulators. For example, [+consonantal] implies that a stricture must exist, and the stricture is located in the oral cavity which is controlled by the labial, coronal and dorsal articulators. Thus, these 
articulators are grouped together under the "Oral Place" node. The manner features are generated from the root, and are articulator-free. [Continuant] can combine with Labial, Coronal and Dorsal to generate stops and fricatives at each of the three major oral places of articulation. Kenstowicz (1994) argues that [lateral] is always dependent on coronal, and should possibly be designated under the [coronal] node, and [strident] is also questioned for its applications in [-coronal] segments. This model recognizes two mechanisms to establish feature groupings; dependency among tiers, and the arrow designation that indicates the relationship between multiple articulators.

Figure 2.1.a The Halle-Sagey Model of Feature Geometry

\section{Halle-Sagey Model}

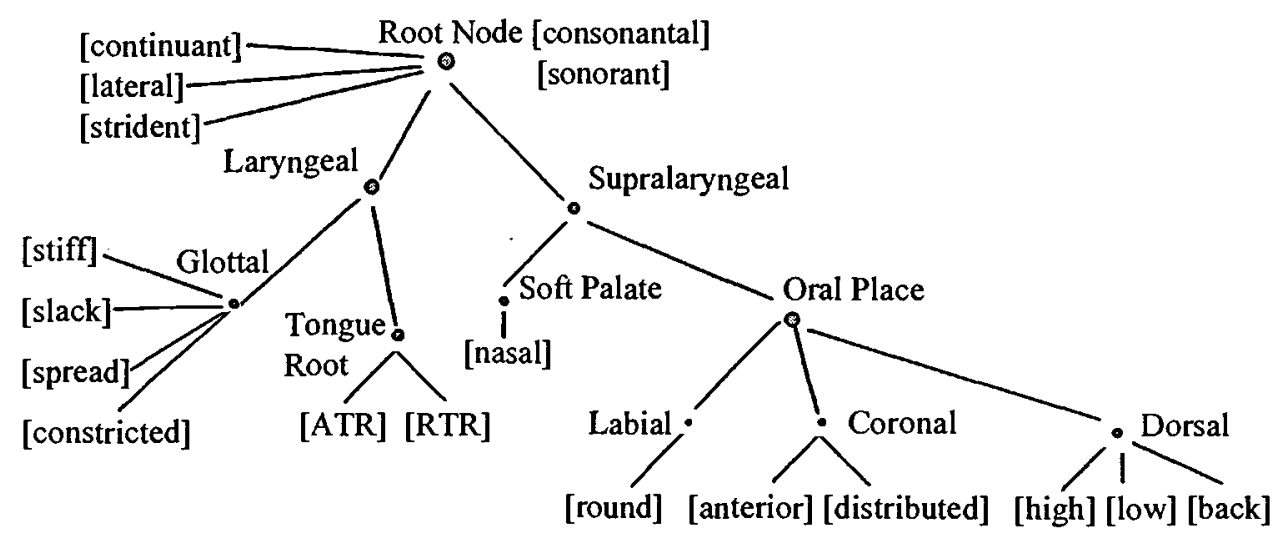

The Clements-Hume model (Figure 21.b) assigns the major class features [sonorant], [approximant], and [vocoid] to the root node. Together, these features can define obstruents, nasals, liquids and vocoids (vowels and glides) based on sonority rankings. In defining consonants, there are three nodes under the root node: laryngeal, nasal and oral cavity. Laryngeal is proposed as a node because laryngeal features (spread glottis, constricted glottis, and voice) may spread individually or together as a group in 
some languages. The oral tract features, [labial],[coronal], and [dorsal] can also spread as a single unit, so they are grouped under the place node. The Oral Cavity node comes between the place node and the root node, dominating the place node and the feature [continuant]. An argument for this organization is that it can explain intrusive stops that occur between English nasals and the following voiceless fricatives in examples like "sense" [sints] and "prince" [prints]. According to the model, the intrusive stop is formed due to the spreading of the oral cavity node onto the root node of the fricative (Clements \& Hume 1995). There is also a guttural node which is attached to the root node and dominates the larynx and tongue root features. Autosegmental phonology proposes that consonants and vowels exist on separate tiers (Goldsmith 1995), so separate hierarchy trees also exist for the two groups. Since I am not discussing vowels in this thesis, I will not elaborate on the authors' description of a vowel hierarchy. There is some controversy on this point, as Clements (1988) proposes a C-place for consonants and a V-place for vowels under the same tree organization.

Figure 2.1.b The Clements-Hume Model of Feature Geometry

\section{Clements-Hume Model}

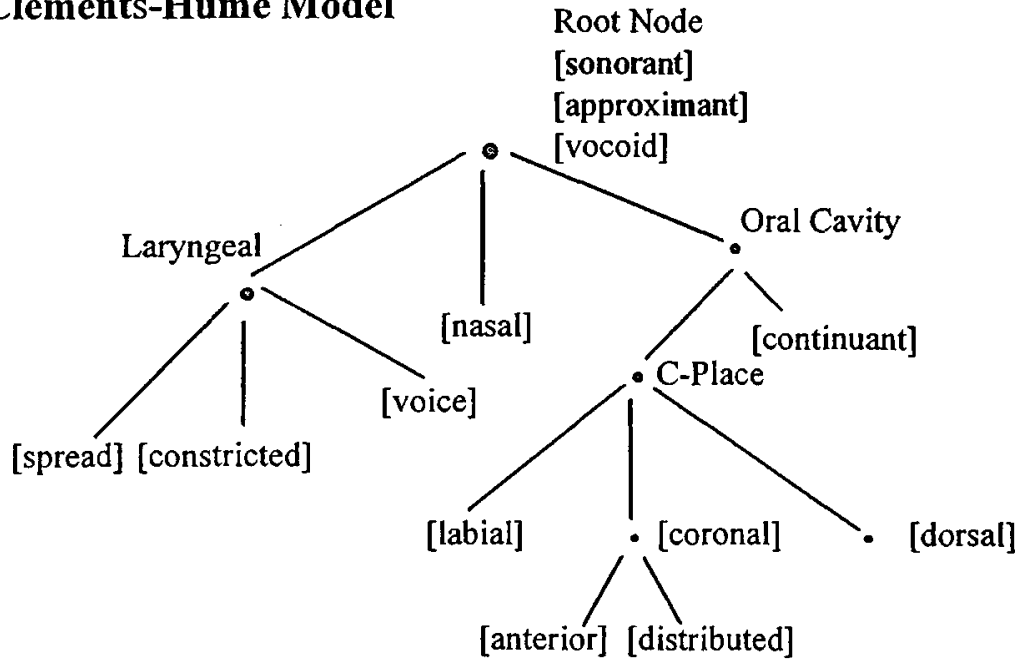


McCarthy's model differs from the other models in the features that it assigns to the root node. McCarthy (1988) assigns the major class features [sonorant] and [consonantal] to the root node on the basis of making basic oppositions as argued in the Halle-Sagey model. Also included in the root node are the terminal features [continuant] and [nasal] which define classes of stops, fricatives and nasals. Although manner features do not function as a group in phonological rules, they can be realized over different places of articulation, so they are made dominant over place features in the geometry. The root node dominates two nodes: laryngeal and place. The laryngeal node defines the glottal characteristics of the segment. The place node defines the oral cavity, as outlined earlier. McCarthy's model does not differentiate between vowel and consonant place nodes.

Bernhardt's model (Figure 2.1.c) is based on and differs only slightly from McCarthy's. Organization of the root and laryngeal nodes is the same as McCarthy's. McCarthy includes a possible pharyngeal node under the place nodes, but Bernhardt does not. Also, McCarthy places [lateral] under the coronal node, while Bernhardt does not include the feature [lateral]. Bernhardt reduces the features under McCarthy's laryngeal nodes to [spread glottis] and [voice]. Place nodes are [labial], [coronal] and [dorsal]. The terminal node for Labial is [round]. For the Coronal node, terminal features are [distributed] and [anterior], and for the Dorsal node, terminal features are [back], [high] and [low]. 
Figure 2.1.c The Bernhardt Model of Feature Geometry

\section{Bernhardt Model}

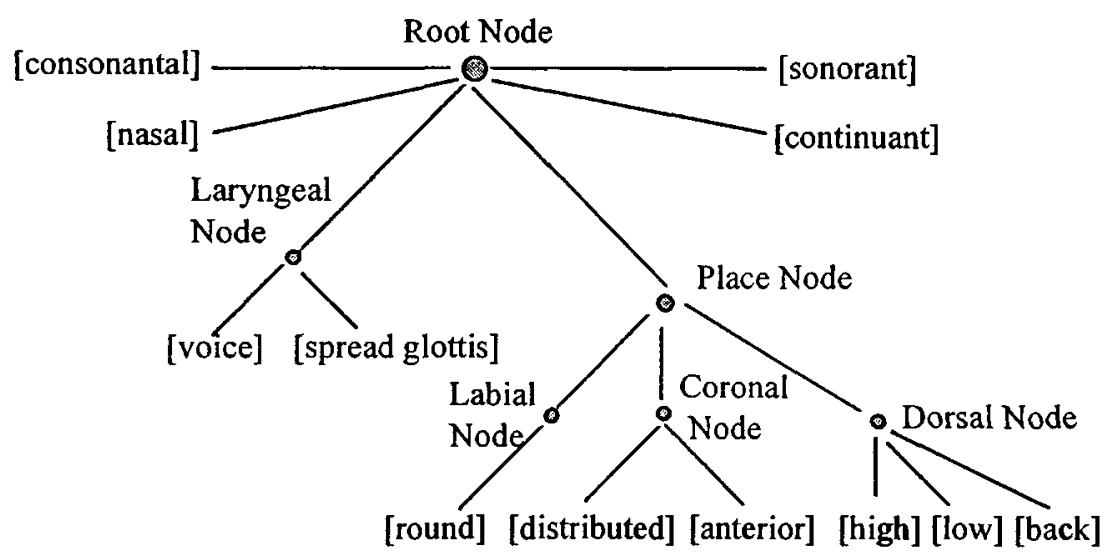

\subsection{Underspecification}

The concept of underspecification is also tied to autosegmental phonology, and therefore to feature geometry. Underspecification holds that only the features which are not predictable in the underlying representation should be specified. It is not necessary to specify all features in an underlying representation, and there is phonological and phonetic evidence that complete specification at the underlying representation level is undesirable (Archangeli 1988). In addition to complete specification, I will discuss two types of underspecification: contrastive and radical. Complete specification is the listing of all distinctive features that comprise a segment. The specification for [i] under this framework would include [+high, -low, -back, +voice]. This method of specifying the features of a segment in an underlying representation is not always desirable. We can 
look at the nasalization of vowels in English to see this point. Whereas underlyingly, the vowel in bean is [i], at the surface level, the phonetic environment of [i] next to the alveolar nasal [n] causes some nasalization of the vowel. In this case, it would not be accurate to say that [i] includes the feature [+nasal] in the underlying representation. This shows that complete specification alone is not a sufficient condition to predict output of the phonological and phonetic components (Archangeli 1988).

Under contrastive specification, only the features which contrast one segment with another in a given language are specified. Using the simple vowel system [a e i o u], we look at the vowels in terms of closely related contrasting vowel pairs, [i] v. [u], [o] v. [u], [i] v. [e], and so on. The features which distinguish between the two segments are considered relevant for contrastive underspecification, and all the remaining features -which are not relevant to the contrast are eliminated. That leaves a specification that looks like this (Archangeli 1988):

contrasts contrastive specification

\begin{tabular}{|c|c|c|c|c|c|}
\hline & & $\mathrm{i}$ & $\mathrm{e}$ & a & o \\
\hline$\{\mathrm{i}, \mathrm{e}\}\{\mathrm{o}, \mathrm{u}\}$ & high & + & - & & - \\
\hline$\{a, o\}$ & low & & & + & - \\
\hline$\{i, u\}\{e, o\}$ & $\begin{array}{l}\text { back } \\
\text { voice }\end{array}$ & - & - & & + \\
\hline
\end{tabular}

In contrastive underspecification, the features which distinguish between any two features are specified for. So, to contrast between $\{i, e\}$, the features [+high] for [i] and [-high] for [e] are specified, and the features that are unnecessary for the contrast, such as 
[low] and [voice] are left blank. It is apparent that contrastive underspecification is specifying for segments based on the contrasts within one specific language.

In radical underspecification, the unit of concern is the feature, not the segment. Under this model, only the features that are not considered "predictable" for a segment are specified for. This means that all other features are filled in by redundancy rules. According to Archangeli, values are predictable if it is possible to formulate a contextfree or a context-dependent rule that will generate the absent values. This means that absent values can be inserted at derivation rather than at the underlying level. For example, for sonorants, [+voice] is a predictable feature, so it is redundant and does not need to be specified for at the underlying level. Relatedly, it is assumed that only universally marked values would be specified underlyingly (Archangeli 1988). So, a voiceless sonorant would need to be specified for its lack of voicing. For example, looking at the same five-vowel system above, there are some default values that we can eliminate from the representation of full specification. These default values indicate the predictable values of features.

Listed below are the default values for the vowels based on universals and language-specific rules (Archangeli 1988):

$$
\begin{aligned}
& {[\text { +low }] \rightarrow[\text {-high }]} \\
& {[\text { +low }] \rightarrow[\text { +back }]} \\
& {[\text { low }] \rightarrow[- \text { low }]} \\
& {[\text { high }] \rightarrow[\text { +high }]} \\
& {[\text { back }] \rightarrow[\text {-back }]}
\end{aligned}
$$



1988).

The following chart represents the full specification for the vowels (Archangeli

\begin{tabular}{l|ccccc} 
& $\mathbf{i}$ & $\mathbf{e}$ & $\mathbf{a}$ & $\mathbf{0}$ & $\mathbf{u}$ \\
\hline high & + & - & - & - & + \\
low & - & - & + & - & - \\
back & - & - & + & + & +
\end{tabular}

Radical underspecification of the vowels is derived by first considering full specification of the vowels as above, and then eliminating all predictable values (default rules). Radical specification for the vowels is as follows (Archangeli 1988):

\begin{tabular}{l|lllll} 
& $\mathbf{i}$ & $\mathbf{e}$ & $\mathbf{a}$ & $\mathbf{0}$ & $\mathbf{u}$ \\
\hline high & & - & & - & \\
low & & & + & & \\
back & & & & + & +
\end{tabular}

Because radical underspecification treats the feature as the most basic phonological unit, a feature inventory rather than a segment inventory is required for any given language. By combining the features, all the sounds of the language can be derived according to universals and considerations of the language's rules and constraints. In this sense, radical underspecification is favored by Archangeli over contrastive underspecification because a feature inventory has validity in describing all languages of the world.

Another argument given by Archangeli (1988) for proposing radical underspecification as the preferred theory is that it accounts for markedness. Markedness, 
sometimes also called naturalness, describes the preference for certain segments or sequences of segments over others. What is natural is called unmarked, and what is not natural is called marked (Katamba 1989). Not all possible feature combinations are equally probable. The unlikely or rare feature combinations are considered marked. It is generally the case that unmarked combinations of features can be seen to recur in languages with great frequency.

Chomsky and Halle (1968) proposed a theory of markedness so that certain feature values in combination with other features would be considered either marked or unmarked. For example, back vowels are more commonly rounded than are front vowels. Among the languages of the world, the vowels /i/ and /u/ occur much more frequently than the rounded front vowels /ø/ and /y/ or the back unround vowel /w/ (Madiessen 1984). So, [+round] would be an unmarked feature for back vowels, and [+round] would be a marked feature for front vowels. Phonologists use inventories of the world's languages, patterns of phonological acquisition, phonological disorders, historical changes and slips of the tongue to determine which sounds are marked (Yavas, in preparation). Production factors that may make a segment more marked than other segments include articulatory complexity and perceptual saliency (Grunwell 1987).

Distinctive feature theory and generative phonology do not have a standard and principled way of accounting for markedness. Counting the features that make up a segment or a group of segments is an insufficient method of determining markedness. This can be seen in sets of segments that form a natural class; a set such as [ $\mathrm{t} k$ ] requires 
more features [-son, -cont, - del rel, - voice] to describe the group of voiceless stops, and a group such as $[\mathrm{v}, ð, \mathrm{z}, 3]$ can be specified with fewer features [+cons, + cont, + voice]. We know from the world's languages and from child language data that voiceless stops are less marked compared to the group of voiced fricatives (Ingram 1989, Madiesson 1984). Although generative phonology has arrived at several conventions to attempt to account for markedess, none has been found to account for markedness with crosslinguistic validity (Yavas, in preparation).

In applying the idea of markedness to Archangeli's radical underspecification, it can be said that segments which are less specified are also less marked, and segments which are more specified are more marked. Thus, radical underspecification can handle the idea of markedness within its model, whereas contrastive underspecification requires a separate theory for markedness. The default rules that fill in further specification in radical underspecification are those rules that correspond to cross-linguistic markedness considerations. Therefore, markedness is included in the analysis of a language's system through universal default rules, and language-specific rules are also considered (Archangeli 1988).

Radical Underspecification also has importance in studies of language acquisition. The specifications and redundancy rules should have the ability to predict the order of acquisition of speech sounds and the kinds of errors that children make (Ingram 1997). I will return to this discussion in the section on language acquisition. Following is a table of English phonemes and their features as outlined by radical underspecification. 
Table 1 Underspecification of Adult English Consonants (Bernhardt \& Stoel-Gammon 1994)

\begin{tabular}{|c|c|c|c|}
\hline Segment & Root Node & Laryngeal Node & Place Node \\
\hline$/ \mathrm{m} /$ & $\begin{array}{l}{[+ \text { consonantal }]} \\
{[+ \text { nasal }]}\end{array}$ & & Labial \\
\hline$/ \mathrm{n} /$ & [+consonantal], [+nasal] & & \\
\hline$/ y /$ & {$[+$ consonantal $],[+$ nasal $]$} & & Dorsal \\
\hline$/ \mathrm{p} /$ & [+consonantal] & & Labial \\
\hline $\mathrm{b} /$ & {$[+$ consonantal $]$} & [+voice $]$ & Labial \\
\hline$/ \mathrm{t} /$ & {$[$ + consonantal $]$} & & \\
\hline$/ d /$ & [+consonantal $]$ & [+voice] & \\
\hline$/ \mathrm{k} /$ & [+consonantal] & & Dorsal \\
\hline$/ g /$ & {$[+$ consonantal $]$} & [+voice] & Dorsal \\
\hline$/ \mathrm{f} /$ & [+consonantal], [+continuant $]$ & & Labial \\
\hline$/ \mathrm{v} /$ & $\begin{array}{l}{[+ \text { consonantal }]} \\
{[+ \text { continuant }]}\end{array}$ & [+voice] & Labial \\
\hline$/ \theta /$ & $\begin{array}{l}{[+ \text { consonantal }]} \\
{[+ \text { continuant }]}\end{array}$ & & Coronal:[+distributed $]$ \\
\hline /る/ & $\begin{array}{l}\text { [+consonantal }], \\
{[+ \text { continuant }]}\end{array}$ & [+voice] & Coronal:[+distributed] \\
\hline$/ \mathrm{s} /$ & $\begin{array}{l}{[+ \text { consonantal }],} \\
{[+ \text { continuant }]}\end{array}$ & & \\
\hline$|z|$ & $\begin{array}{l}\text { [+consonantal }] \\
{[\text { +continuant }]}\end{array}$ & [+voice] & \\
\hline $15 /$ & $\begin{array}{l}{[+ \text { consonantal }]} \\
{[\text { + continuant }]}\end{array}$ & & Coronal:[-anterior] \\
\hline$|3|$ & $\begin{array}{l}{[+ \text { consonantal }],} \\
{[+ \text { continuant }]}\end{array}$ & [+voice] & Coronal:[-anterior] \\
\hline$/ \mathrm{t} \mathrm{J} /$ & $\begin{array}{l}{[+ \text { consonantal }]} \\
(\text { complex })\end{array}$ & & Coronal:[-anterior] \\
\hline$/ \mathrm{d}_{3} /$ & $\begin{array}{l}\text { [+consonantal }] \\
\text { (complex) }\end{array}$ & [+voice] & Coronal:[-anterior] \\
\hline$/ \mathrm{w} /$ & [+sonorant] & & Labial \\
\hline $\mathrm{h} /$ & $\begin{array}{l}{[+ \text { consonantal }]} \\
{[+ \text { continuant }]}\end{array}$ & $\mathrm{LN}$ & \\
\hline$/ \mathrm{j} /$ & [+sonorant] & & \\
\hline $\begin{array}{l}/ \mathrm{l} / \\
/ \mathrm{r} /\end{array}$ & $\begin{array}{l}\text { [+consonantal], [+sonorant }] \\
{[+ \text { consonantal }],[+ \text { sonorant }]}\end{array}$ & & $\begin{array}{l}\text { Labial + Coronal Place or } \\
\text { Coronal:[-anterior] }\end{array}$ \\
\hline
\end{tabular}

\subsection{Phonological Development}

Understanding the development of normal phonological patterns is essential to identifying and explaining what constitutes unusual or idiosyncratic patterns. There are 
various stages of development, from the prelinguistic stages of cooing and babbling in the first year, to production of the first fifty words around one year to $1 ; 6$, and the stage of systematic development which lasts from the end of the word spurt around $1 ; 6$ to acquisition of the majority of adult phonemes by around 4;0 (Ingram 1989). I will focus on phonemic development from $1 ; 6$ to completion of the inventory, which is mostly completed by $4 ; 0$, but continues to full completion by approximately $6 ; 0$ to $7 ; 0$.

Research in the area of phonological development has identified two important factors in the acquisition process: patterns that are common among the great majority of children, and strong evidence of individual variation within the patterns and acquisition process. For example, the acquisition of certain sounds and syllable structures appears to be universal, whereas the order of acquisition of phonemes is highly individual (StoelGammon \& Dunn 1985). In order to identify what falls outside the normal range, it is necessary to understand the role of general patterns and the nature of individual variation.

At the end of the first fifty-word stage $(1 ; 6)$, children begin to develop a phonological system with more stable and systematic correspondence between their productions and the adult form. By reviewing large sample studies conducted by Templin (1957) and others, Stoel-Gammon has identified an "Age of Mastery" for various phonemes, at which production of the phoneme is correct $75 \%$ of the times tested. She also shows results of a study by Sander (1972) which gives the customary age of production of phonemes, which is the age at which the phoneme is correct about $50 \%$ of the times it is produced. The order of acquisition of sound classes appears to be the same 
for most children. Stops, nasals, and glides are mastered first, then liquids, and finally

fricatives and affricates (Stoel-Gammon \& Dunn 1985).

Table 2 Order of Acquisition of Phonemes (Stoel-Gammon \& Dunn 1985 ). Based on data from Templin's 1957 study

\begin{tabular}{cl}
\hline Age & Phoneme \\
\hline $3 ; 0$ & $\mathbf{p}, \mathrm{m}, \mathrm{n}, \mathrm{g}, \mathrm{f}, \mathrm{w}$ \\
$3 ; 6$ & $\mathrm{j}$ \\
$4 ; 0$ & $\mathrm{~b}, \mathrm{k}, \mathrm{g}, \mathbf{r}$ \\
$4 ; 6$ & $\mathrm{~s}, \mathrm{\int}, \mathrm{t} \int$ \\
$5 ; 0$ & \\
$6 ; 0$ & $\mathrm{t}, 1, \theta, \mathrm{v}$ \\
$7 ; 0$ & $\mathrm{~d}, \mathrm{z}, 3, \mathrm{~d} 3$ \\
\hline
\end{tabular}

Table 3 Customary Age of Production and Mastery of Consonantal Phonemes (Stoel-Gammon \& Dunn 1985 ). Based on data from Sander (1972)

\begin{tabular}{|c|c|c|}
\hline Age & Consonants Customarily Produced & Consonants Mastered \\
\hline Before $2 ; 0$ & $\mathrm{p}, \mathrm{b}, \mathrm{m}, \mathrm{n}, \mathrm{w}, \mathrm{h}$ & \\
\hline $2 ; 0$ & $\mathrm{t}, \mathrm{d}, \mathrm{k}, \mathrm{g}, \mathrm{g}$ & \\
\hline $3 ; 0$ & $f, s, r, 1, j$ & $\mathbf{p}, \mathbf{m}, \mathbf{n}, \mathbf{w}, \mathbf{h}$ \\
\hline $4 ; 0$ & $v, z, \int, t \int, d_{3}$ & $\mathrm{~b}, \mathrm{~d}, \mathrm{k}, \mathrm{g}, \mathrm{f}, \mathrm{j}$ \\
\hline $5 ; 0$ & $\theta$, д & \\
\hline $6 ; 0$ & 3 & $t, \mathrm{~g}, \mathrm{r}, \mathrm{l}$ \\
\hline $7 ; 0$ & & $\theta, \int, \mathrm{t} \int, \mathrm{d} 3$ \\
\hline $8 ; 0$ & & $\mathrm{v}, \mathrm{\partial}, \mathrm{s}, \mathrm{z}$ \\
\hline
\end{tabular}

There are developmental factors in determining when phonemes are acquired, as seen above, and there are also environmental or contextual factors. It is well known that sounds may appear first in one environment and may not appear in other environments until much later. For example, interdental fricatives $/ \theta, \partial /$ in word-final position, as in eighth or breathe, occur much later than they do in word-initial position, thin and they (Templin 1957).

One approach in analyzing how children acquire phonological systems is by examining their errors. Child productions do not always match the adult targets, but there 
is a relationship between the two forms that can be described in terms of phonological processes (Stoel-Gammon \& Dunn 1985). Stampe first developed the processes in 1969 as part of the theory of natural phonology, and posited that the processes are "mental operations" which transform a target segment into a segment which is less difficult to articulate. Stampe found that the processes occur among groups of children and form a general pattern for acquisition. Patterns can modify the syllabic structure of the target word, substitute one sound for another, and assimilate one sound to another. StoelGammon (1985) does not accept Stampe's assertion that the processes are mental operations, and she uses the processes merely as a mechanism to describe the relationship between the child and adult forms.

Grunwell (1987) also limits the definition of processes as causing a simplification of the pronunciation of a phonological unit. Substitution processes include gliding liquids, vocalization, stopping, depalatalization, and velar fronting. Since I am concerned with the context-free sound substitutions, I list only the substitutions that reflect the data for this study. I will follow Grunwell and Stoel-Gammon and consider the processes as operations that modify the structure of the target word rather than as mental constructs. It is generally thought that the substitutions involve replacement of later-acquired classes by early-acquired sound classes. For example, stops are substituted for fricatives. Processes continue some time in normal development, with many disappearing by about age three, and some persisting longer until acquisition of the target phoneme is complete (Grunwell 1987, Stoel-Gammon \& Dunn 1985). 
Table 4 Age of Disappearance of Processes (Stoel-Gammon \& Dunn 1985)

\begin{tabular}{ll}
\hline Processes Disappearing by 3;0 & Processes Persisting after 3;0 \\
\hline Unstressed Syllable Deletion & Cluster Reduction \\
Final Consonant Deletion & Epenthesis \\
Doubling & Gliding \\
Diminutization & Vocalization \\
Velar Fronting & Stopping \\
Consonant Assimilation & Depalatalization \\
Reduplication & Final Devoicing \\
Prevocalic Voicing &
\end{tabular}

Table 5 Chronology of Processes (Grunwell 1987)

\begin{tabular}{|c|c|c|c|c|c|c|c|}
\hline & $2 ; 0-2 ; 6$ & $2 ; 6-3 ; 0$ & $3 ; 0-3 ; 6$ & $3 ; 6-4 ; 0$ & $4 ; 0-4 ; 6$ & $4 ; 6-5 ; 0$ & $\begin{array}{l}5 ; 0 \\
\rightarrow\end{array}$ \\
\hline Stopping $\quad / \mathrm{s} / \rightarrow[\mathrm{t}]$ & & $=-$ & & & & & \\
\hline $\begin{array}{l}\text { Fronting } \\
\qquad \mathrm{k}, \mathrm{g}, \mathrm{n} /\end{array}$ & & $-=$ & $=$ & & & $-=$ & - \\
\hline $\begin{array}{l}\text { Fricative } \\
\text { Simplification } \\
\qquad / S / \rightarrow[s] \\
/ \theta / \rightarrow[\mathrm{f}]\end{array}$ & & & & $=$ & - & - & - \\
\hline $\begin{array}{ll}\text { Gliding } & \\
& / \mathrm{r} / \rightarrow[\mathrm{w}]\end{array}$ & & & $-=$ & - & - & $-=$ & $=$ \\
\hline
\end{tabular}

Gliding: a glide is substituted for a prevocalic liquid. Ex. $/ \mathrm{r} / \rightarrow[\mathrm{w}], / \mathrm{l} / \rightarrow[\mathrm{w}]$ or

[j]. Rabbit $\rightarrow$ [wæbit], look $\rightarrow$ [wuk], leaf $\rightarrow[$ jif]. According to Grunwell, this pattern may continue until age $4 ; 0$ or $5 ; 0$ in some speakers, but generally disappears by about $3 ; 6$.

Stopping: A stop replaces an affricate or fricative, or an affricate replaces a fricative. This process usually occurs in word-initial position. Ex. $/ f / \rightarrow[\mathrm{p}], / \mathrm{v} / \rightarrow[\mathrm{b}]$, $/ \mathrm{s} / \rightarrow[\mathrm{t}], / \mathrm{z} / \rightarrow[\mathrm{d}]$. Feet $\rightarrow[$ pit], van $\rightarrow[\mathrm{bæn}]$, house $\rightarrow[$ haut $]$, nose $\rightarrow[$ nod $]$. For most fricatives, this process stops around 3;6, but may continue for voiced fricatives and interdental fricatives until 5;0. 
Depalatalization: Alveolar fricatives and affricates replace palatal fricatives and affricates, respectively. $/ S / \rightarrow$ s]. Ex. ship $\rightarrow[$ sip].

Velar Fronting: Alveolar consonants replace velar consonants. $/ \mathrm{k} / \rightarrow[\mathrm{t}], / \mathrm{g} / \rightarrow[\mathrm{d}]$. Ex. $k e y \rightarrow[\mathrm{ti}], g o \rightarrow[\mathrm{do}]$. This process ends by around $3 ; 0$.

Fricative Simplification: After Stopping is suppressed, simplification of fricatives occur. The most common simplifications are $/ \theta / \rightarrow[\mathrm{f}], / \mathrm{g} / \rightarrow[\mathrm{s}], / \mathrm{t} / \rightarrow[\mathrm{ts}]$, $/ \mathrm{d} / \rightarrow[\mathrm{v}]$

Children who are phonologically disordered may use normal processes for a longer period of time (these children are "phonologically delayed"), or they may use more processes than normally-developing children. There are some processes which Grunwell acknowledges occur in the general population, but she says they are much less common than the regular processes. Examples of much less common processes are the realization of fricatives as approximants, and stopping of $/ 1, \mathrm{r} /$ to [d]. In addition to this, she identifies some processes which never or rarely occur in the general population, but which frequently appear in the disordered population. These are referred to as unusual substitutions. Unusual processes include frication of approximants, reduction of obstruent + approximant clusters to the approximant segment (atypical cluster reduction), glottal replacement, backing, fricatives substituted for stops, and stops substituted for glides (Grunwell 1987, Stoel-Gammon \& Dunn 1985). Children who use the unusual processes in addition to normal ones may be perceived as having a more severe disorder 
(Stoel-Gammon \& Dunn 1985). Following are descriptions of some less common and unusual processes that I will examine in detail.

Fricatives as Approximants: $/ \mathrm{f} / \rightarrow[\mathrm{w}], / \mathrm{s} / \rightarrow[\mathrm{l}]$ or $[\mathrm{j}]$.

Stopping of Liquids: $/ 1, \mathrm{r} /$ are stopped and become [d].

Backing: Alveolar sounds are backed to become velar sounds. $/ \mathrm{t} / \rightarrow[\mathrm{k}], / \mathrm{d} / \rightarrow[\mathrm{g}]$.

Frication of approximants: $/ 1 / \rightarrow[\delta] / \mathrm{w} / \rightarrow[\mathrm{v}]$

Stops substituted for glides: $/ \mathrm{w} / \rightarrow[\mathrm{b}], / \mathrm{j} / \rightarrow[\mathrm{t}]$

Frication of stops: $/ \mathrm{b} / \rightarrow[\mathrm{v}]$

When we look at normal and unusual processes, we see that markedness also

plays a role. In general development patterns, it is believed that the less-marked segments are acquired first, and more marked segments are acquired later. Therefore, when a child makes substitutions, s/he is using a less-marked segment to substitute for a more marked one. For example in the case of stopping, $[\theta] \rightarrow[t]$, the unmarked and early-acquired $[t]$ replaces the marked and late-acquired [ $\theta]$. In unusual substitutions, the reverse seems to be the case.

\subsection{Acquisition, Feature Geometry and Underspecification}

Feature hierarchy may be able to account for how children acquire features. It is suggested that features at the top of the hierarchy may be acquired first, followed by more embedded, lower features. This is a kind of Jakobsonian analysis in which children acquire phonological oppositions by acquiring features, but it is a more detailed analysis because it offers an order in which acquisition occurs (Ingram 1997). A problem with 
this kind of analysis is that there are many different models of feature hierarchy, and those models incorporate different features in the root node.

Bernhardt (1992) identifies a relationship between language acquisition and the organization of a feature hierarchy. She posits that higher and dominant nodes in a hierarchy would have developmental precedence over subordinate nodes. Higher level features in the geometry will tend to be specified before deeply embedded, lower level features. So, manner features which exist at the root node would be developed before deeply embedded features of place. In Bernhardt's example, the manner [nasal] may be acquired, such as the segment $/ \mathrm{n}$, but if [dorsal] has not yet been acquired, then the phoneme $/ \mathfrak{y} /$ would not appear. This is predictable under feature geometry because the manner node which contains [nasal] dominates the place node which contains [dorsal]. The pattern of acquisition of features results in an expanding hierarchy that reflects increasing complexity (Beers 1996).

Radical underspecification also makes predictions about when children acquire phonemes based on the number of marked features in a segment. There are "default" segments that are determined by a minimum requirement of feature specification, and they are expected to be acquired early (Bernhardt \& Stoel-Gammon 1994). For English, default consonants might be the coronal stops $/ \mathrm{t} /$ and $/ \mathrm{d} /$. The frequent appearance of these sounds in children's speech would not be due to error patterns, but to the fact that those segments are default segments in cases where specified features are not yet acquired by the child (Bernhardt \& Stoel-Gammon 1994). Development would proceed with 
children adding specified values gradually to the unspecified features (Bernhardt \& Gilbert 1992).

Bernhardt and Gilbert (1992) outline developmental implications of the feature hierarchy and underspecification theories: (1) More deeply embedded features should be learned later than major node features that occur higher in the hierarchy; (2) Manner features could apply or fail to apply to all place features at once, because they dominate the place node, or they could be blocked from applying to all place nodes because each place is autonomous; (3) Input confirms default features, and presents evidence for specified values. A child is expected to add specified values gradually to the set of universally unspecified features. 'Default' segments can be expected early in acquisition as a result of minimum specification rather than as the result of a set of rules or processes. As new features are acquired, over- or undergeneralization may occur until the feature is fully acquired.

Chin and Dinnsen (1991) compared place-manner-voice and distinctive feature frameworks with feature geometry, in production errors of 40 children. They examined processes such as cluster coalescence, fricative/affricate alternations and alveolar stop/glottal alternations. They concluded that feature geometry captured the nature of the processes better than the other frameworks by restricting the classes of sounds that acted together. Beers (1996) found that a feature geometry based on a model by Sagey accounted for the acquisition of Dutch phonemes. Higher level features were acquired before lower ones in the expected developmental order. There were some unlikely developmental orders in the data, and those involved lower level manner features. 
Abnormal developmental patterns were accounted for because the model could not explain them. In the case of deviant phonology, development of segments and contrasts by a child would violate the principles of the feature hierarchy. Beers concluded that the feature geometry theory outlines universal principles of acquisition which allow for some individual variation and accounts for the data which included normally-developing and deviant phonological development.

There is a recent model by Rice and Avery (1995) which accounts for individual variation in child language acquisition. It was not studied as a part of this thesis, but its ability to account for general and individual patterns of acquisition suggests that it should be considered in assessments of feature geometry models.

\subsection{Goal of the Thesis}

As we have seen, use of phonological processes to describe children's normal or unusual substitutions falls short as a theory. While it is descriptive to use processes to compare the child and adult forms, the processes lack explanatory power. Research to date has shown, tentatively, that feature geometry and radical underspecification hold both descriptive and explanatory power for child substitutions and the process of phonological acquisition. Representations of markedness are incorporated into both feature geometry and radical underspecification. As such, it should follow that segments which are less specified can be represented by a tree structure which is less complex than a tree structure that represents more specified segments. Patterns of normal acquisition should proceed by acquiring features from the root of the tree first, followed by feature progressively lower in the tree. According to radical underspecification, the features 
acquired first are least specified, then the additional specifications are acquired. We should be able to relate these two proposals by looking at specified features as they appear on the feature geometry tree. Less specified features should appear higher than more specified features. Similarly, we should be able to use representations from feature geometry and underspecification to account for normal substitution processes and distinguish them in a principled way from unusual substitutions.

I have looked at the relationship between feature geometry, underspecification and language acquisition. Now I would like to look at the ability that feature geometry and underspecification have in identifying unusual processes in disordered phonology. I will look at previously published data consisting of context-free substitutions commonly found in normally-developing children, and substitutions which are considered unusual or idiosyncratic. My hypothesis is that while normal substitutions involve substitutions of early-acquired features (located higher in the hierarchy and less-specified features) for later-acquired features (more embedded and more specified), unusual substitutions do not follow the same pattern. With unusual substitutions, I expect that substitutions will occur with more embedded and more specified features replacing ones located higher in the hierarchy, which are also less specified. If it is the case that the substitutions can be predicted and explained in this manner, then analyzing substitutions based on feature hierarchy and underspecification can provide a principled way to account for normal and unusual substitutions.

I will compare three types of substitutions identified by Grunwell (1987): normal substitutions which represent common developmental substitutions that result from 
normal processes, less common substitutions which result from processes used to a limited degree by normally-developing children, and unusual substitutions which result from processes not used by normally-developing children. I will evaluate each substitution against three models of feature geometry and radical underspecification. In order for the models of feature geometry or radical underspecification to account for the three types of substitutions, distinct patterns should emerge for each type of substitution. Common processes and substitutions should involve a less specified segment substituting for a more specified segment, and a higher level feature substituting for a lower level feature. Unusual substitutions should show the reverse situation with more specified segments replacing less specified ones and lower-level features substituting for higher level ones. Some general pattern should also emerge for the less common substitutions that accounts for their limited use by the general population and greater use by children who use more unusual processes.

Below are the processes and segments that represent the substitutions that I will examine. The feature geometry models are the Bernhardt model, the Halle-Sagey model and the Clements-Hume model. I will base underspecification on Bernhardt's table of Marked Consonant Specifications for Adult English.

\section{Normal Processes:}

Stopping: $/ \mathrm{s} / \rightarrow[\mathrm{t}], / \mathrm{d} / \rightarrow[\mathrm{d}]$

Gliding: $/ \mathrm{l} / \rightarrow[\mathrm{j}], / \mathrm{r} / \rightarrow[\mathrm{w}]$

Fronting: Depalatalization, $/ \mathrm{S} / \rightarrow[\mathrm{s}]$ 


\section{Velar Fronting: $/ \mathrm{k} / \rightarrow[\mathrm{t}]$}

Fricative Substitution: $/ \theta / \rightarrow[\mathrm{s}], / \theta / \rightarrow[\mathrm{f}]$

\section{Less Common Processes}

Fricatives as Approximants: $/ \mathrm{s} / \rightarrow[\mathrm{l}]$

Stopping of Liquids: $/ 1, \mathrm{r} / \rightarrow$ [d]

\section{Unusual Processes:}

Backing: $/ \mathrm{t} / \mathrm{k}]$

Frication of approximants: $/ 1 / \rightarrow[\delta] / \mathrm{w} / \rightarrow[\mathrm{v}]$

Stopping glides: $/ \mathrm{w} / \rightarrow[\mathrm{b}], / \mathrm{j} / \rightarrow[\mathrm{t}]$

\section{Analysis of Feature Geometry Models and Substitutions}

In analyzing the substitutions, I will look at the specification of features in the target and the substitute. The hypothesis of underspecification held that for normal processes, more specified targets would be replaced by less specified substitutes, and the opposite would be true for unusual substitutions. One way we can assess this by simply counting the number of features specified in the target and the substitute. It is also a goal of this thesis to determine if the feature geometry models accurately reflect this information. Do the geometry models give an account of normal versus unusual substitutions? To check this, the specified features which differ between the target and the substitute are designated on the tree. The geometry hypothesis holds that normal substitutions involve features which are located lower on the tree, while unusual substitutions should affect features located higher on the tree models. Last, I will look at 
the nature of change of specified features. It is useful to know if substitutions involve features changing in a particular way with respect to markedness. I will investigate whether normal substitutions involve targets with marked specifications becoming unmarked (default) specifications for segments, and whether unusual substitutions involve targets with unmarked or less marked specifications becoming more marked for the substitute segment. The unmarked specification for place of articulation of obstruents is [+coronal], thus other places are more marked. For manner of articulation of obstruents [-continuant] is the unmarked specification, and for voicing of obstruents, [voice] is unmarked. In more general terms, for place of articulation, [+sonorant] is less marked than [+sonorant, +consonantal]. Markedness relationships should be evident from the geometry trees since it is proposed that more marked features are located lower on the trees.

\subsection{Normal Processes}

These substitutions involve the normal processes outlined by Grunwell (1987) and Stoel-Gammon and Dunn (1985). They will be examined first in terms of the features specified for each segment in radical underspecification, and then in terms of each feature geometry model. These processes include stopping, fronting, liquid gliding, and fricative replacement.

\subsubsection{Stopping: $/ \mathrm{s} / \rightarrow[\mathrm{t}], / \mathrm{d} / \rightarrow[\mathrm{d}]$}

$\begin{array}{lll}\stackrel{1}{/ s} / & \rightarrow & {[\mathbf{t}]} \\ {[\text { +consonantal }]} \\ {[\text { +continuant }]} & & {[\text { +consonantal }]}\end{array}$


Figure 3.1.a Bernhardt Model of $/ \mathrm{s} / \rightarrow[\mathrm{t}]$

\section{Bernhardt Model}

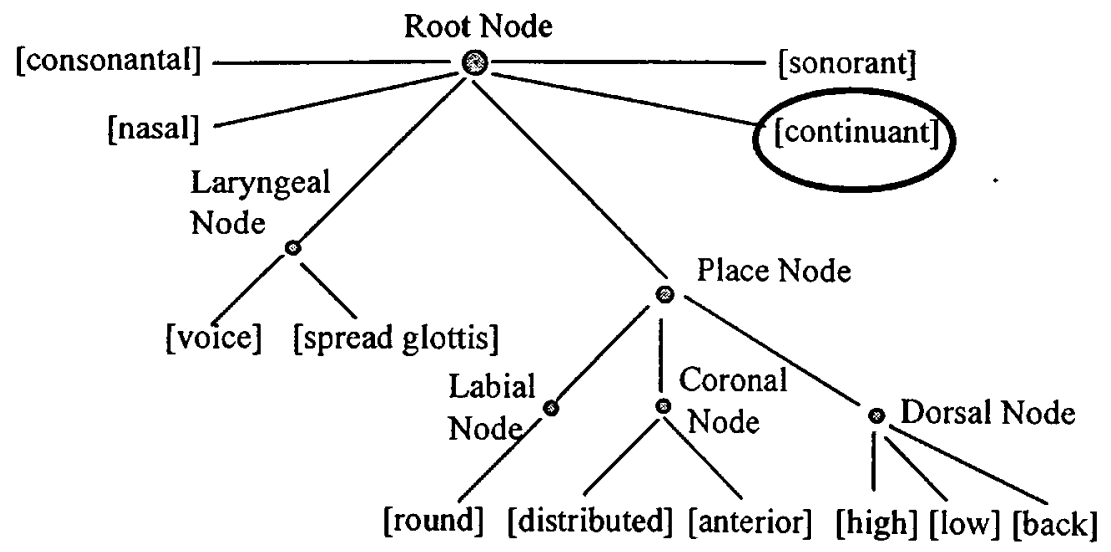

Figure 3.1.b Clements-Hume Model of $/ s / \rightarrow[t]$

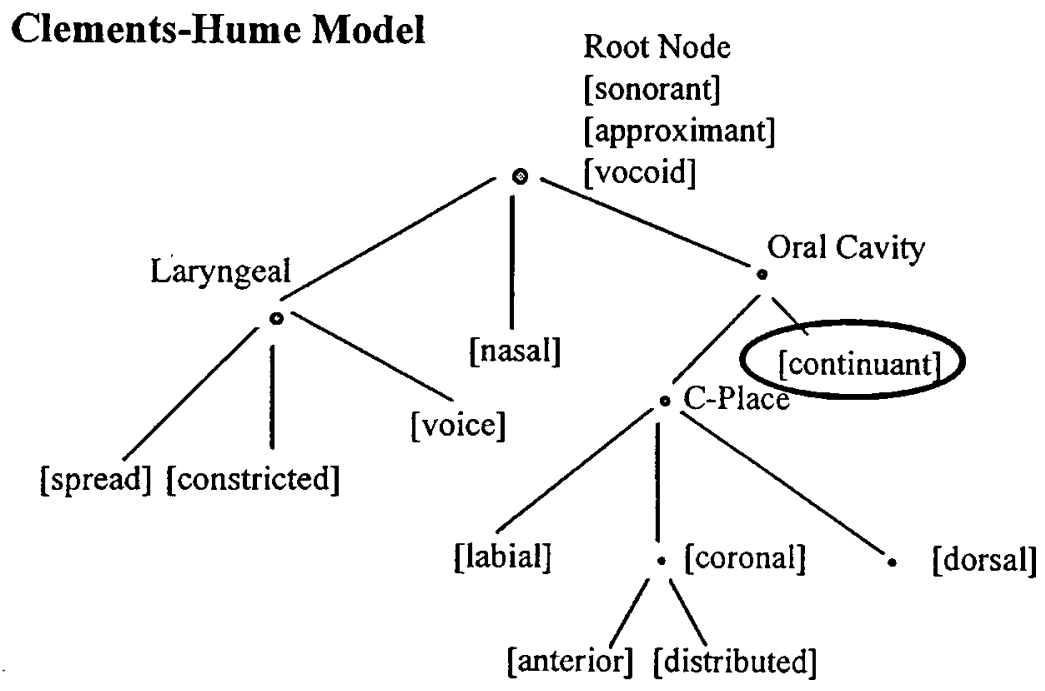


Figure 3.1.c Halle-Sagey Model of $/ s / \rightarrow[t]$

\section{Halle-Sagey Model}

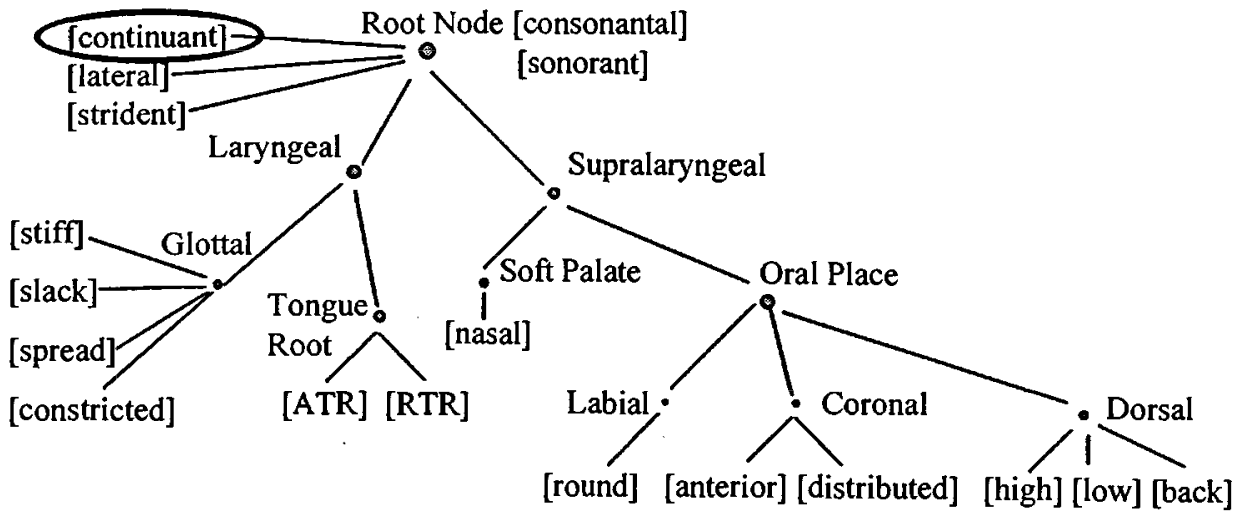

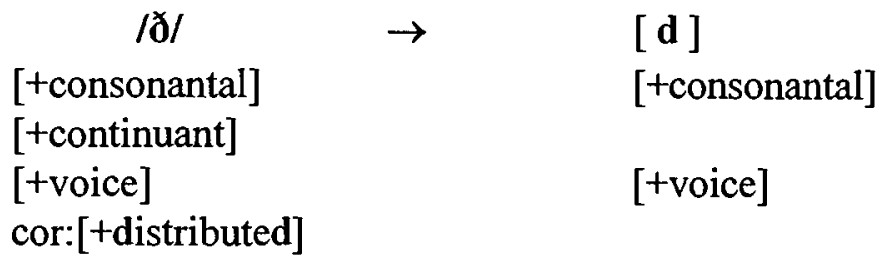

Figure 3.1.d Bernhardt Model of $/ \delta / \rightarrow[d]$

\section{Bernhardt Model}

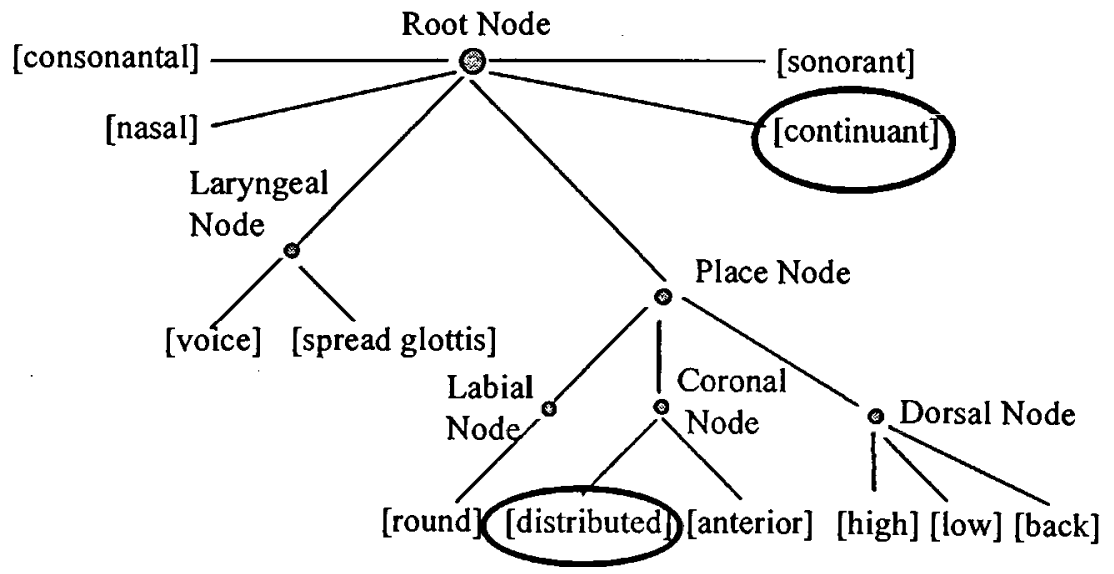


Figure 3.1.e Clements-Hume Model of $/ \mathbf{d} / \rightarrow$ [d]

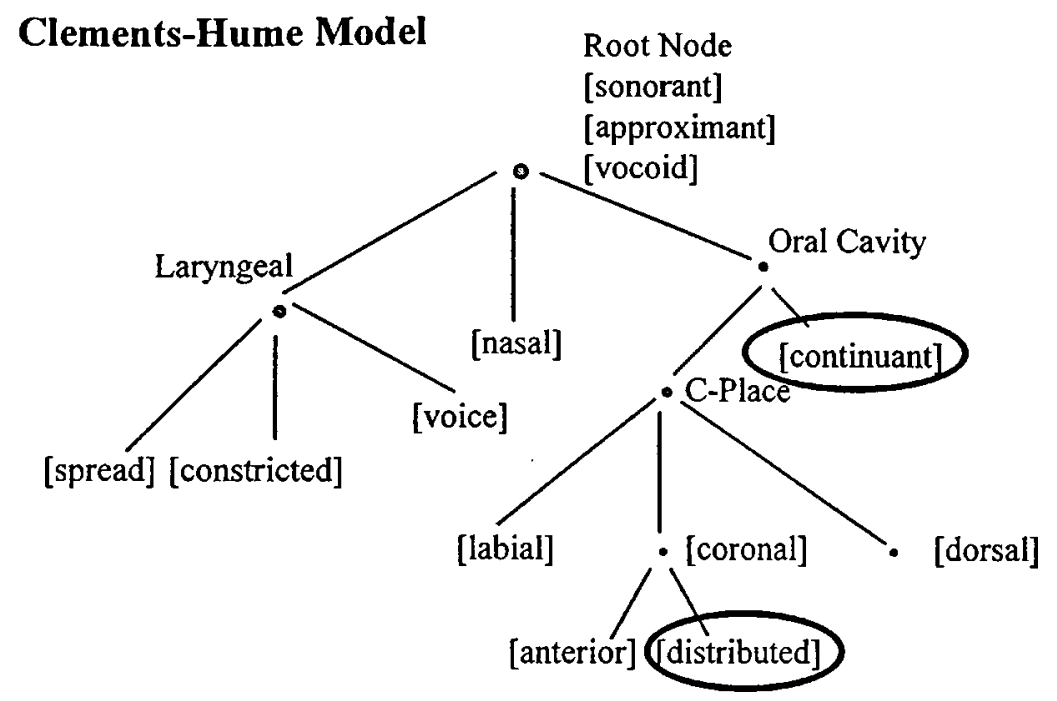

Figure 3.1.f Halle-Sagey Model of $/ \delta / \rightarrow$ [d]

\section{Halle-Sagey Model}

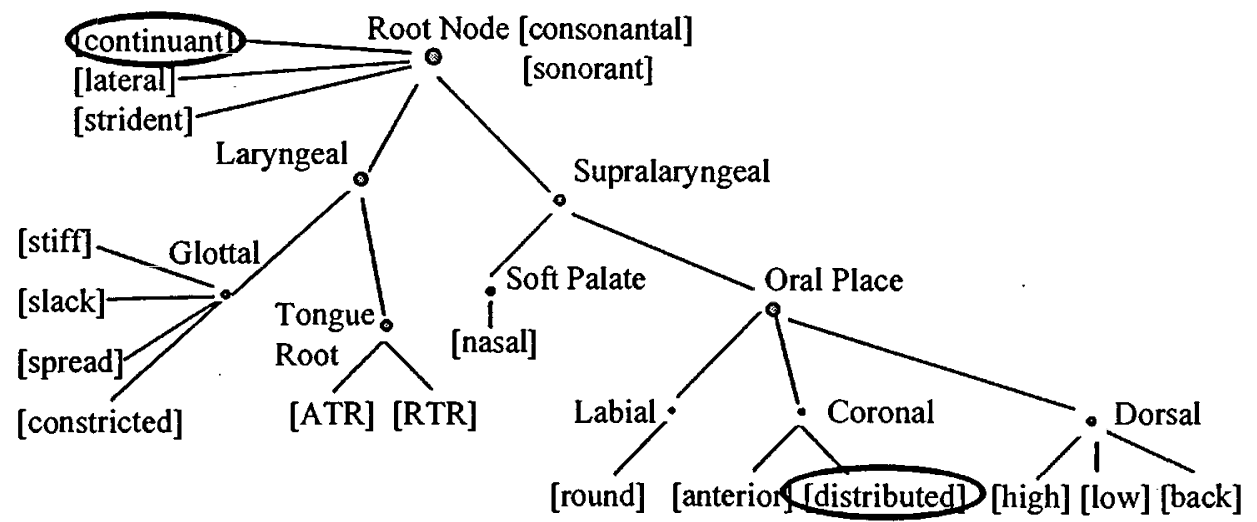

Stopping involves a target which is more specified being substituted by a segment which is less specified. Two features specified in $/ \mathrm{s} /$ become one specified feature in [ $\mathrm{t}]$. The process involves changes in the [continuant] feature for both substitutions. A target which is specified for [+continuant] changes to a substitute which is [-continuant], and therefore not specified for that feature. Additionally, in $/ \delta / \rightarrow[d]$, place of articulation is specified for cor:[+distributed] in the target, but not in the substitute. Both substituted 
segments, $[t]$ and $[d]$, are unspecified for place of articulation because they occur at the coronal place, which is the unspecified default place of articulation.

In the Bernhardt model, the feature [continuant] is located at the root node of the tree, and this feature is affected in both substitutions. The Halle-Sagey model also presents the case of the root node being affected by the [continuant] change. In the Clements-Hume model, [continuant] is not located in the root node, so no root node features change. The cor:[distributed] feature which is affected in the $/ ð / \rightarrow[d]$ substitution is located at the place node (lowest level features) for all geometry models.

In terms of markedness, place of articulation is specified for $/ \mathrm{\partial} /$, but not for [d], so a marked form in the target becomes unmarked in the substitute. Both $/ t /$ and $/ \mathrm{s} /$ are [+coronal] and unspecified for place of articulation, so the target and substitute do not differ in markedness regarding that feature. For manner of articulation, both $/ \delta /$ and $/ \mathrm{s} /$ are marked for [+continuant] and the substitutes are not marked for manner. That indicates a markedness relationship in which the target is more marked than the substitute. For voicing, the markedness remains the same between the target and substitute in both cases, either marked for both segments, or unmarked for both segments.

\subsubsection{Fronting:}

$\begin{array}{ll}\begin{array}{l}\text { (velar) } \\ \text { (depalatalization) }\end{array} & \begin{array}{l}/ \mathrm{k} / \rightarrow[\mathrm{t}] \\ / \mathrm{J} / \mathrm{S}]\end{array} \\ / \mathrm{k} / \mathrm{s}] & {[\mathrm{t}]} \\ & {[\text { +consonantal }]}\end{array}$


Figure 3.1.g Bernhardt Model of $/ k / \rightarrow[t]$

\section{Bernhardt Model}

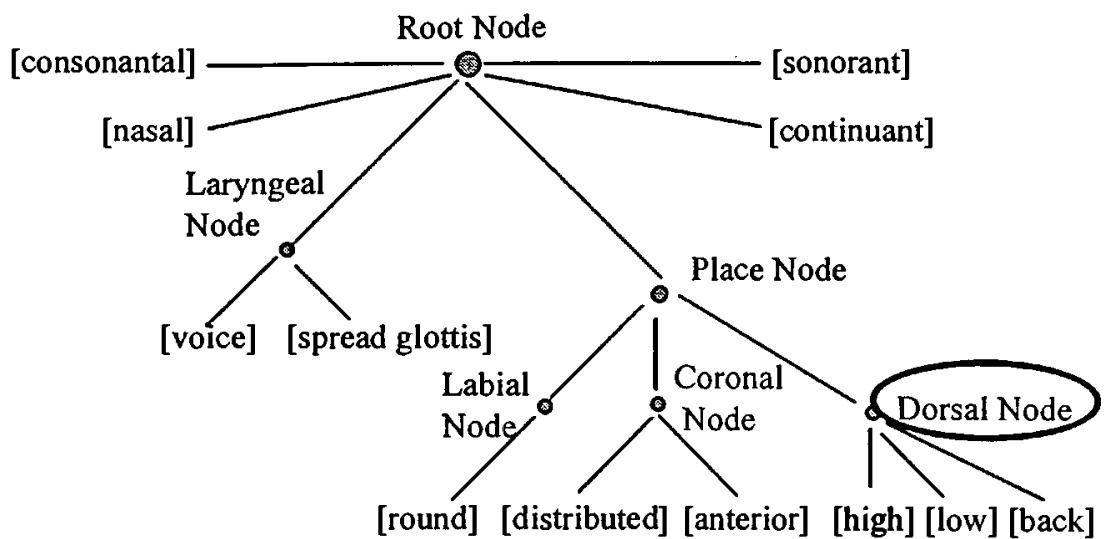

Figure 3.1.h Clements-Hume Model of $/ \mathrm{k} / \mathrm{t} \mathrm{t}]$

\section{Clements-Hume Model}

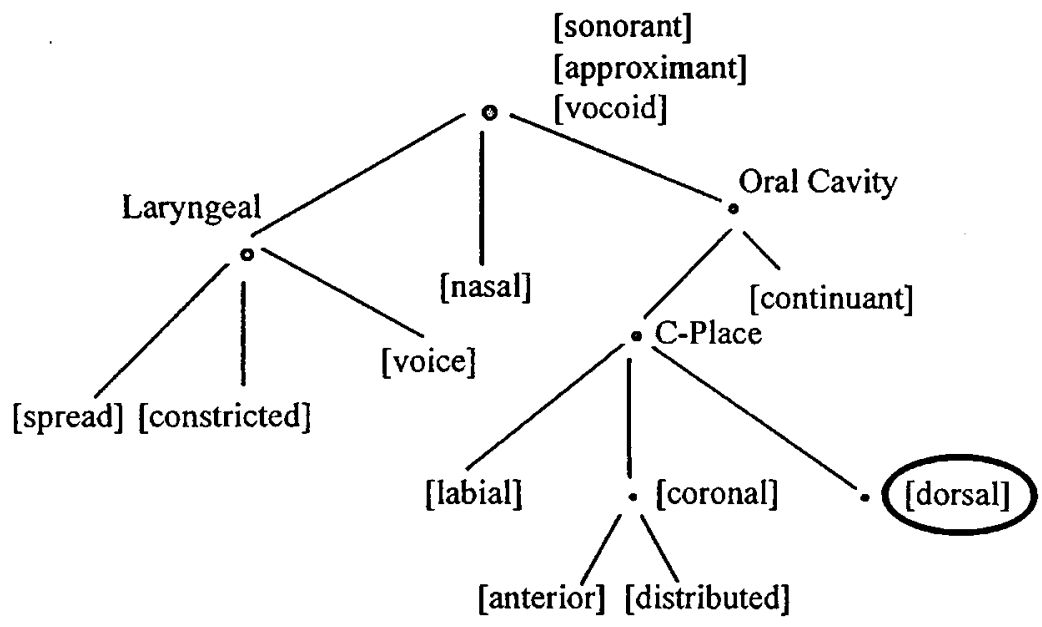


Figure 3.1.i Halle-Sagey Model of $/ \mathrm{k} / \mathrm{t}]$

\section{Halle-Sagey Model}
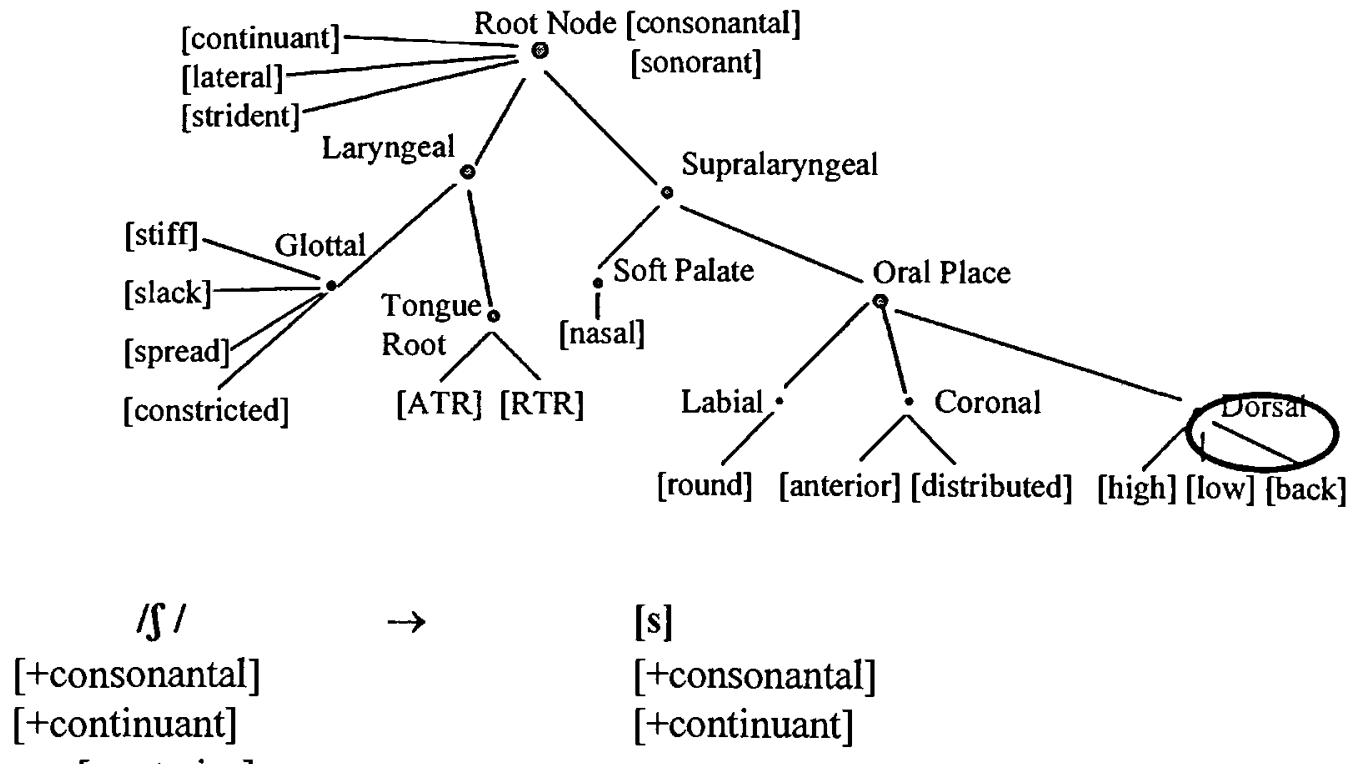

cor:[-anterior]

Figure 3.1.j Bernhardt Model of $/ \mathcal{S} / \rightarrow[s]$

\section{Bernhardt Model}

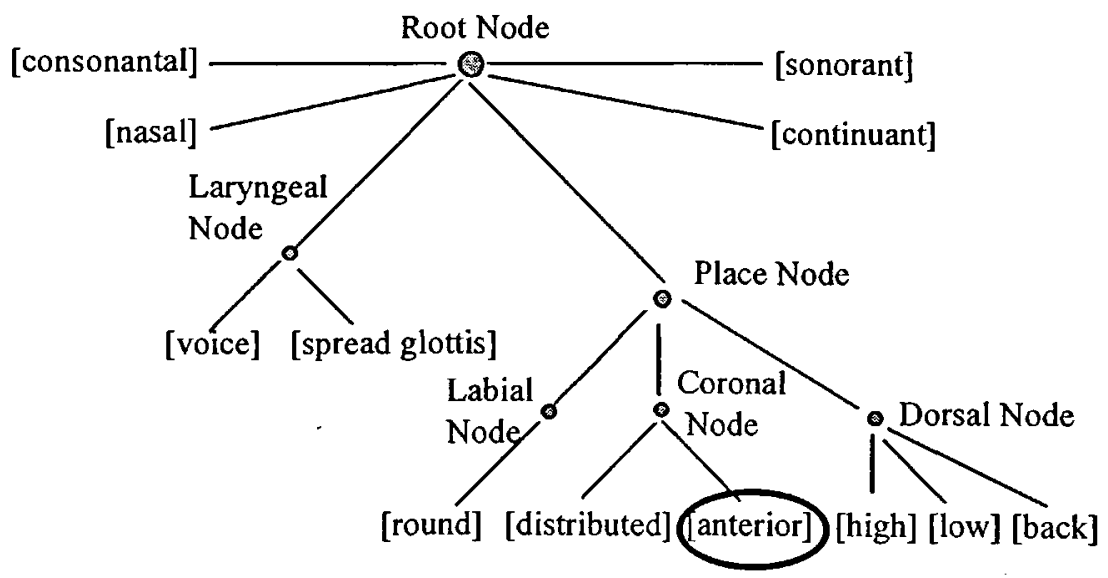


Figure 3.1.k Clements-Hume Model of $/ \mathfrak{g} / \rightarrow[\mathrm{s}]$

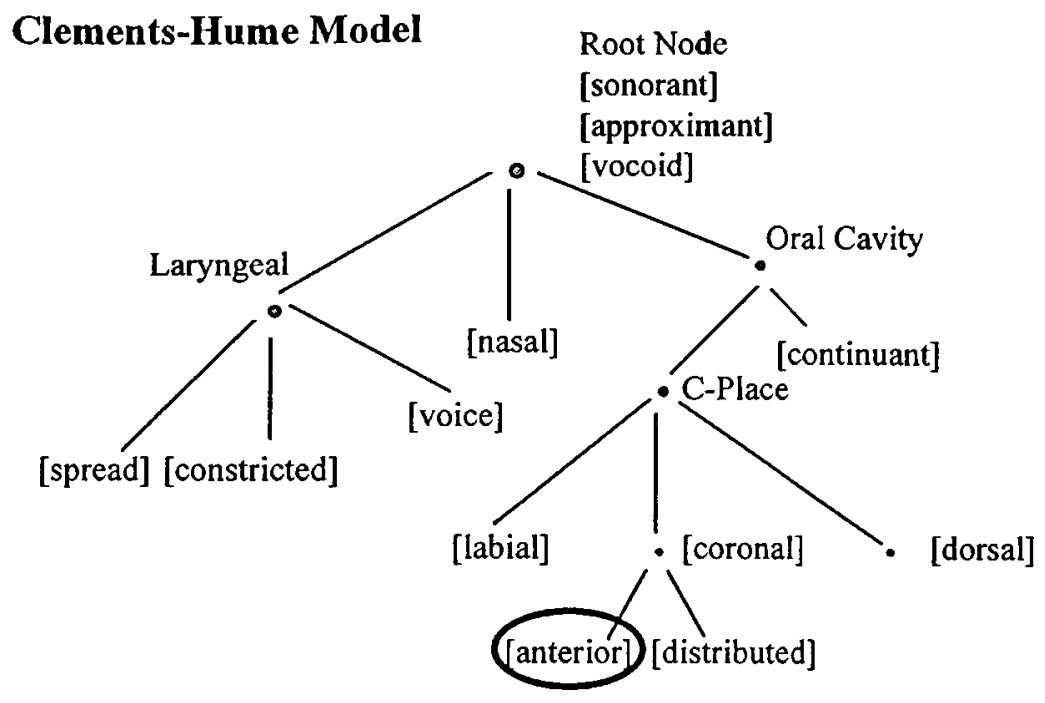


Figure 3.1.I Halle-Sagey Model of $/ \mathrm{f} / \rightarrow[\mathrm{s}]$

\section{Halle-Sagey Model}

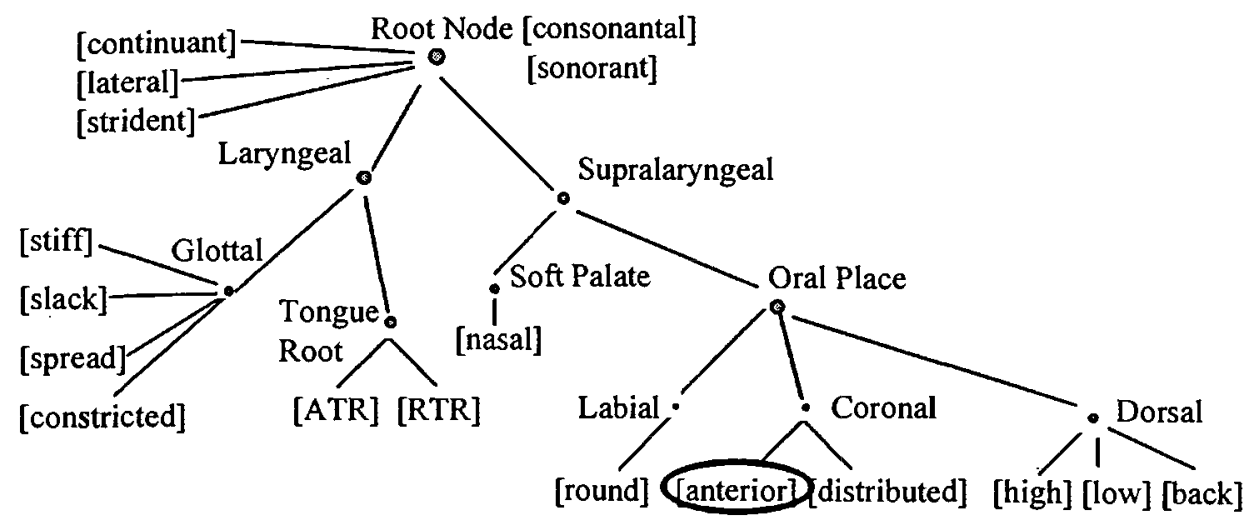

In fronting, a more specified target is substituted by a less specified substitute.

For $/ \mathrm{k} / \rightarrow[\mathrm{t}]$, two specified features change to one; in $/ \mathrm{S} / \rightarrow[\mathrm{s}]$, three specified features change to two. Places of articulation are specified in the target, butt the substitute is unspecified for place. In $/ \mathrm{k} / \mathrm{t}$ ], the [dorsal] place is specified in the target, and no place is specified in the substitute. In $/ \mathrm{J} / \rightarrow[\mathrm{s}]$, cor:[-anterior] is specified in the target, but no place of articulation is specified for the substitute. Both substitutes are unspecified for place because they occur at the default place, which is unspecified [+coronal].

In all the feature geometry models, only lower level nodes are affected. The coronal:[anterior] node is affected for $/ \mathrm{S} / \rightarrow$ [s], and the [dorsal] node is affected for $/ \mathrm{k} / \rightarrow[\mathrm{t}]$

For both cases of fronting, the place of articulation is marked for the target ([dorsal] for $/ \mathrm{k} /$ and cor:[-anterior] for $/ \mathrm{S} /$ ), and the substitutes are unmarked for place of articulation. This involves a more marked segment becoming less marked in terms of 
place of articulation. Manner of articulation is unspecified ([-continuant $]$ ) for $/ \mathrm{k} /$ and $[\mathrm{t}]$, so there is no change in degree of markedness from target to substitute. In the $/ \mathrm{S} / \rightarrow$ [s] substitution, both target and substitute are specified for [+continuant], so the relationship does not change. All the segments, targets and substitutes, are unmarked for voice, so the voicing specification is not affected.

3.1.3 Liquid Gliding: $/ \mathrm{r} / \rightarrow[\mathrm{w}], / \mathrm{L} / \rightarrow[\mathrm{j}]$

\begin{tabular}{lll}
\multicolumn{1}{c}{$/ \mathbf{r} /$} & $\rightarrow$ & {$[\mathbf{w}]$} \\
[+sonorant] & & {$[$ +sonorant] } \\
[+consonantal] & & \\
cor:[+distributed] & & [labial]
\end{tabular}

Figure 3.1.m Bernhardt Model of $/ \mathrm{r} / \rightarrow[\mathrm{w}]$

\section{Bernhardt Model}

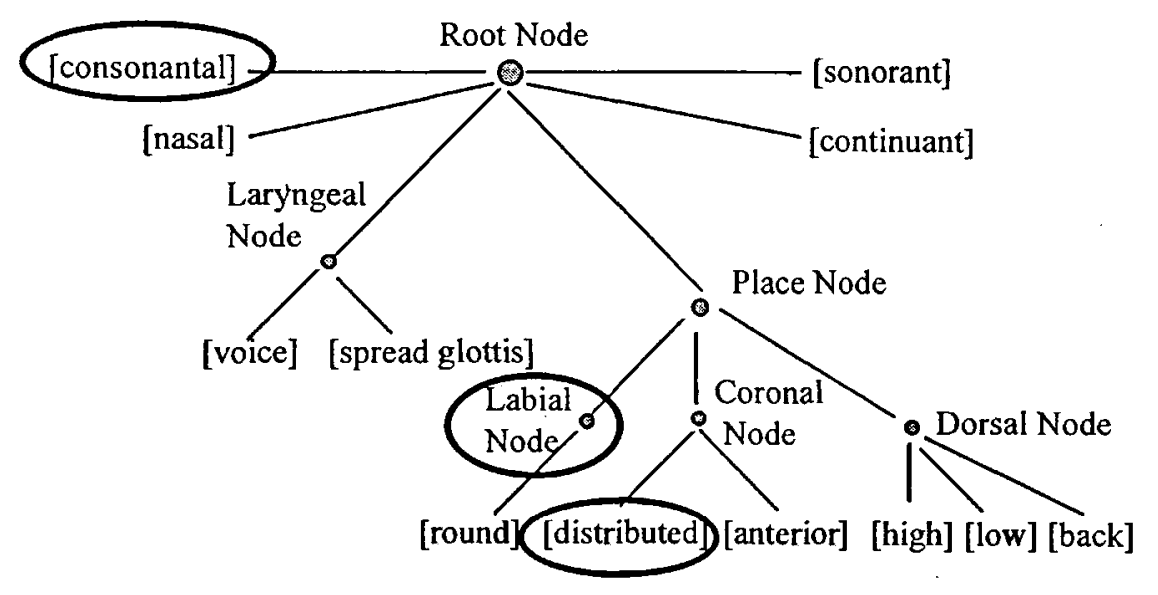


Figure 3.1.n Clements-Hume Model of $/ r / \rightarrow$ [w]

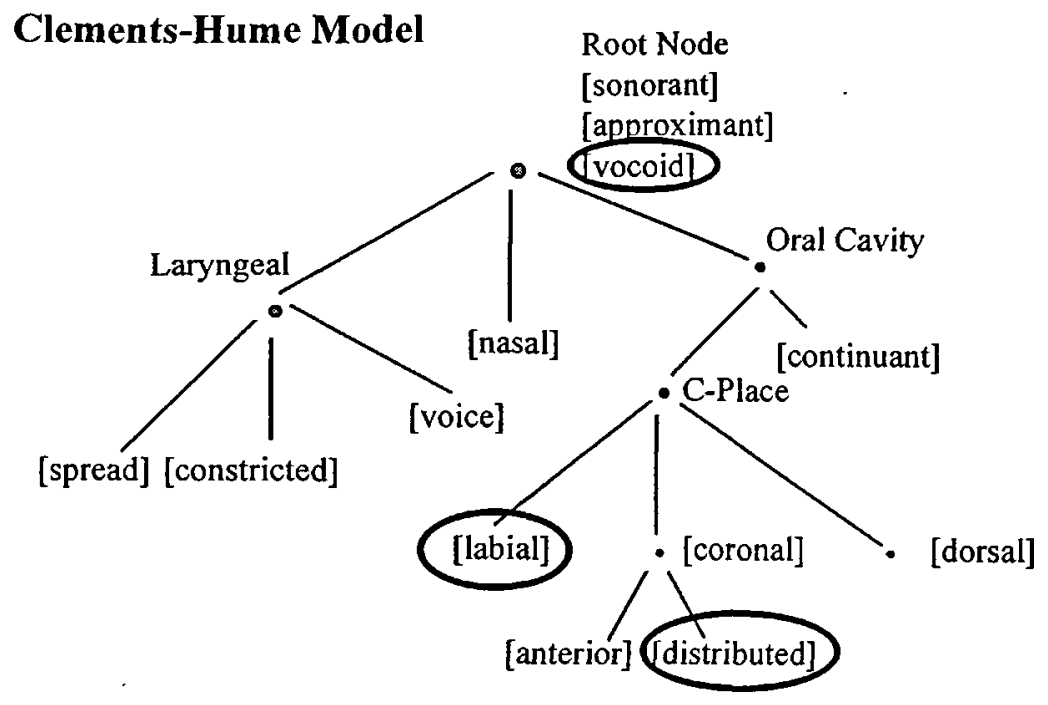

Figure 3.1.o Halle-Sagey Model of $/ r / \rightarrow[w]$

\section{Halle-Sagey Model}

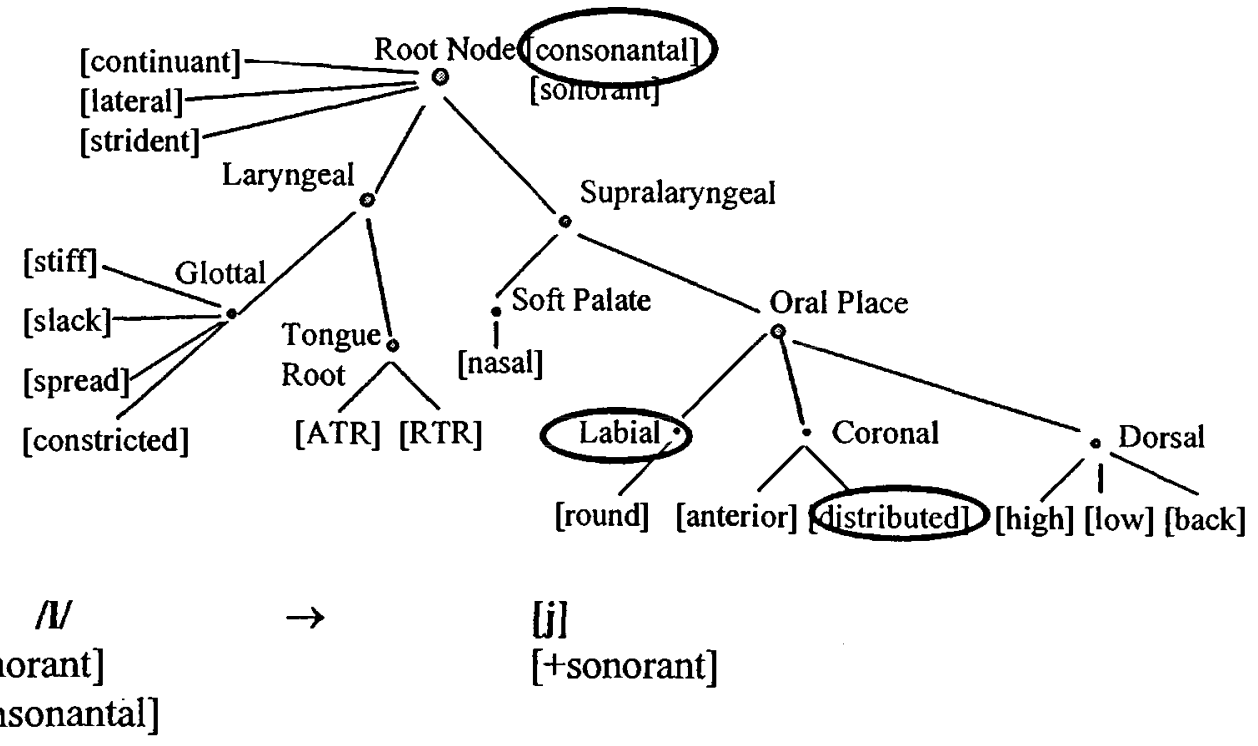


Figure 3.1.p Bernhardt Model of $/ \mathrm{V} \rightarrow[\mathrm{j}]$

\section{Bernhardt Model}

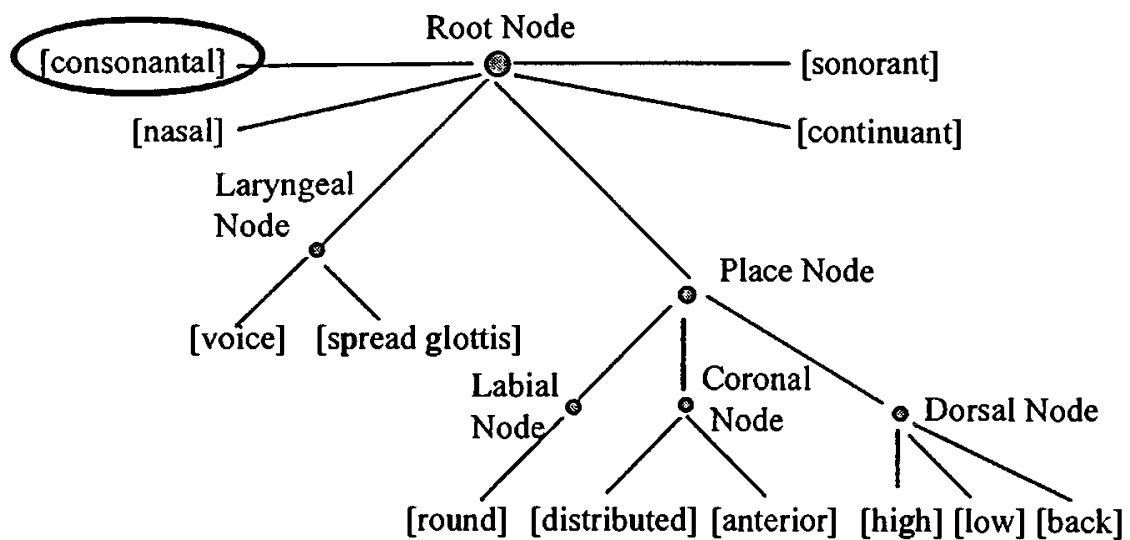

Figure 3.1.q Clements-Hume Model of $N / \rightarrow[j]$

\section{Clements-Hume Model}

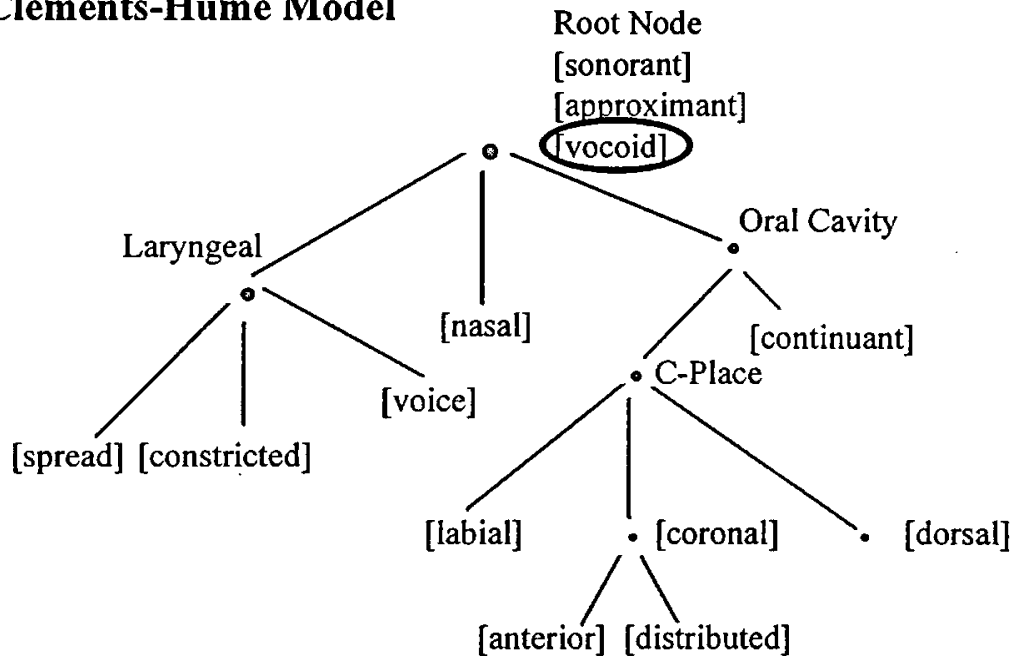


Figure 3.1.r Halle-Sagey Model of $/ \mathrm{l} / \mathrm{b}]$

\section{Halle-Sagey Model}

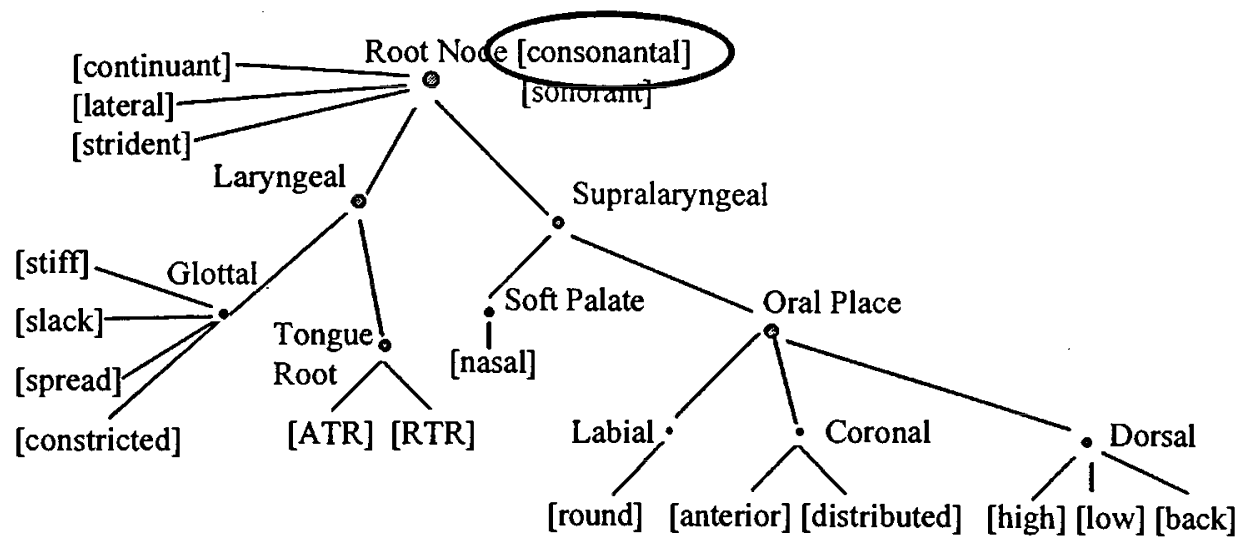

Liquid gliding shows more specified targets becoming less specified substitutes.

$/ 1 / \rightarrow[\mathrm{j}]$ involves two specified features in the target and only one in the substitute, and $/ r / \rightarrow[w]$ involves three specified features being substituted by two specified features. The difference between $/ r /$ and $[w]$ involves place of articulation: $/ r /$ is specified for cor:[distributed], and / $\mathrm{w} /$ is not, and $/ \mathrm{w} /$ is specified for labial whereas $/ \mathrm{r} /$ is not. The feature [consonantal] is also affected in the substitution of $[\mathrm{w}]$ for $/ \mathrm{r} / . \quad / \mathrm{l} / \rightarrow[\mathrm{j}]$ involves a difference in specification for [consonantal] because $/ \mathrm{L} / \mathrm{is}$ specified for [consonantal] whereas [i] is not, and is specified for [sonorant]. Both $/ 1 /$ and $/ \mathrm{j} /$ are unspecified for place of articulation as they are articulated at the default coronal place.

In both cases of gliding, root node features are changed for all three models of feature geometry. In the Bernhardt and Halle-Sagey models, the [consonantal] feature at the root node is affected, and in the Clements-Hume model, the feature [vocoid] is affected. Additionally, all models reflect involvement of the place nodes, [coronal] and [labial] for $/ \mathrm{r} / \rightarrow[\mathrm{w}]$. 
Both cases of liquid gliding involve targets which are [+sonorant, +consonantal] being substituted by segments which are unspecified for [+consonantal]. This involves a decrease in markedness for manner of articulation from the target to the substitute. Specification of voicing is not affected in this process. In terms of place of articulation, both $/ 1 /$ and [j] are articulated at the default place, so there is no change in markedness. But, $/ \mathrm{r} /$ is specified for cor:[+distributed] and [w] is specified for [labial]. There is a difference in specification, but the markedness relationship is not immediately clear in this case since these are both place nodes. However, [labial] is not a terminal node, whereas cor:[+distributed] is. This means that cor:[+distributed] is located lower on the trees and is therefore more marked than [labial].

3.1.4 Fricative Replacement: $/ \theta / \rightarrow[\mathrm{s}], / \theta / \rightarrow[\mathrm{f}]$

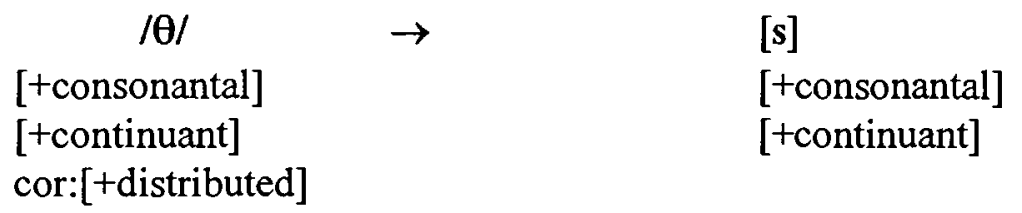

Figure 3.1.s Bernhardt Model of $/ \theta / \rightarrow[s]$

Bernhardt Model

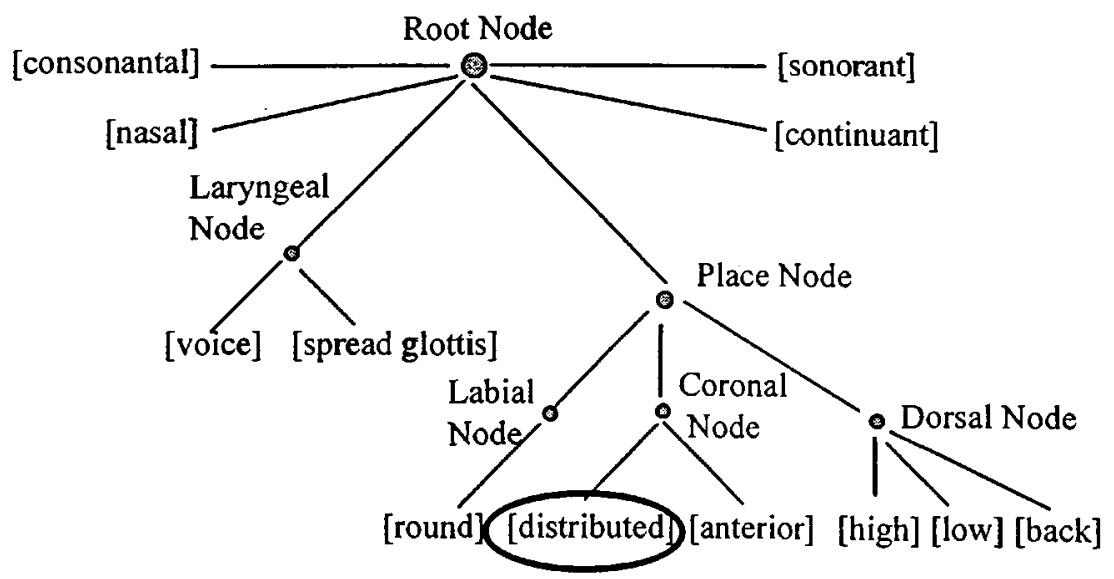


Figure 3.1.t Clements-Hume Model of $/ \theta / \rightarrow$ [s]

\section{Clements-Hume Model}

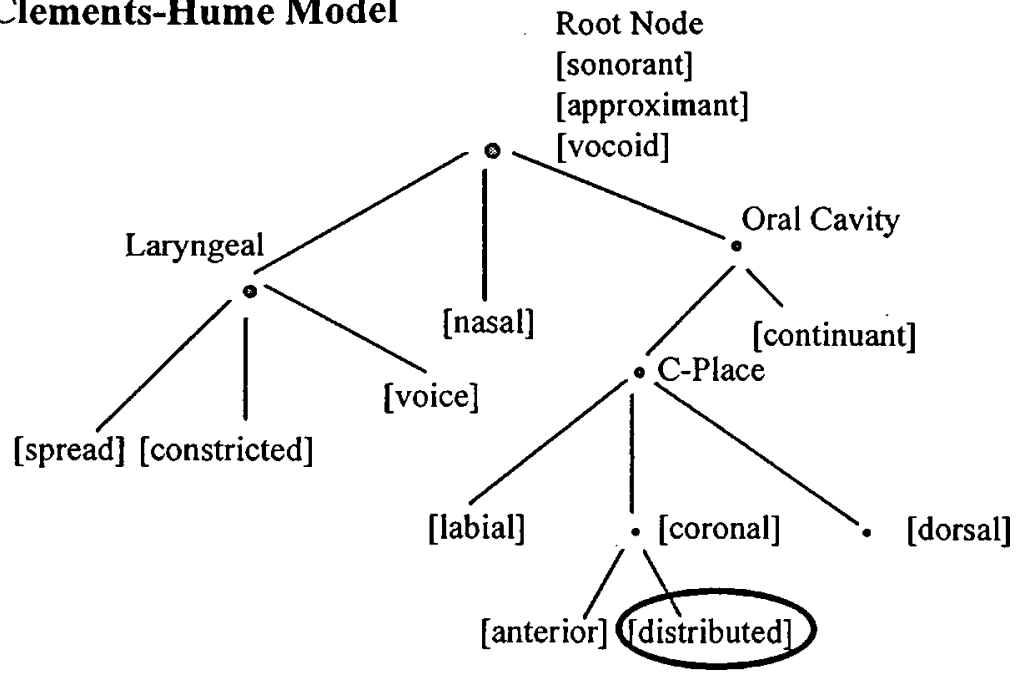

Figure 3.1.u Halle-Sagey Model of $/ \theta / \rightarrow[\mathrm{s}]$

\section{Halle-Sagey Model}

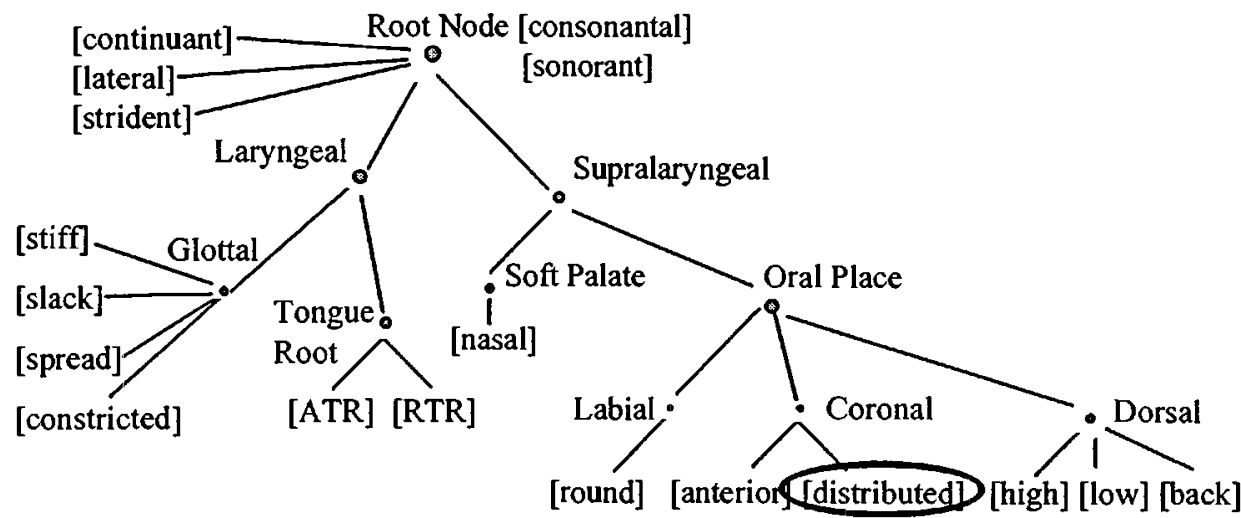

$/ \theta /$

[+consonantal]

[+continuant]

cor:[+distributed] [f]

[+consonantal]

[+continuant]

[labial] 
Figure 3.1.v Bernhardt Model of $/ \theta / \rightarrow[1]$

\section{Bernhardt Model}

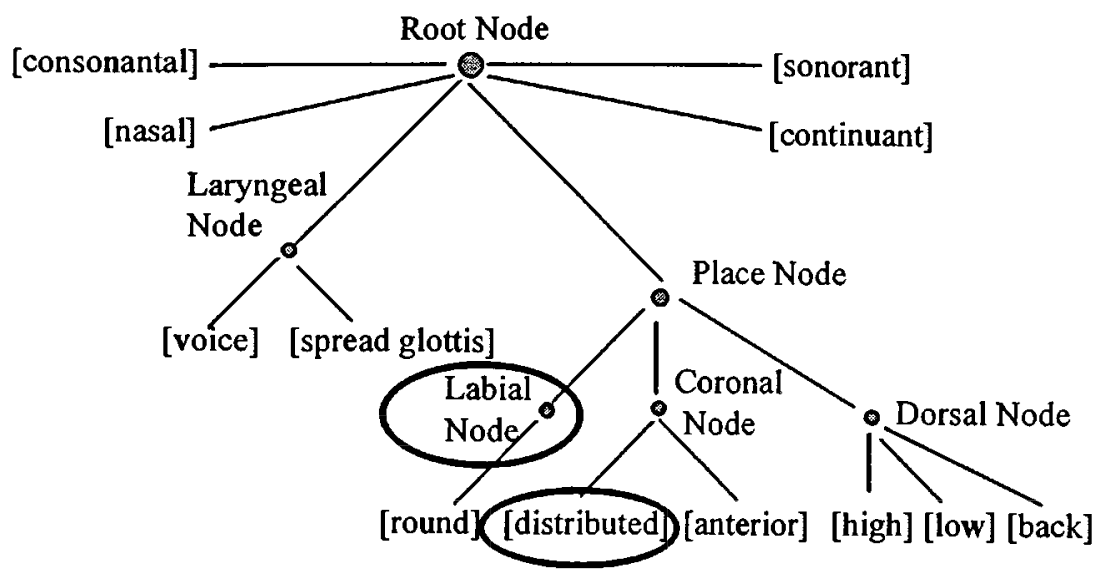

Figure 3.1.w Clements-Hume Model of $/ \theta / \rightarrow[f]$

\section{Clements-Hume Model}

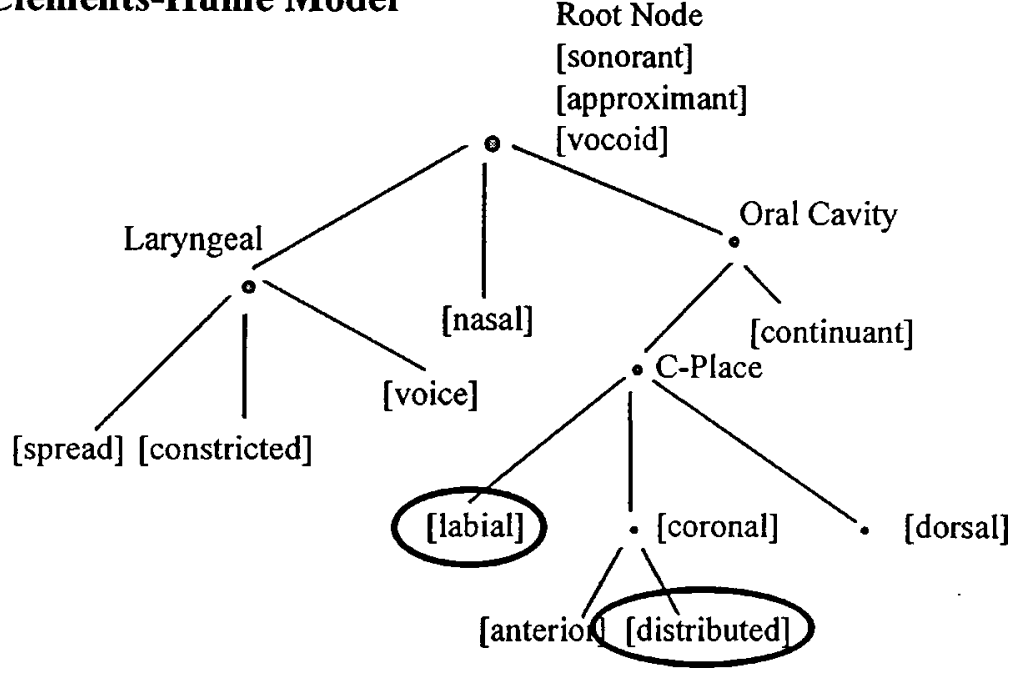


Figure 3.1.x Halle-Sagey Model of $/ \theta / \rightarrow$ [f]

\section{Halle-Sagey Model}

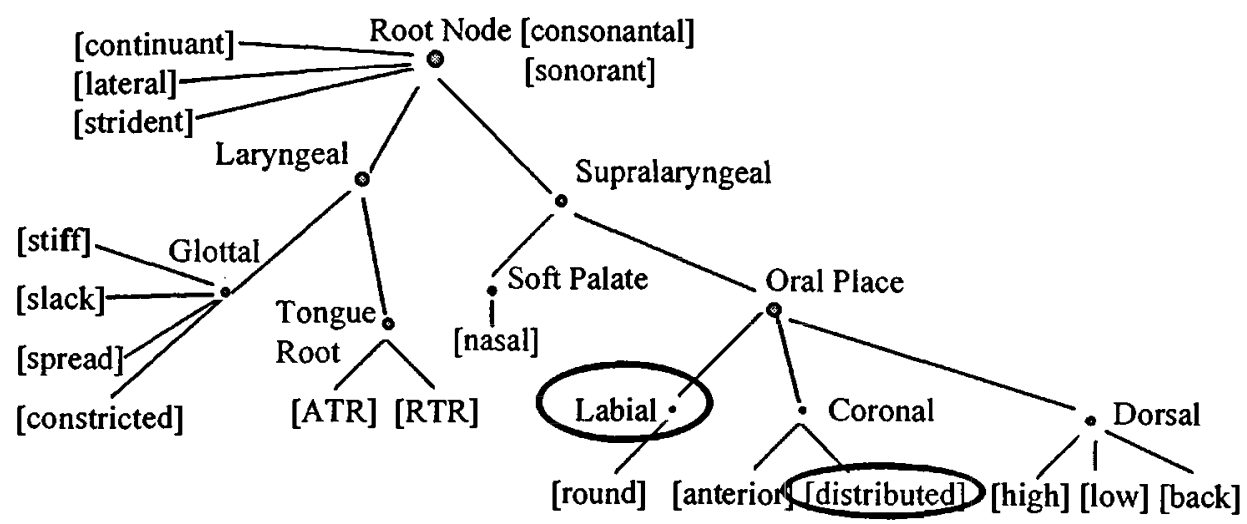

Fricative replacements show that more specified targets are replaced by equally specified or less specified substitutes. In the $/ \theta / \rightarrow[s]$ substitution, three specified features are reduced to two, and in the $/ \theta / \rightarrow / f /$ substitution, the number of specified features remains the same (three for both segments). For the $/ \theta / \rightarrow$ ff] substitution, the place of articulation feature specification differs from the target to the substitute, cor: [distributed] is specified for $/ \theta /$, and [labial] is specified for [f]. In both cases, the target sound is specified for cor:[+distributed], and the substitute is not specified for that feature. While [f] is specified for place [labial], [s] is not specified for place since it occurs at the default coronal place.

In all three feature hierarchy models, the lower level place nodes are affected in cor:[distributed] for both substitutions. Additionally, [labial] is specified for $/ \theta / \rightarrow[\mathrm{f}]$. No higher nodes are affected. 
Manner of articulation ([+consonantal,+continuant $])$ is the same for all the segments, targets and substitutes, so there is no change in degree of markedness of manner. All the segments are unmarked for voicing, so there is no difference in markedness. In the first substitution, $/ \theta / \rightarrow[\mathrm{s}]$, the target is specified for cor:[+distributed], but the substitute is not specified for place of articulation, so there is a more marked segment that is replaced by a less marked one. In $/ \theta / \rightarrow[\mathrm{f}]$, the markedness relationship is not as clear because the target is marked for cor:[+distributed] and the substitute is marked for [labial], but we can assume that cor:[+distributed] is more marked than [labial] due to its location on the tree.

\subsubsection{Summary of Normal Processes}

For normal processes in general, we can say that targets are more specified than the substitutes. The exception to this is $/ \theta / \rightarrow[\mathrm{f}]$ in which target and substitute are equally specified. Specification for place features differs from target to substitute in many cases. The place node which is most often affected is the coronal node, which is specified in the target, but not in the substitute. In most cases, the features specified in the substitute are a subset of features specified in the target. Exceptions to this include cases where the target is specified for cor:[distributed], $/ \theta / \rightarrow[\mathrm{f}]$ and $/ \mathrm{r} / \rightarrow[\mathrm{w}]$. In both of these substitutions, the target is specified for cor:[distributed] as place of articulation, and the substitute is specified for [labial].

All normal processes, with the exception of $/ \mathrm{s} / \rightarrow[\mathrm{t}]$ involve low level features. However, some normal substitutions also affect higher nodes. Gliding affects the root 
feature [consonantal], and stopping affects [continuant], which is a root feature in two models.

Most of the processes involve a segment which is more marked being replaced by a segment which is less marked. There are two cases in which this is not certain, and those are $/ \mathrm{r} / \rightarrow[\mathrm{w}], / \theta / \rightarrow[\mathrm{f}]$. Both cases involve the target specified for cor:[+distributed], and the substitute specified for [labial]. We can assume these involve a decrease in markedness from target to substitute. In the case of gliding, manner of articulation and place of articulation are both affected for markedness with the target more marked in one or both of these features, and the substitute less marked. For the fricative substitution, only place features are affected, but this still reveals a change in markedness from more marked to less marked.

\subsection{Less Common Substitutions}

These substitutions result from processes used to a limited degree by normallydeveloping children and to a greater extent by phonologically-disordered children. They include fricatives becoming liquids, and stopping of liquids to [d].

\subsubsection{Fricative to Liquid: $/ \mathrm{s} / \rightarrow[\mathrm{l}]$}

$\begin{array}{lll}\stackrel{1}{/ s} / & \rightarrow & {[\mathrm{l}]} \\ {[\text { +consonantal }]} & & {[+ \text { consonantal }]} \\ {[\text { +continuant }]} & & {[\text { +sonorant }]}\end{array}$

In this substitution, there is no change in number of features specified for in the target and substitute. Both the target and the substitute are specified for [consonantal], so the features [continuant] and [sonorant] are affected by the substitution. 
Figure 3.2.a Bernhardt Model of $/ s / \rightarrow[l]$

\section{Bernhardt Model}

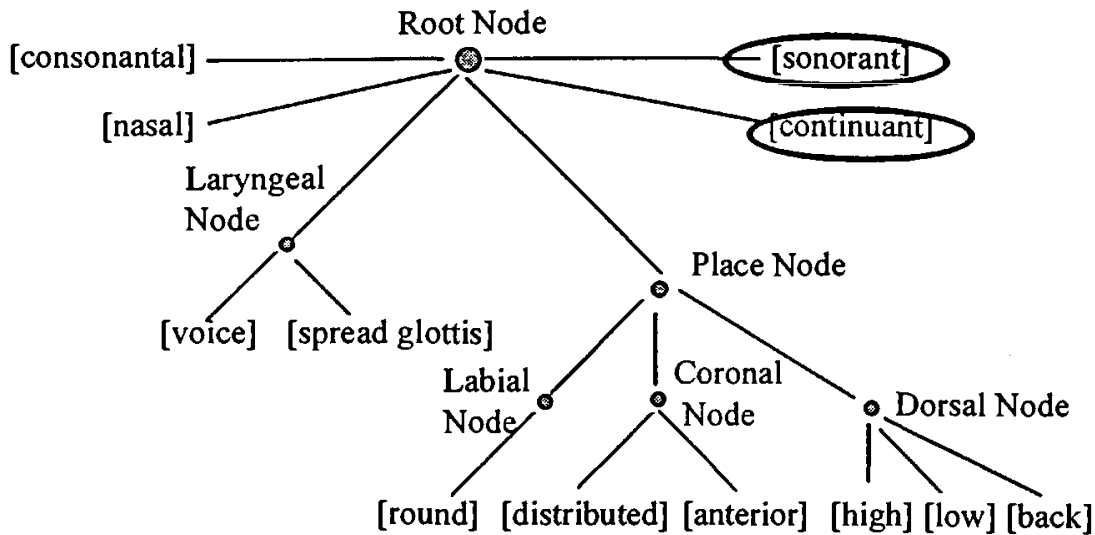

Figure 3.2.b Clements-Hume Model of $/ s / \rightarrow[1]$

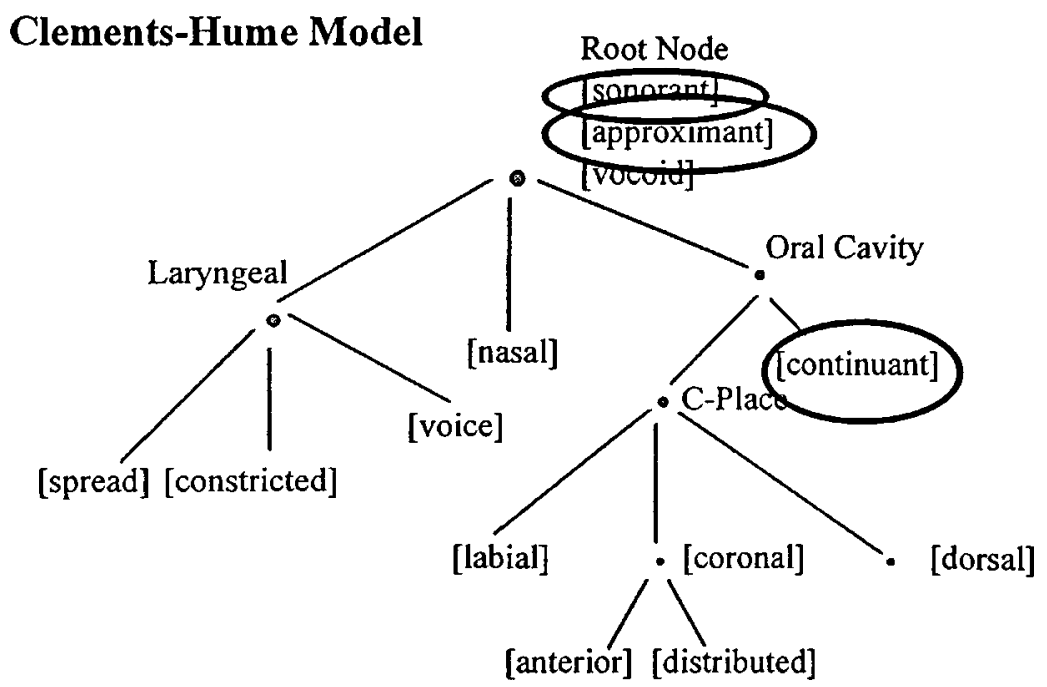


Figure 3.2.c Halle-Sagey Model of $/ s / \rightarrow[1]$

\section{Halle-Sagey Model}

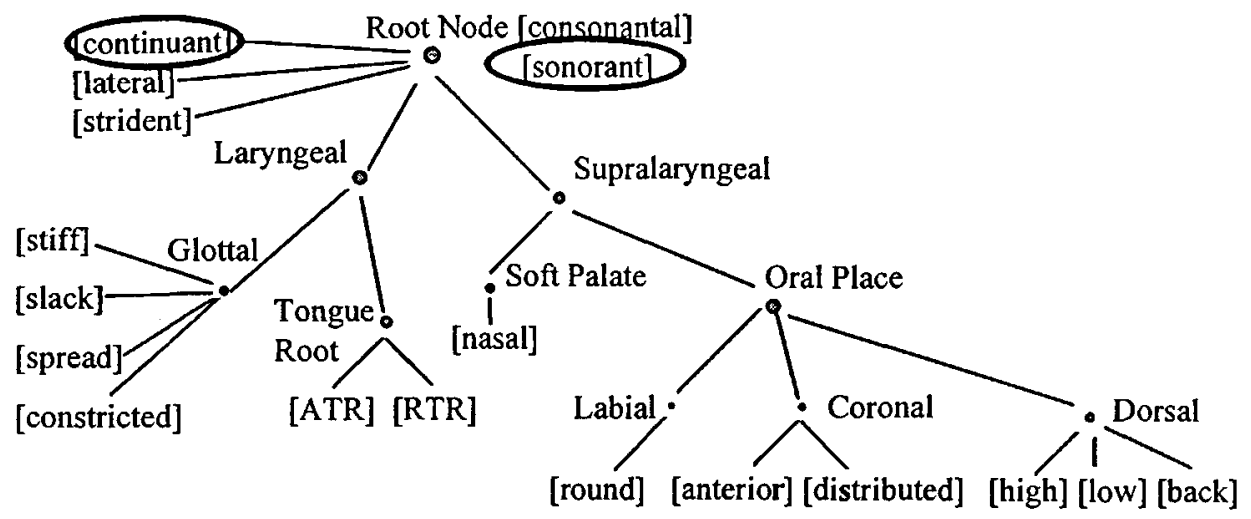

The Bernhardt and Halle-Sagey models are affected at the root node for [sonorant] and [continuant]. The Clements-Hume model differs in that the root features which are affected are [sonorant] and [approximant], and [continuant] is an oral cavity rather than a root feature.

The target is marked for manner of articulation [+continuant] while the substitute is not marked for this feature. However, the substitute is marked for manner [+sonorant, +consonantal]. The markedness relationship between these segments is not readily determined.

3.2.2 Stopping of Liquids: $/ \mathrm{N} \rightarrow[\mathrm{d}], / \mathrm{r} / \rightarrow[\mathrm{d}]$

N/

[+consonantal]

[+sonorant] [d]

[+consonantal]

[+voice] 
Figure 3.2.d Bernhardt Model of $/ \mathrm{l} / \rightarrow$ [d]

\section{Bernhardt Model}

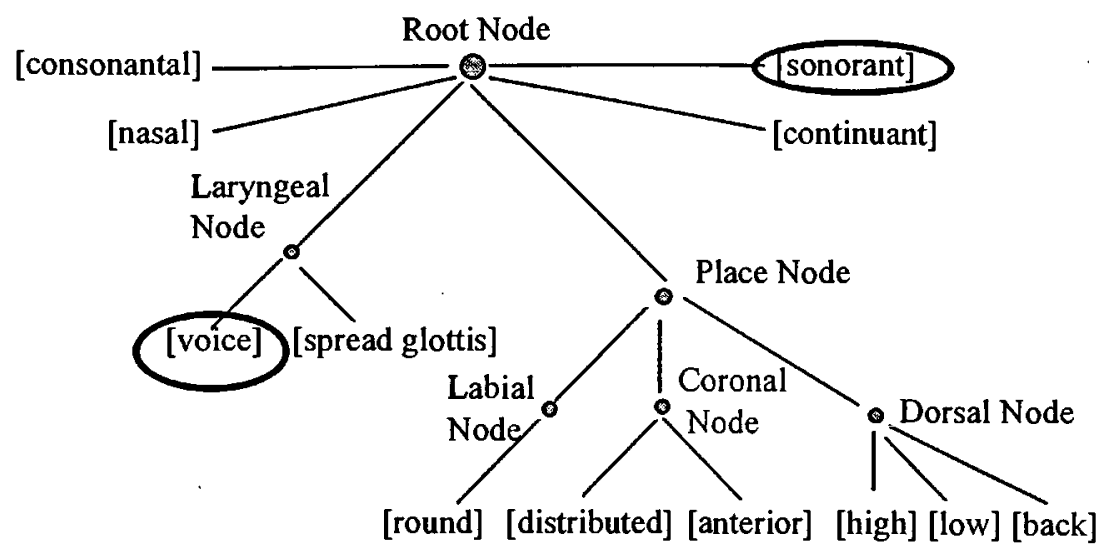

Figure 3.2.e Clements-Hume Model of $/ V \rightarrow$ [d]

\section{Clements-Hume Model}

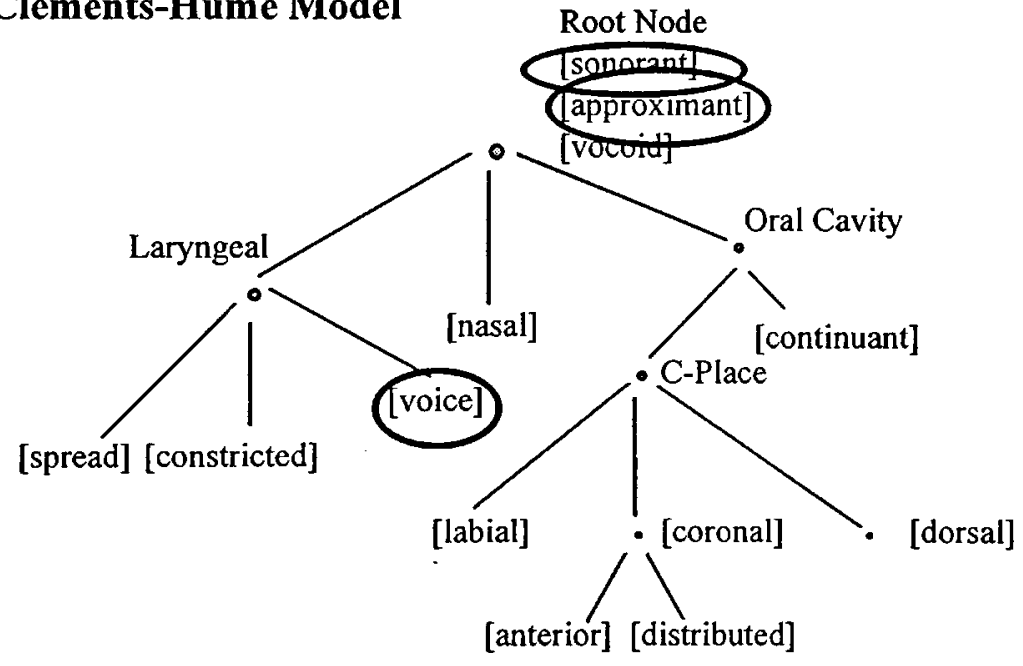


Figure 3.2.f Halle-Sagey Model of $/ / \rightarrow$ [d]

\section{Halle-Sagey Model}

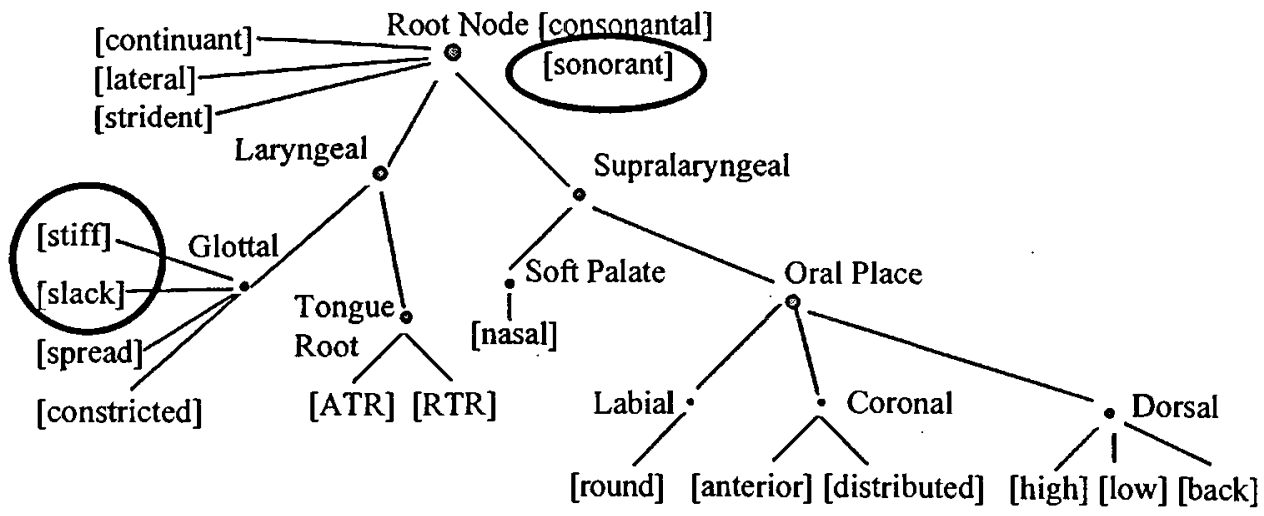

$\begin{array}{lll}\quad \rightarrow \mathbf{r} / & \rightarrow & {[\mathbf{d}]} \\ {[+ \text { consonantal }]} & & {[+ \text { consonantal }]} \\ {[+ \text { sonorant }]} & & {[+ \text { voice }]} \\ \text { cor:[+distributed }] & & \end{array}$

Figure 3.2.g Bernhardt Model of $/ \mathbf{r} / \rightarrow$ [d]

\section{Bernhardt Model}

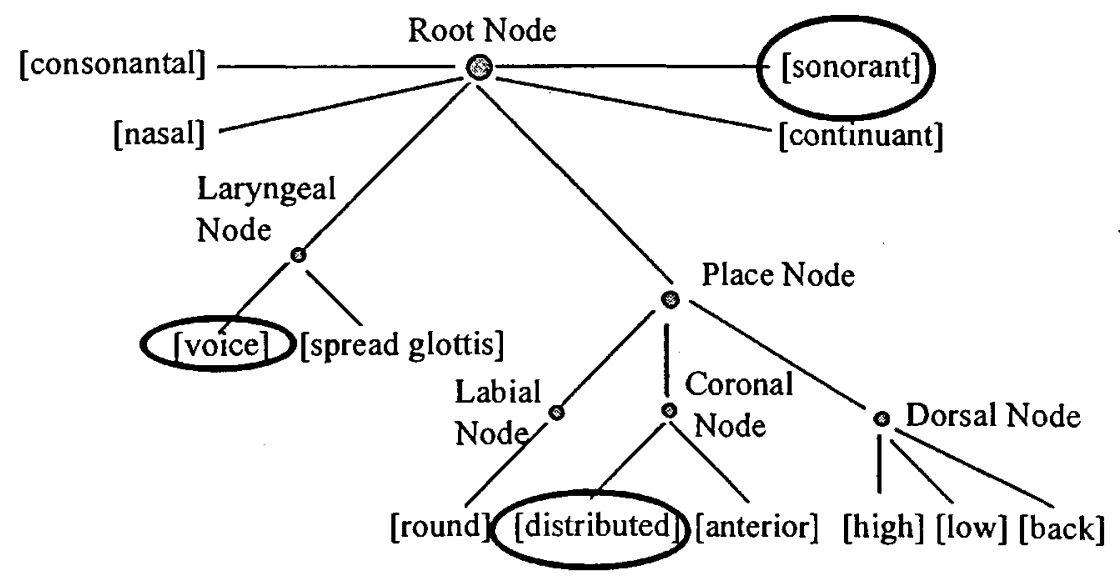


Figure 3.2.h Clements-Hume Model of $/ \mathrm{r} / \rightarrow$ [d]

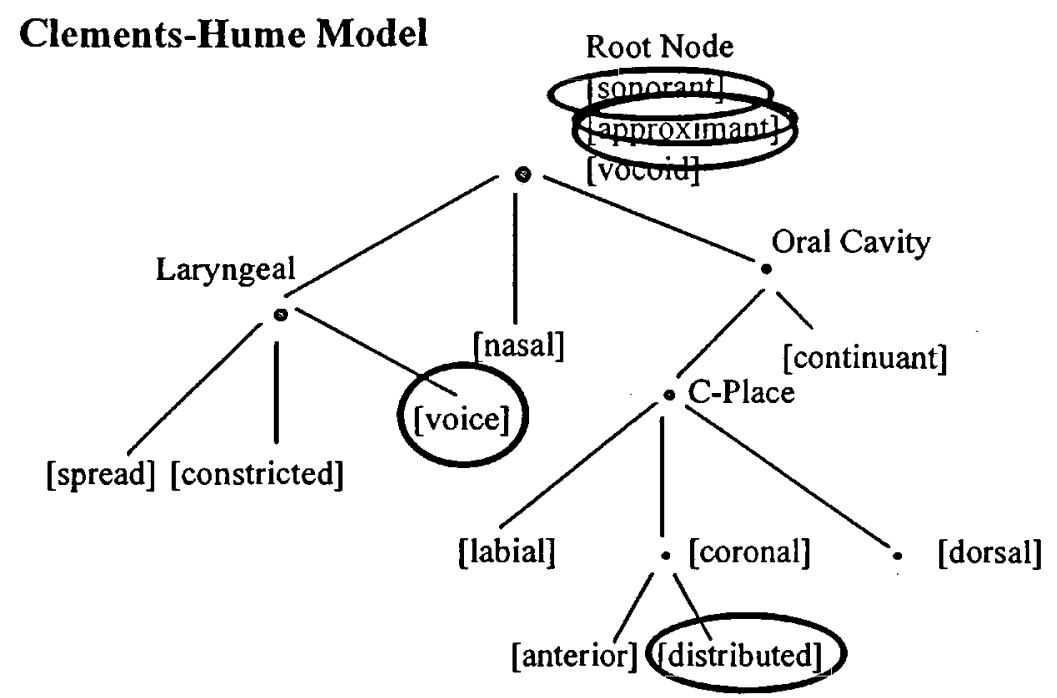

Figure 3.2.i Halle-Sagey Model of $/ r / \rightarrow[d]$

\section{Halle-Sagey Model}

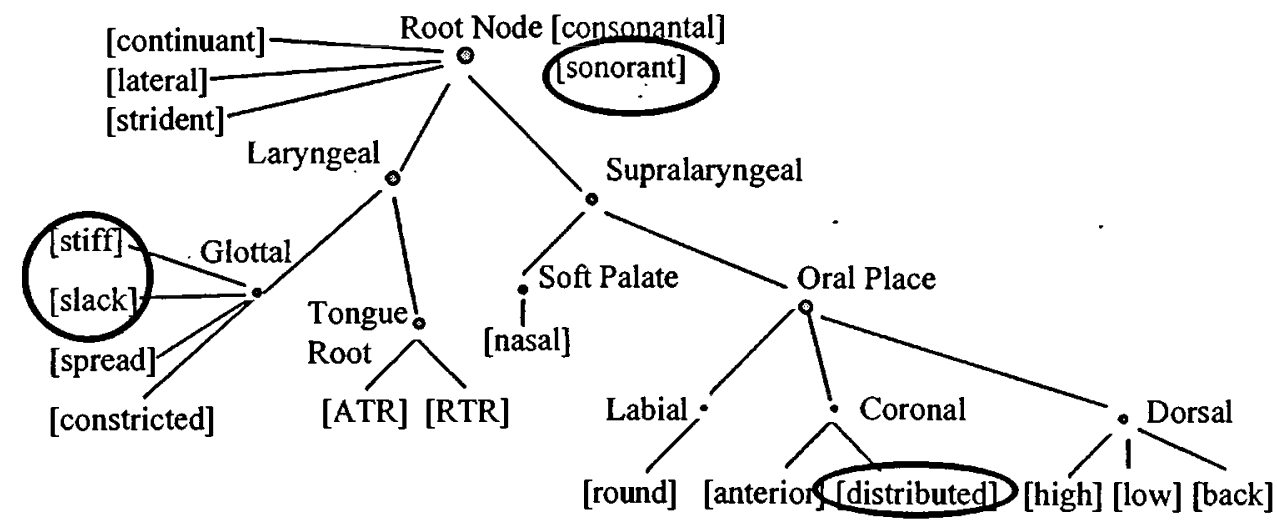

Stopping of liquids involves substitutes which are less specified than or equally as specified as the targets they replace. $/ 1 /$ and $/ d /$ are specified for the same number of features. [consonantal] is shared by both segments, but $/ / /$ is specified for [sonorant] and [d] is specified for voice. The other substitution, $/ \mathrm{r} / \rightarrow[\mathrm{d}]$ involves three specified features in the target, and two in the substitute. 
For the $/ \mathrm{l} / \rightarrow[\mathrm{d}]$ substitution, the Bernhardt model shows that the root feature [sonorant] and the laryngeal feature [voice] are affected. The Clements-Hume model shows differences in the root node [sonorant] and in the laryngeal feature [voice]. The Halle-Sagey model shows a change in the root node [sonorant] and in the glottal features [stiff] and [slack].

For the $/ \mathrm{r} / \rightarrow[\mathrm{d}]$ substitution, the Bernhardt model is affected at the root node for [sonorant], the laryngeal node for [voice], and the coronal node for [distributed]. The Clements-Hume model is affected in the root node at [sonorant] and [approximant], in the laryngeal node for [voice] and in the coronal node for [distributed]. The Halle-Sagey model is affected at the root node for [sonorant], the glottal node for [stiff] and [slack], and the coronal node for [distributed].

In both cases, the target is specified for [+consonantal,+sonorant] but the substitute is marked only for [+consonantal] which indicates a decrease in markedness for manner of articulation from the target to the substitute. For voicing, the targets are unmarked and the substitutes are both marked [+voice]. This indicates an increase in markedness from the target to the substitute for voicing. For place of articulation, $/ 1 /$ and [d] are both unmarked, so there is no change in markedness, but $/ \mathrm{r} /$ is specified for cor:[+distributed], so a decrease in markedness of place occurs from $/ r /$ to [d].

\subsubsection{Summary of Less Common Processes}

Some less common substitutions involve the specification of the same number of features from target to substitute (fricatives to liquids, stopping of liquids), and other substitutions involve a more specified target being replaced by a less specified substitute 
(stopping of liquids). None of these substitutions involves a more specified substitute replacing a less specified target.

The only lower level place feature which is affected by these substitutions is cor:[distributed]. In general, these processes involve the root node [sonorant], or the feature [continuant]. We also see that the laryngeal node is affected for [voice], and the coronal node is affected. These substitutions primarily involve features which are located higher than the place node.

Markedness relationships are not easily determined. Some features are more marked in the target and less marked in the substitute form, and others are more marked in the substitute than in the target. Additionally, there is a case $(/ \mathrm{s} / \rightarrow[1])$ in which the markedness relationship is not clear for manner of articulation where $[+$ consonantal, + continuant $]$ is replaced by $[+$ consonantal, +sonorant $]$. However, in all three less common substitutions, when the root node is specified for [consonantal] in the target, it is also specified for [consonantal] in the substitute, although there is no regular pattern for other root node features.

\subsection{Unusual Processes}

These substitutions result from processes which are not used by the normallydeveloping population. They include frication of approximants, backing, stopping glides, frication of stops, and gliding of fricatives.

\subsubsection{Frication of Approximants: $/ \mathrm{l} / \rightarrow[\partial], / \mathrm{w} / \rightarrow[\mathrm{v}]$}




\begin{tabular}{|c|c|c|}
\hline \begin{tabular}{l}
\multicolumn{1}{c}{$\mathbf{N}$} \\
{$[$ +sonorant] } \\
[+consonantal]
\end{tabular} & $\rightarrow$ & \begin{tabular}{l}
\multicolumn{1}{c}{$[\boldsymbol{\complement}]$} \\
[+consonantal] \\
[+continuant] \\
[+voice] \\
cor:[+distributed]
\end{tabular} \\
\hline
\end{tabular}

Figure 3.3.a Bernhardt Model of $/ / \rightarrow[\delta]$

\section{Bernhardt Model}

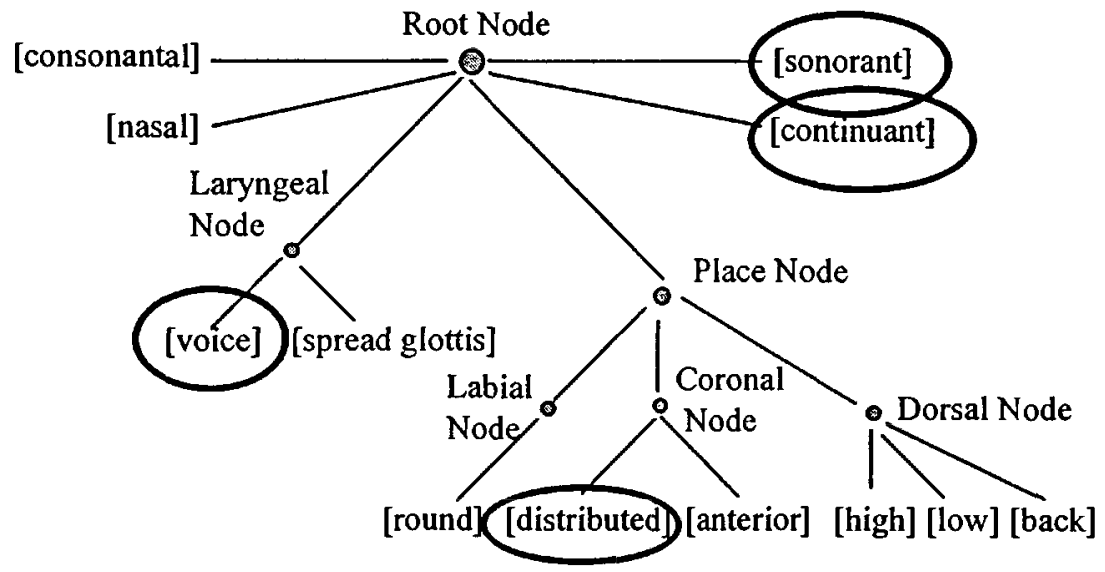

Figure 3.3.b Clements-Hume Model of $/ / \rightarrow[$ [ $]$

\section{Clements-Hume Model}

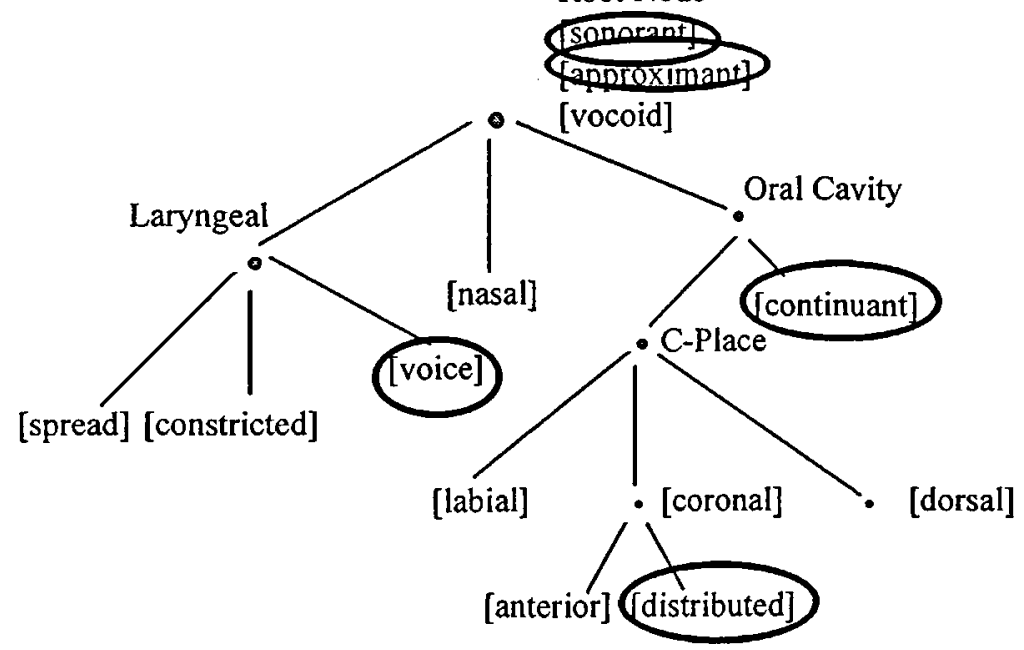


Figure 3.3.c Halle-Sagey Model of $\Lambda \rightarrow[\overline{0}]$

\section{Halle-Sagey Model}

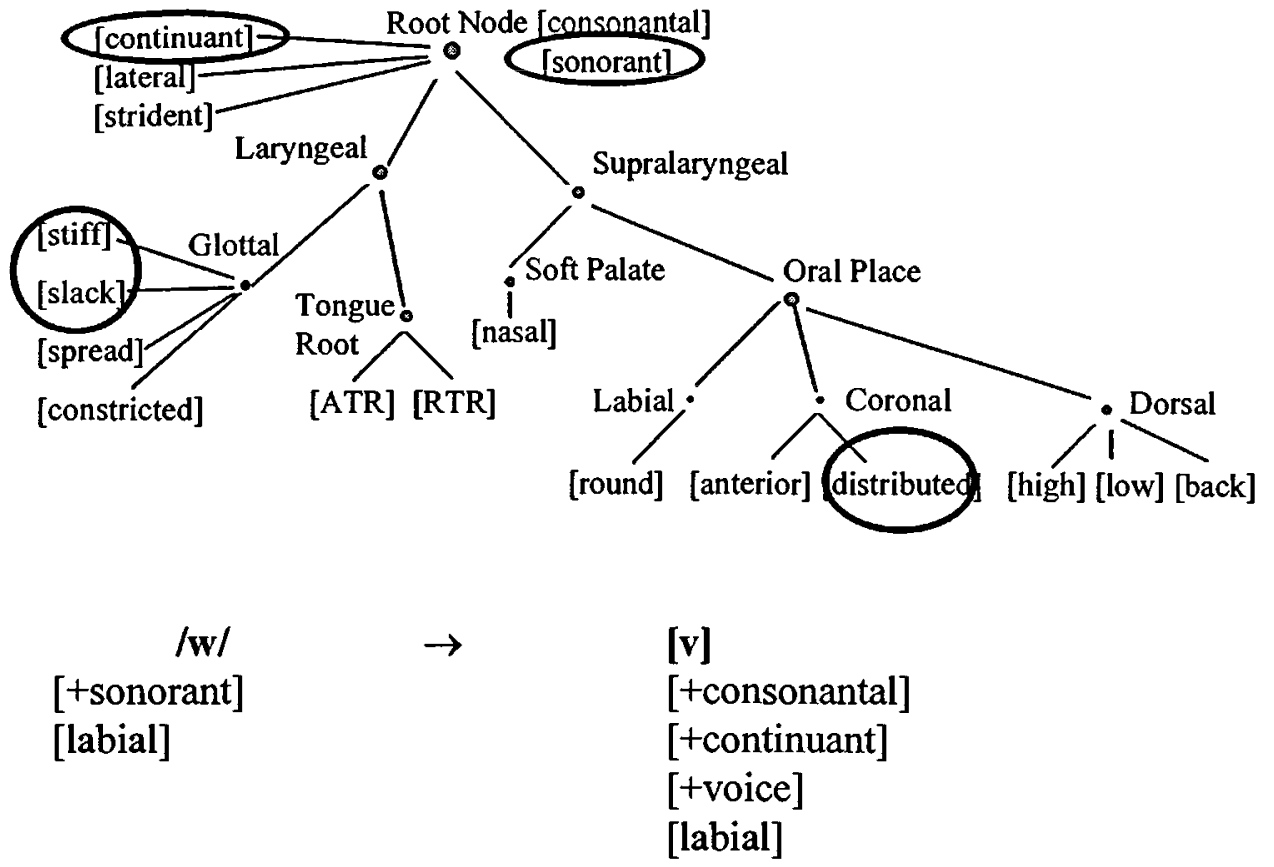

Figure 3.3.d Bernhardt Model of $/ w / \rightarrow[v]$

\section{Bernhardt Model}

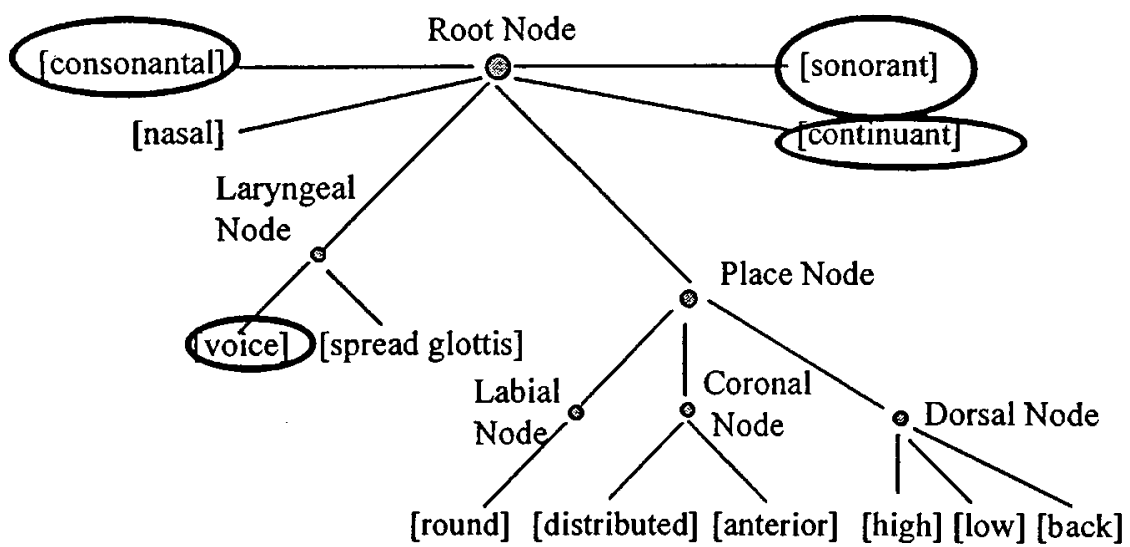


Figure 3.3.e Clements-Hume Model of $/ w / \rightarrow[v]$

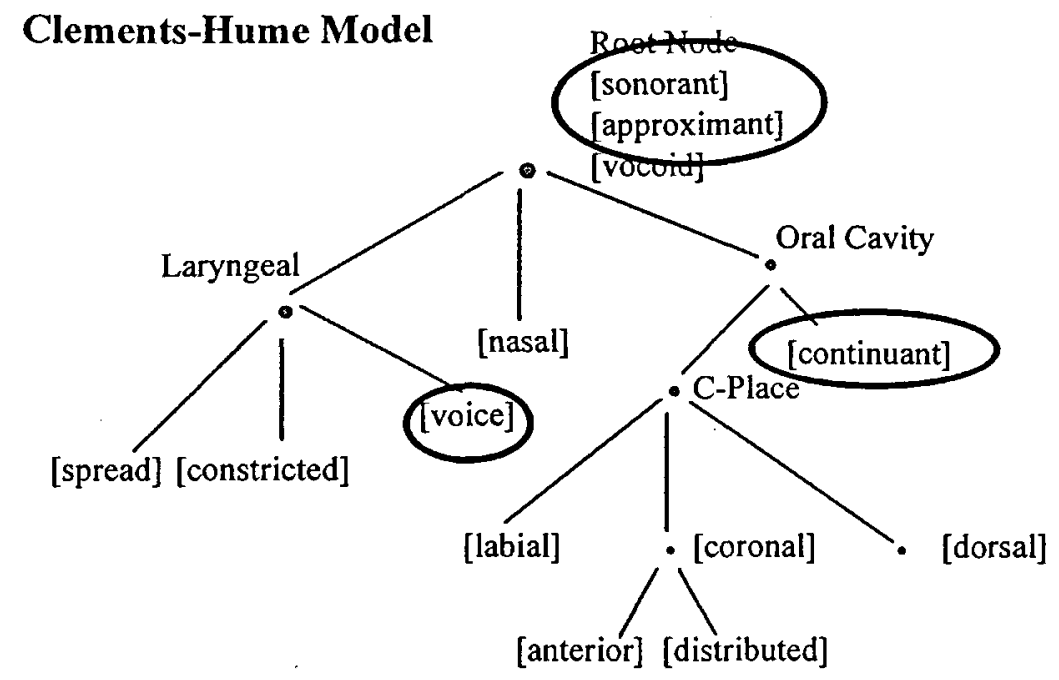

Figure 3.3.f Halle-Sagey Model of $/ w / \rightarrow[v]$

\section{Halle-Sagey Model}

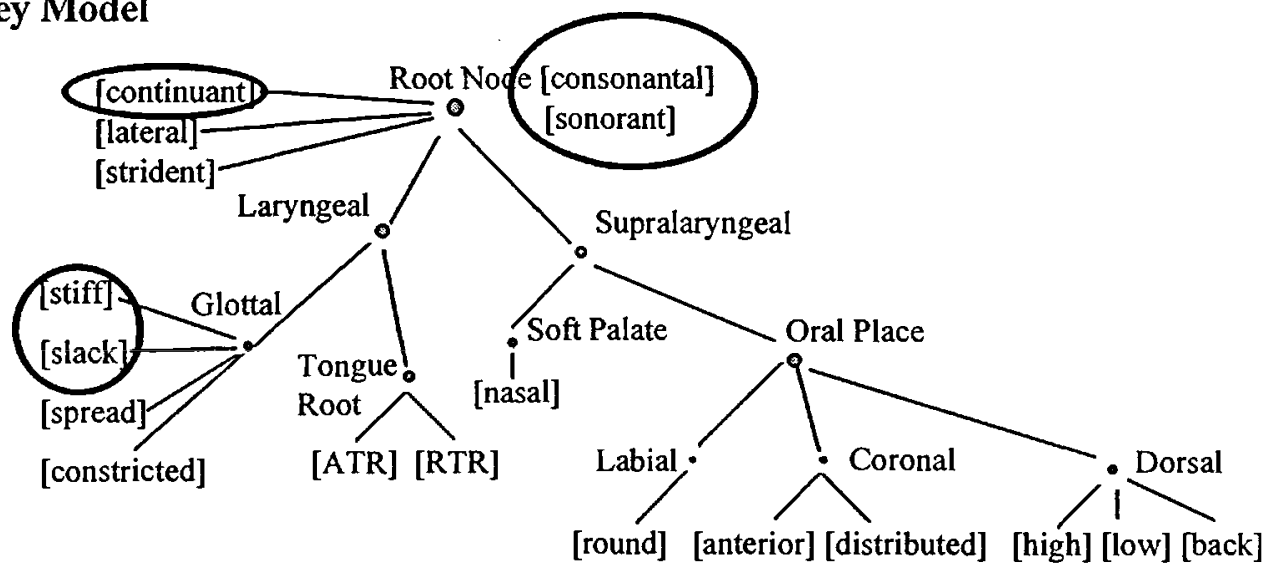

This process involves a target which has less specified features being substituted by a segment which has more specified features. In both substitutions, the target is specified for [sonorant], but the substitute is not. The substitute forms are specified for [continuant] and [voice] although the target is not. The place of articulation is not specified in the target $/ 1 / \rightarrow[ð]$, but it is specified in the substitute, cor:[+distributed].

While in $/ 1 / \rightarrow[\delta]$, consonantal is specified for in the target and the substitute, in $/ \mathrm{w} / \rightarrow[\mathrm{v}]$ 
only the substitute is specified for [consonantal]. Both the target and the substitute are specified for place of articulation, [labial] in $/ \mathrm{w} / \rightarrow[\mathrm{v}]$.

The Bernhardt model is affected at the root node [sonorant], in the coronal node [distributed], and at the laryngeal node for [voice] in the $/ 1 / \rightarrow[\delta]$ substitution. For the $/ \mathrm{w} / \rightarrow[\mathrm{v}]$ substitution, the root is affected at [consonantal] and [sonorant], and the [voice] feature is affected. In the Clements-Hume model, both substitutions show that [sonorant] and [approximant] are affected at the root node, as well as [voice] in the laryngeal node. The $/ 1 / \rightarrow[ð]$ substitution is additionally affected at the coronal node for [distributed]. In the Halle-Sagey model both substitutions affect the root node at [sonorant] and at the laryngeal node for [voice]. $/ \mathrm{w} / \rightarrow[\mathrm{v}]$ also affects the [continuant] feature, and $/ 1 / \rightarrow[\gamma]$ affects the place node for cor:[distributed].

For $/ 1 / \rightarrow[\delta]$, there are changes in markedness for voicing and place and manner of articulation. The target is unmarked for voice and place of articulation, but the substitute is marked for those features. The target is marked [+sonorant, + consonantal], and the substitute is marked for [+consonantal,+continuant]. Whereas [continuant] is unmarked for [sonorant], it is marked for [consonantal], and thus must be specified in the substitute. In the other substitution, $/ \mathrm{w} / \rightarrow[\mathrm{v}]$, the target and substitute are both marked [labial] for place of articulation, so no change occurs in markedness. $/ \mathrm{w} /$ is marked for [sonorant], but $[\mathrm{v}]$ is marked for [+consonantal, + continuant]. This indicates a change in markedness, although the nature of the change is not completely clear at this point. 


\subsubsection{Backing: $/ \mathrm{t} / \rightarrow[\mathrm{k}]$}

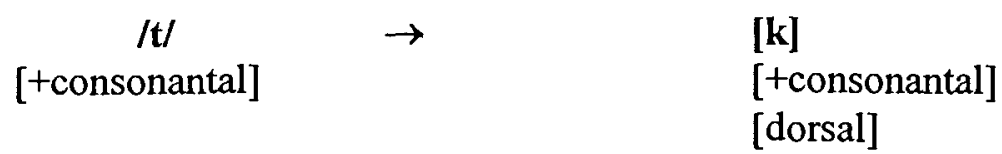

Backing shows an increase in the number of specified features in the substitute over the target. In this substitution, only one feature is specified in the target, but two are specified in the substitution. Place of articulation [dorsal] is specified in the substitute, but it is unspecified in the target.

Figure 3.3.g Bernhardt Model of $/ t / \rightarrow[k]$

\section{Bernhardt Model}

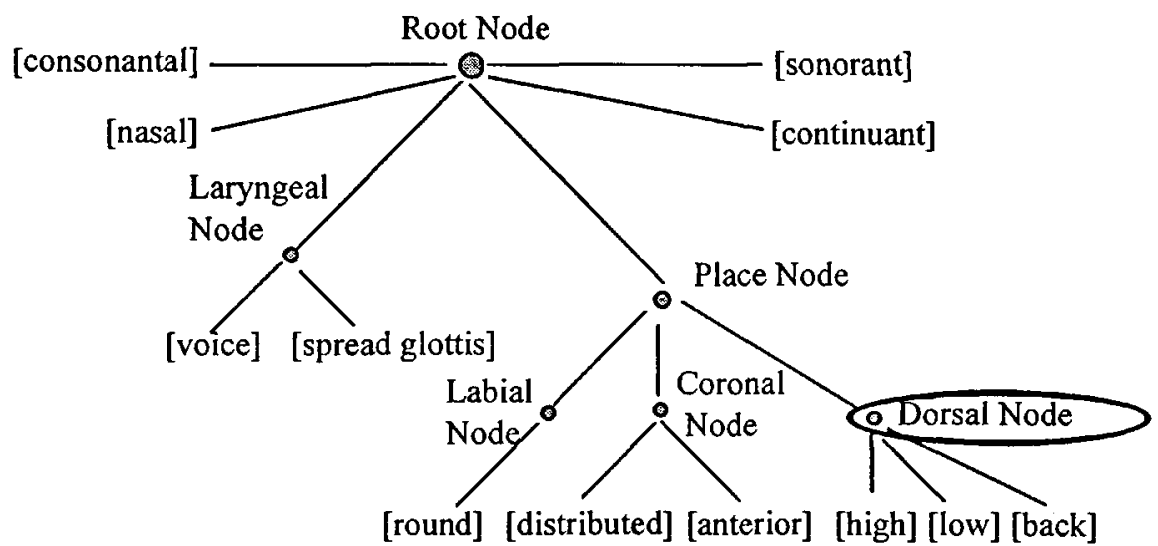


Figure 3.3.h Clements-Hume Model of $/ \mathrm{k} / \rightarrow[\mathrm{t}]$

Clements-Hume Model Root Node

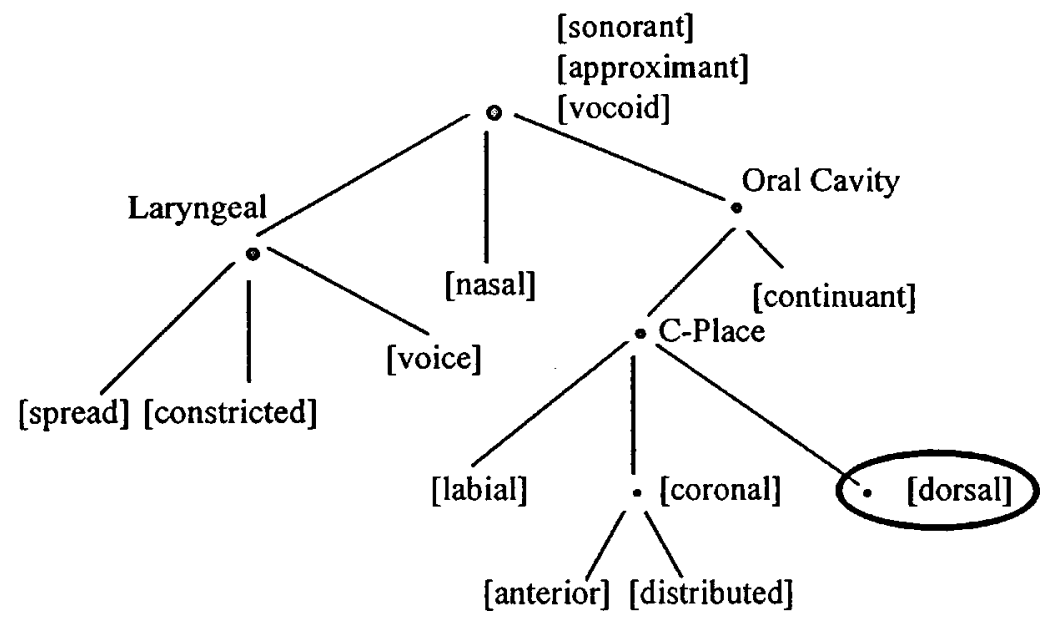

Figure 3.3.i Halle-Sagey Model of $/ \mathrm{k} / \rightarrow[\mathrm{t}]$

\section{Halle-Sagey Model}

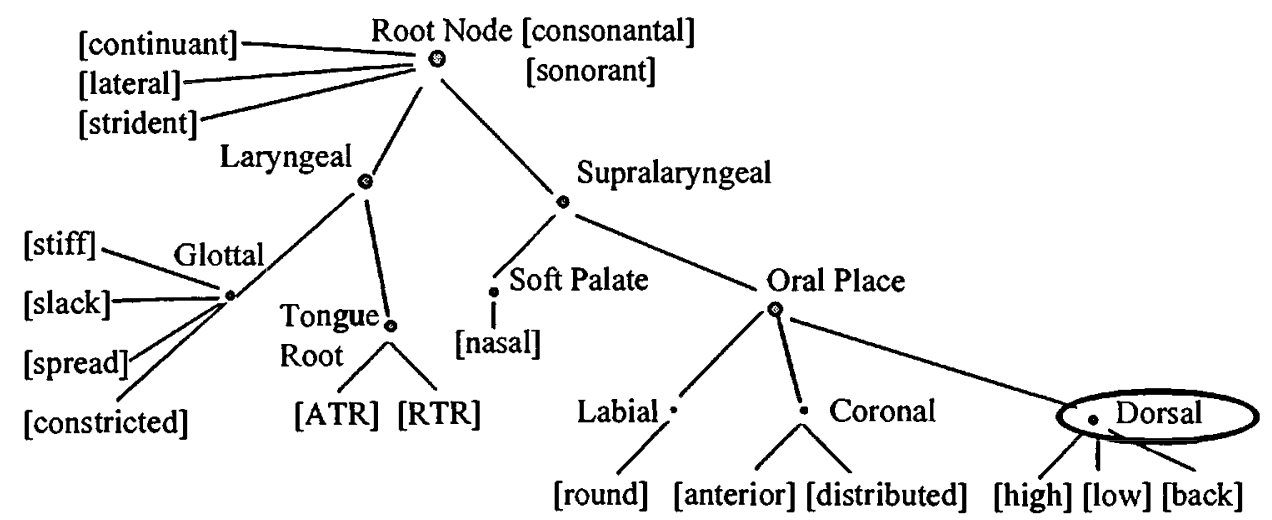

In all feature hierarchy models, the only node which is affected is the place node for [dorsal]. No higher level nodes are affected in the models.

Place of articulation is affected for markedness. $/ t /$ is unspecified because it occurs at the default place, and [k] is specified for [dorsal]. The substitution is therefore more marked than the target for place of articulation. 


\subsubsection{Stopping Glides: $/ \mathrm{w} / \rightarrow[\mathrm{b}], / \mathrm{j} / \rightarrow[\mathrm{t}]$}

\begin{tabular}{lll}
\multicolumn{1}{c}{$/ \mathbf{w} /$} & $\rightarrow$ & {$[\mathrm{b}]$} \\
[+sonorant] & & {$[$ +consonantal $]$} \\
[labial] & & {$[$ +voice $]$} \\
& & {$[$ labial $]$}
\end{tabular}

For $/ \mathrm{w} / \rightarrow[\mathrm{b}]$, the substitute is more specified than the target. $/ \mathrm{w} /$ is specified for two features [sonorant] and [labial], and the substitute sound is specified for three features [consonantal], [voice] and [labial]. Both segments are specified for place of articulation, [labial]. The differences in the target and substitute are that $/ \mathrm{w} /$ is specified for [sonorant], [b] is specified for [consonantal] and [voice].

Figure 3.3.j Bernhardt Model of $/ w / \rightarrow[b]$

Bernhardt Model

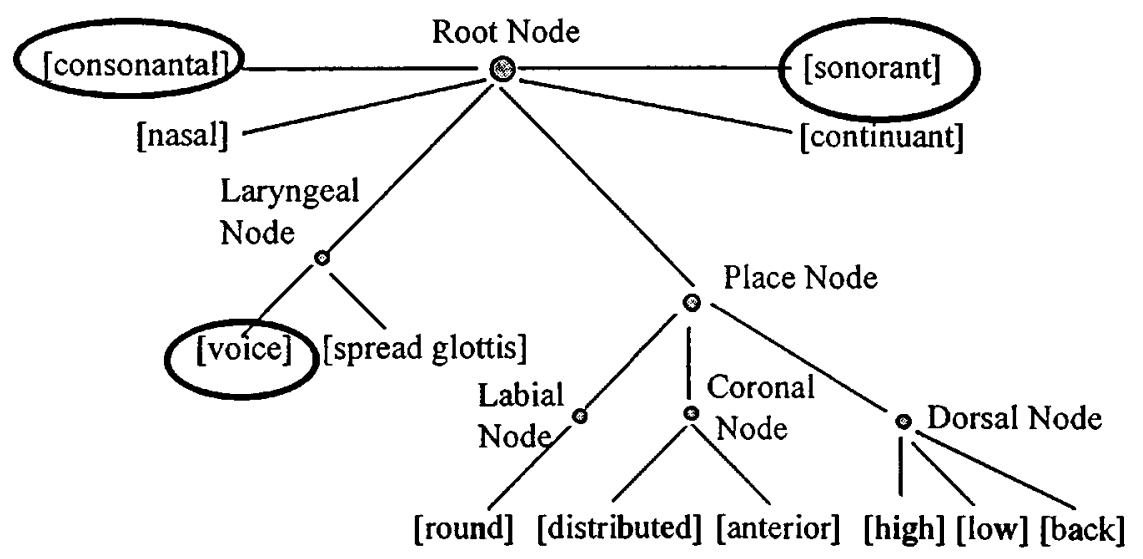


Figure 3.3.k Clements-Hume Model of $/ w / \rightarrow[b]$

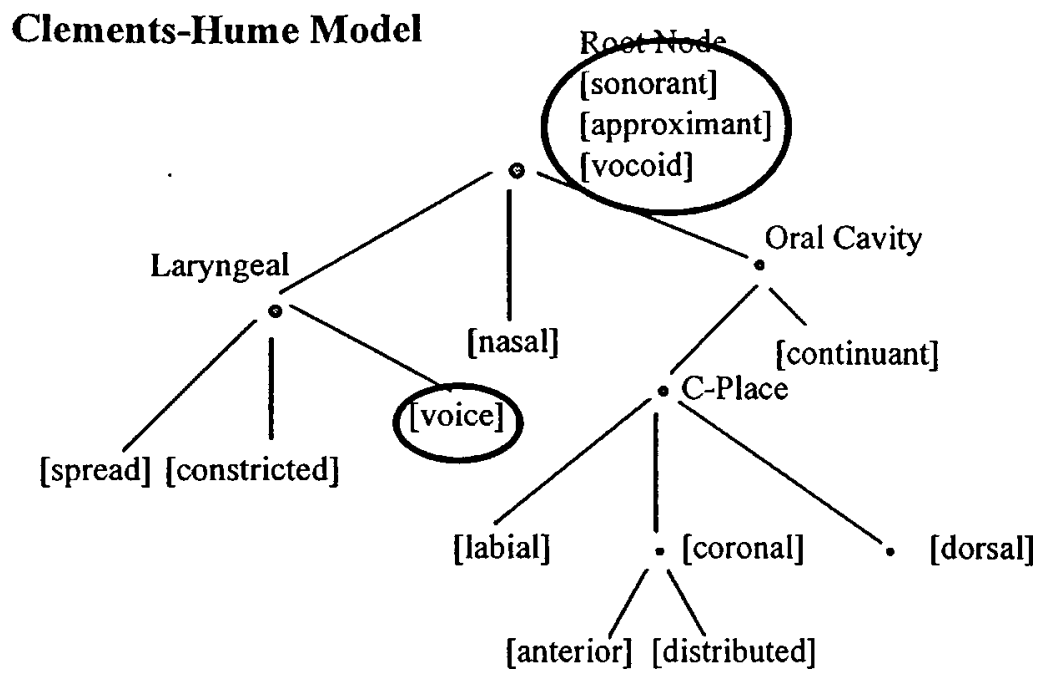

Figure 3.3.I Halle-Sagey Model of $/ w / \rightarrow[b]$

Halle-Sagey Model

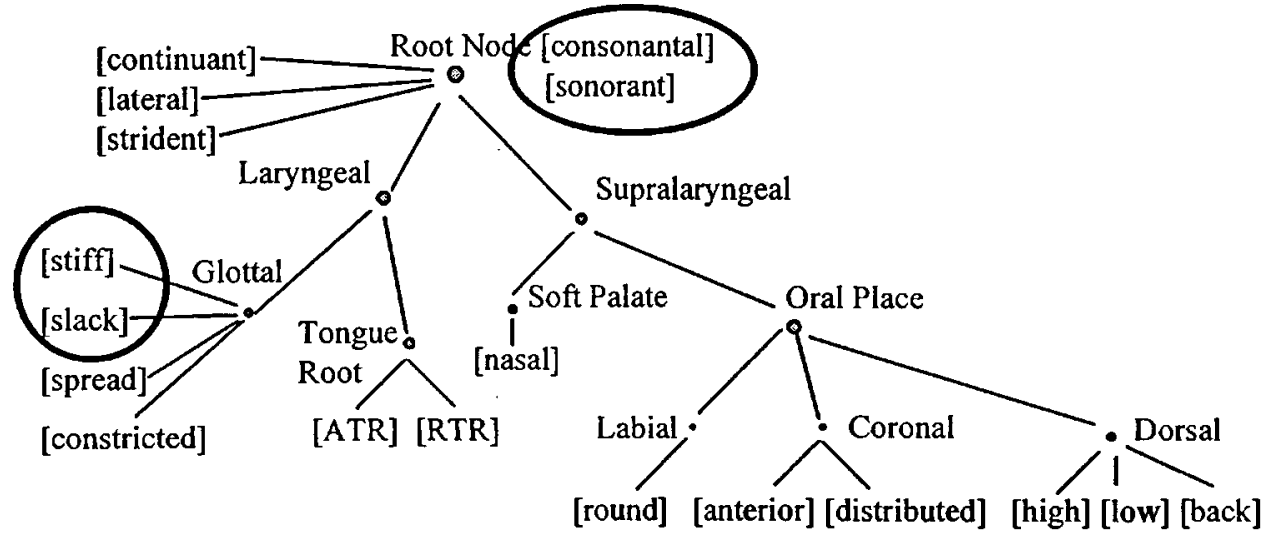

In the Bernhardt model, the root node is affected for [sonorant] and [consonantal]

and at the laryngeal node for [voice]. The Clements-Hume mode is affected at the root node for all three root features [sonorant], [approximant] and [vocoid], and at the Laryngeal node for [voice]. The Halle-Sagey model is affected at the root node for [consonantal] and [sonorant], and at the glottal node for [stiff] and [slack]. 


$$
\begin{array}{lll}
/ \mathbf{j} / & \rightarrow & {[\mathbf{t}]} \\
{[\text { +sonorant }]} & & {[+ \text { consonantal }]}
\end{array}
$$

The $/ \mathrm{j} / \rightarrow[\mathrm{t}]$ substitution shows that the target and substitute are specified for the same number of features, only one, but the feature is different for each segment. For $/ \mathrm{j} /$ the specified feature is [sonorant] and for $/ \mathrm{t} /$ it is [consonantal].

Figure 3.3.m Bernhardt Model of $/ \mathrm{j} / \rightarrow[\mathrm{t}]$

\section{Bernhardt Model}

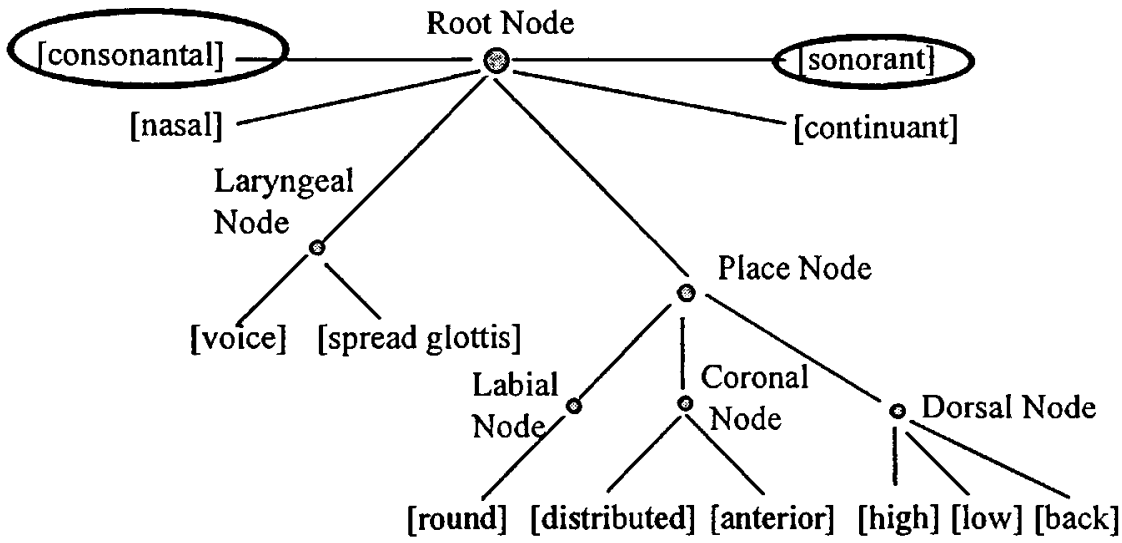

Figure 3.3.n Clements-Hume Model of $/ \mathrm{j} / \rightarrow[\mathrm{t}]$

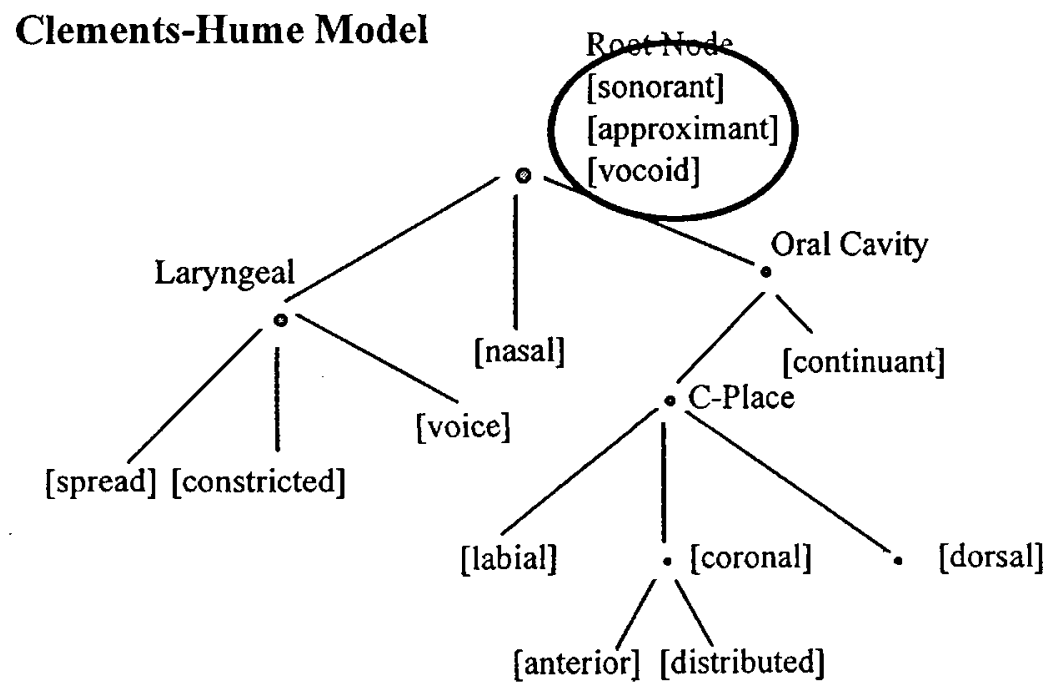


Figure 3.3.0 Halle-Sagey Model of $/ \mathrm{j} / \rightarrow[\mathrm{t}]$

\section{Halle-Sagey Model}

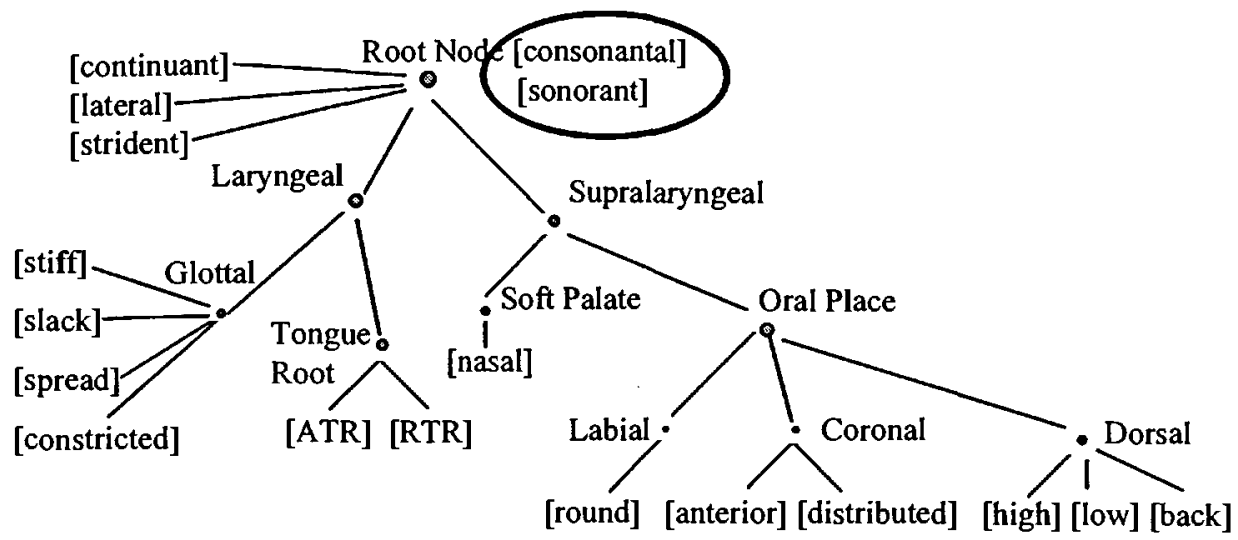

In all three hierarchical models, the difference in specification involves the root

node. For the Bernhardt and Halle-Sagey models, the root node is affected for the features [sonorant] and [consonantal]. For the Clements-Hume model, all three root nodes, [sonorant], [approximant] and [vocoid], are affected. No lower level nodes are affected in this substitution.

Both substitutions involve a change in markedness for manner of articulation. The targets $/ \mathrm{w} /$ and $/ \mathrm{j} /$ are specified for [+sonorant], and the substitutes $[\mathrm{b}]$ and $[\mathrm{t}]$ are specified for [+consonantal]. Both the target and substitute have the same specification for place of articulation, so no markedness relationship exists there. /w/ and [b] are specified for [labial], and $/ \mathrm{j} /$ and $[\mathrm{t}]$ are unspecified for place. For voicing, there is no difference in specification of voicing for $/ \mathrm{j} / \rightarrow[\mathrm{t}]$, so there is no change in markedness for voicing. $/ \mathrm{w} / \rightarrow[\mathrm{b}]$ does show a change in voicing specification. The target is not specified for voice, but the substitute is, so an increase in markedness takes place from the target to the substitute. 
3.3.4 Frication of Stops: $/ \mathrm{b} / \rightarrow[\mathrm{v}]$

\begin{tabular}{lll}
\multicolumn{1}{c}{$\mathbf{b} /$} & $\rightarrow$ & {$[\mathbf{v}]$} \\
{$[$ +consonantal $]$} & & {$[+$ consonantal $]$} \\
& & {$[$ +continuant $]$} \\
[+voice $]$ & & {$[$ +voice $]$} \\
[labial $]$ & & {$[$ labial $]$}
\end{tabular}

Frication of stops involves a substitute which is more specified than the target. In this substitution, the target is specified for three features, and the substitute sound is specified for four. [v] contains all of the features specified for in $/ \mathrm{b} /$, but it is additionally specified for [continuant]. Both target and substitute are specified for [consonantal, voice, labial].

Figure 3.3.p Bernhardt Model of $/ b / \rightarrow[v]$

Bernhardt Model

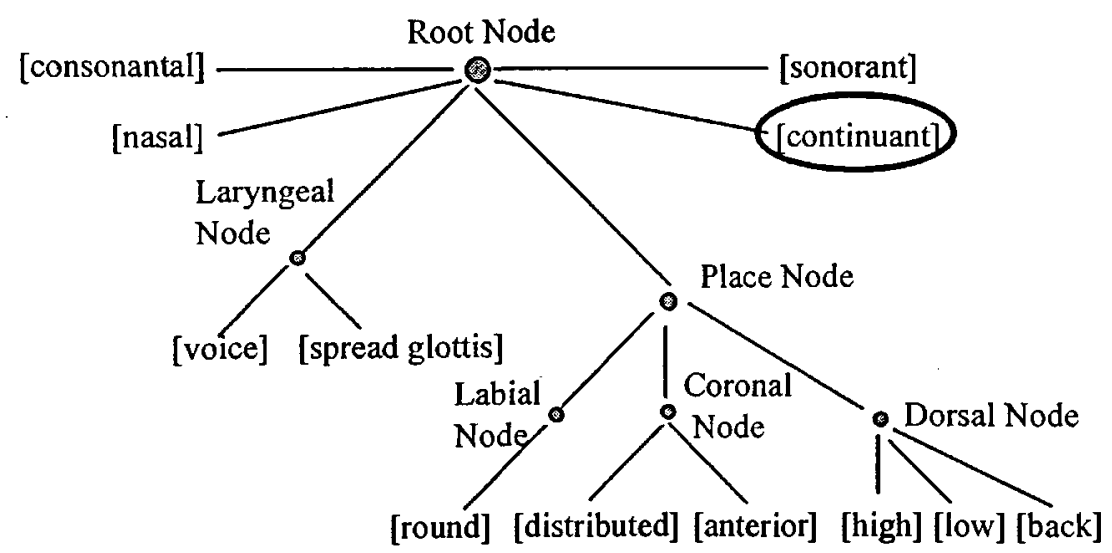


Figure 3.3.q Clements-Hume Model of $/ b / \rightarrow[v]$

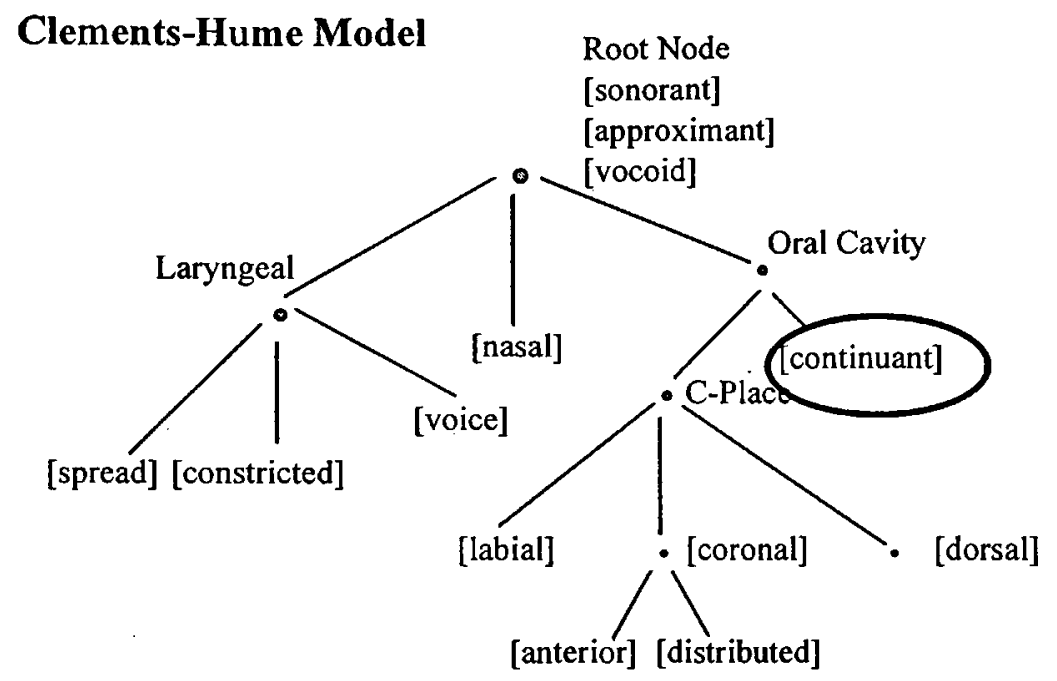

Figure 3.3.r Halle-Sagey Model of $/ b / \rightarrow[v]$

Halle-Sagey Model

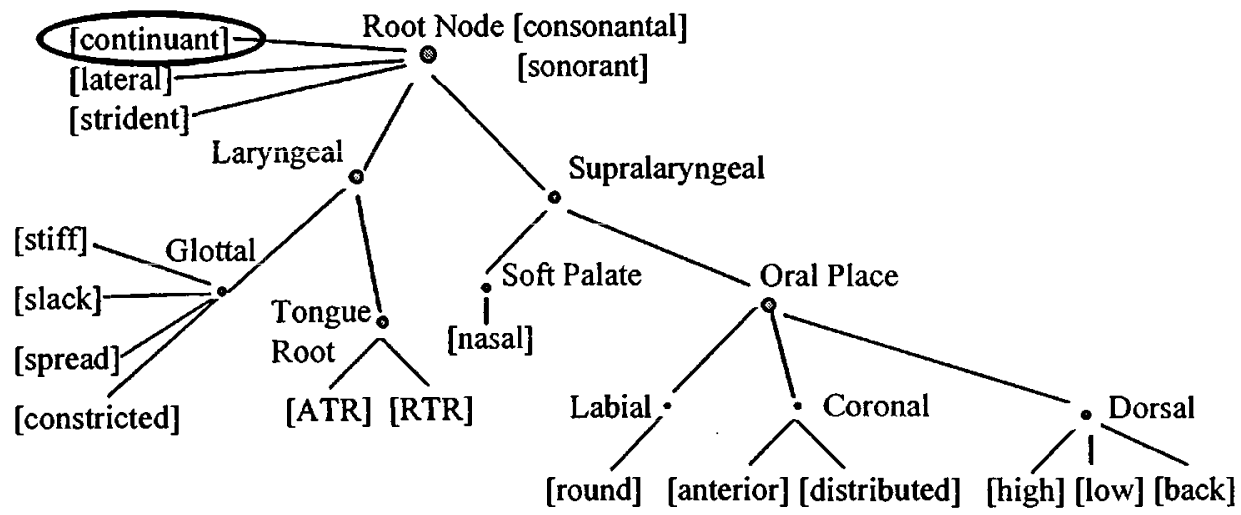

In the feature geometry trees, the only feature which is affected is [continuant].

This occurs at the root node in the Bernhardt and Halle-Sagey models, and at the oral cavity node in the Clements-Hume model. No lower level features are affected, although they are specified.

The target and substitute are both specified for [voice] and [labial], so no change takes place in terms of markedness for those features. However, for manner of 
articulation, [b] is specified for [+consonantal], and [v] is specified for [+consonantal, + continuant]. That means that the substitute is more marked for manner of articulation than the target.

\subsubsection{Gliding of Fricatives: $/ f / \rightarrow[w]$}

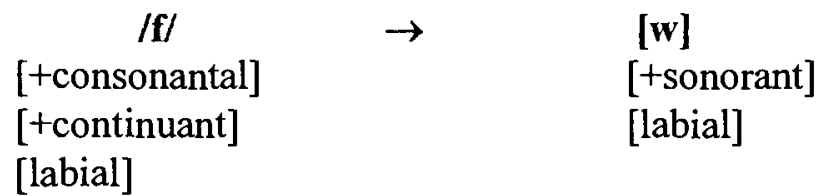

The target sound /f/ contains more specified features than the substitute sound [w]. / $\mathrm{f} /$ is specified for [consonantal] and [continuant], whereas [w] is not, and [w] is specified for [sonorant] though $/ \mathrm{f} /$ is not.

Figure 3.3.s Bernhardt Model of $/ f / \rightarrow$ w $]$

\section{Bernhardt Model}

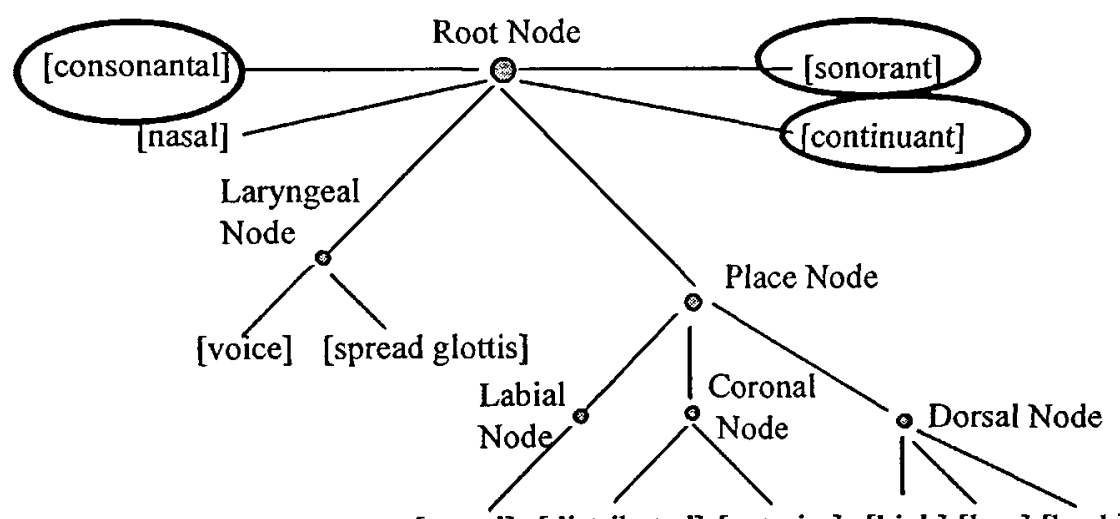

[round] [distributed] [anterior] [high] [low] [back] 
Figure 3.3.t Clements-Hume Model of $/ f / \rightarrow[w]$

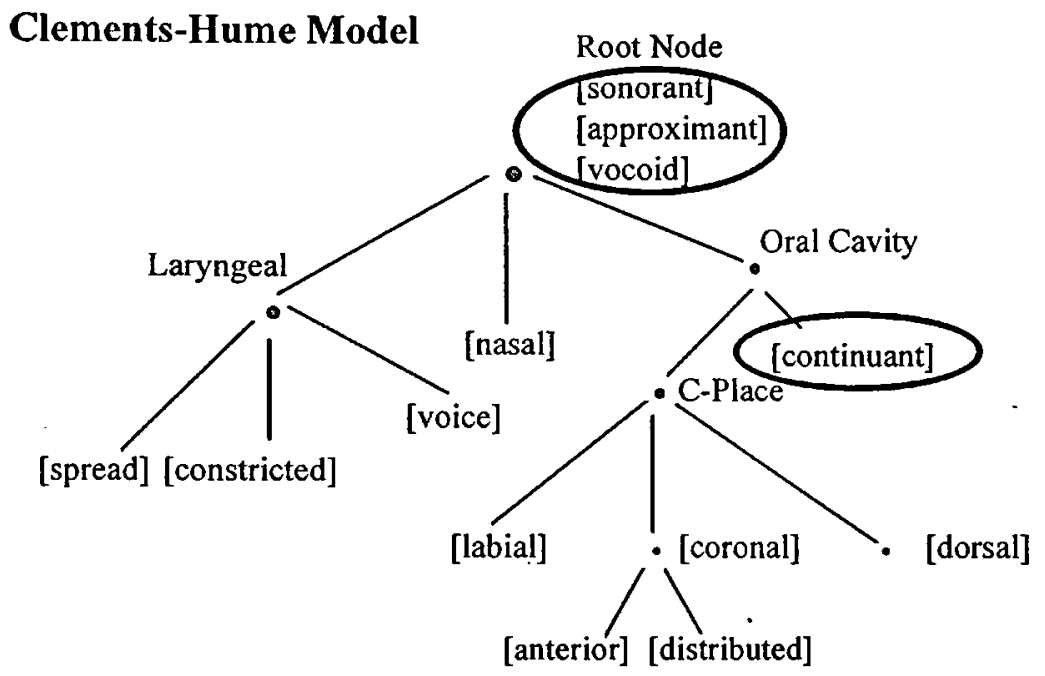

Figure 3.3.u Halle-Sagey Model of $/ f / \rightarrow[w]$

Halle-Sagey Model

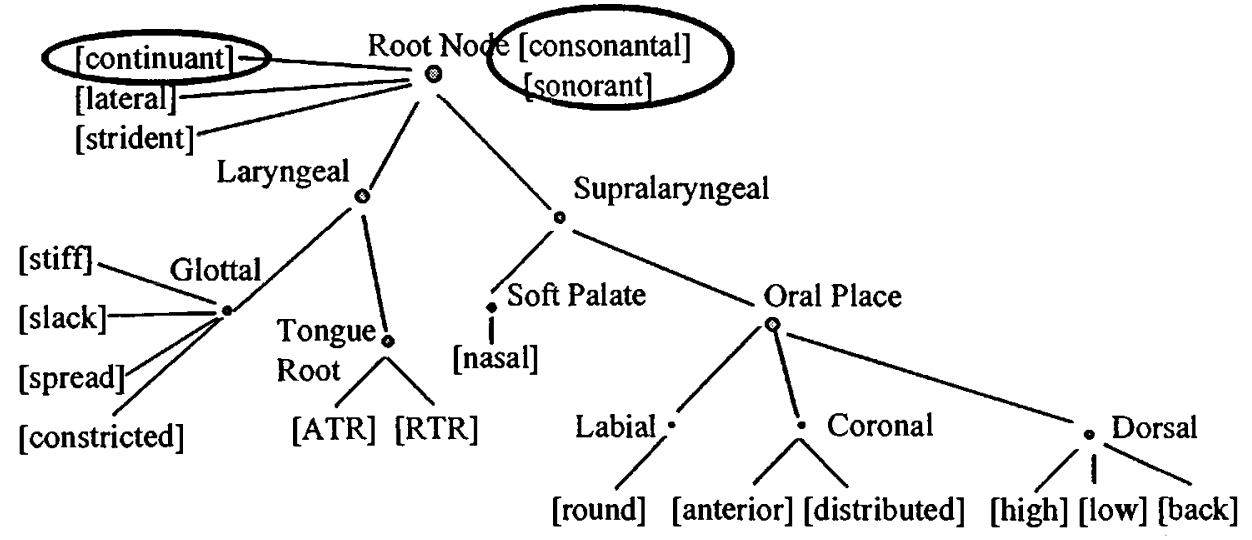

In the Bernhardt and Halle-Sagey models the root node is affected for

[consonantal], [sonorant] and [continuant]. The Clements-Hume model is affected at the root node for all three features, [sonorant], [approximant] and [vocoid], and at the oral cavity node for [continuant].

Both the target and the substitute are specified for place of articulation [labial], so there is no change in markedness for that feature. Voicing is not specified in either target 
or substitute, so no change in markedness takes place. Manner of articulation is specified for $/ \mathrm{f} /$ as [+consonantal, +continuant] and for the substitute $[\mathrm{w}]$, it is specified [+sonorant]. A change in markedness exists, but the exact nature is not determined.

\subsubsection{Summary of Unusual Processes}

For unusual processes, most cases show that the target is specified for fewer features than the substitute. Exceptions are $/ \mathrm{f} / \rightarrow[\mathrm{w}]$ and $/ \mathrm{j} / \rightarrow[\mathrm{t}]$. The main characteristics of this group of processes are that the substitutes are more specified than the targets, and that the specification for [sonorant] is affected.

All but two substitutions $(/ \mathrm{b} / \rightarrow[\mathrm{v}]$ and $/ \mathrm{t} / \rightarrow[\mathrm{k}])$ involve root level features. Only one substitution, $/ \mathrm{t} / \rightarrow[\mathrm{k}]$, involves only lower level features in the hierarchies.

Markedness relationships show that the substitute is usually a more marked form than the target. The greatest change in markedness occurs for manner of articulation, which affects all substitutions. Where markedness is affected for place of articulation, it involves a less marked target being replaced by a more marked substitute. The same occurs for voicing. Where voicing is affected in the specifications, less marked segments become more marked in the substitutes for this feature.

\section{Discussion of Analysis}

In order to reach conclusions about the findings, it is necessary to consider underspecification, feature geometry models and markedness independently first, then in a related manner. 


\subsection{Underspecification}

The underspecification hypothesis partially served to separate normal processes from less common and unusual ones. In all of the substitutions that are considered normal processes, targets which were more specified were replaced by substitutes which were less specified except fricative replacement $/ \theta / \rightarrow[\mathrm{f}]$. By counting the number of features specified in the target and the substitute, it is evident that in normal processes the majority of targets are specified for more features than the substitutes. There is no case in the normal substitutions in which the substitute is specified for more features than the target, and the only case in which they are equally specified is the fricative replacement case mentioned above. Generally, we can say that targets are specified for more features than their substitutes. Since this alone is an insufficient method of determining if a substitution is normal, we will also have to consider which features are specified in the target and the substitute in a subsequent discussion.

In the unusual processes, the number of features specified for did not seem to be a necessary indication of the nature of the process, although unusual processes show a pattern not seen in normal processes. That is, most unusual processes revealed the expected situation of a substitute being more specified than the target. However, there is a case of the target and substitute being equally specified (stopping glides), and of the target being more specified than the substitute (gliding of fricatives). For unusual substitutions, merely counting the number of features specified for does not immediately reveal that the substitution is unusual. If, however, the substitute is more specified than the target, it is an unusual substitution. 
For less common processes, there is no case in which the target is less specified than the substitute, so feature counting serves to separate less common substitutions from some unusual ones. There are cases in which the target is equally as specified as the substitute, and in which the target is more specified as the substitute. Thus for less common processes, we see a pattern which falls between the boundaries of normal processes which generally have more specified targets, and unusual processes which generally have less specified targets.

In most normal processes, features which are specified in the substitute are also specified in the target. That is, specified features of substitutes form a subset of the specified features of the target. There are two exceptions to this: the fricative replacement $/ \theta / \rightarrow[f]$, and liquid gliding $/ r / \rightarrow[w]$. In the case of $/ \theta / \rightarrow[f]$, the manner or root features are specified the same in the target and substitute $[+$ consonantal, + continuant $]$, but the place features differ. $/ \theta /$ is specified for cor:[+distributed], and [f] is specified for [labial]. The same situation is reflected for $/ \mathrm{r} / \rightarrow[\mathrm{w}]$. The target is specified for the manner or root features [+sonorant, +consonantal], and the substitute is specified for [+sonorant]. Place features for the target and substitute differ: / $r$ / is specified for cor:[distributed] and [w] is specified for [labial]. We can say that in general, substitute forms are specified for a set of features which is a subset of features specified in the target. If an exception to this exists, then the root (manner) features are in a set-subset relationship, and the specification for the lowest level features may differ between target and substitute. There are no less common or unusual processes in which this type of relationship exists. 
An unusual substitution which confirms this is $/ \mathrm{j} / \rightarrow[\mathrm{t}]$. In both target and substitute the same number of features is specified, much like the normal substitution $/ \theta / \rightarrow[\mathrm{f}]$. In this unusual substitution, however, only one feature is specified in the target and the substitute, [sonorant] for $/ \mathrm{j} /$, and [consonantal] for [t]. There is no set-subset relationship for manner features in this substitution, and the feature specified for each segment is not a place feature as might be expected for a normal substitution. This confirms the validity of looking at the manner features to determine if a process is normal or unusual.

Feature counting lets us make some observations: 1) If the target is less specified than the substitute, it is an unusual substitution. 2) If the target and substitute are equally specified, other information must be considered. 3) If the target is more specified than the substitute, it is probably a normal process, but if [sonorant] is affected, it is a less common or unusual process. 4) If the specified (manner/root) features of the substitute form a subset of the specified (manner/root) features of the target, it is a normal substitution.

\subsection{Feature Geometry Trees}

Normal processes generally involve lower level place features rather than root node features, although there are exceptions to this generalization. The first is with stopping in which [continuant] is affected. The other is liquid gliding in which [consonantal] is affected. These processes reveal a shared pattern. In the stopping process $/ \mathrm{s} / \rightarrow[\mathrm{t}]$, no place of articulation is specified for in the target or substitute because both are articulated at the unspecified coronal default place. The same is also true for the 
gliding process which involves $/ \mathrm{r} / \rightarrow[\mathrm{w}]$. In the other stopping process, $/ \mathrm{d} / \rightarrow[\mathrm{d}]$, the target place of articulation is specified as cor:[+distributed], and the substitute place of articulation is specified as [labial]. The same pattern of specification is true also for the gliding process $/ \mathrm{r} / \rightarrow[\mathrm{w}]$. From this information we can see that when the higher nodes [continuant] or [consonantal] are affected, lower nodes which are specified are also affected. This implies some kind of dependency relationship between the higher and lower nodes. For example, in the $/ \mathrm{s} / \rightarrow[\mathrm{t}]$ substitution, a higher node, [continuant] is affected, and the process is normal because no lower nodes are specified, yet unaffected by the substitution. In the $/ \delta / \rightarrow$ [d] substitution, a higher node [continuant] is affected, and the target specified lower node cor:[+distributed] is also affected. The substitute place of articulation [labial] which is specified is also affected. A very similar case exists for the gliding substitutions. So, for normal processes, when a lower node is specified and a higher node, such as [continuant], is affected, lower nodes will also be affected.

To provide further evidence for the dependency relationship between higher and lower nodes, we can look at the less common and unusual processes. Among less common processes, there is no substitution in which higher nodes are affected without also affecting specified lower nodes. In the liquid stopping substitution $/ r / \rightarrow[d]$, the [sonorant] and [voice] features are affected, and the place node cor:[+distributed] which is specified in the target is also affected. The other two less common substitutions, $/ \mathrm{l} / \rightarrow[\mathrm{d}]$ and $/ \mathrm{s} / \rightarrow[\mathrm{l}]$ all involve targets and substitutes which are unspecified for place of articulation. So even though higher nodes are affected, the substitutions do not leave 
lower nodes intact while affecting higher nodes, following the pattern for normal processes.

In unusual processes, we can see several examples in which specified lower level features remain unaffected in the substitution (that is, the same feature is specified in both target and substitute) while higher nodes are affected. Some examples are frication of approximants, $/ \mathrm{w} / \rightarrow[\mathrm{v}]$, stopping glides $/ \mathrm{w} / \rightarrow[\mathrm{b}]$, gliding fricatives $/ \mathrm{f} / \rightarrow[\mathrm{w}]$, and frication of stops $/ \mathrm{b} / \rightarrow[\mathrm{v}]$. In all of these substitutions, both target and substitute are specified for place of articulation [labial] which remains untouched, while higher nodes such as [consonantal], [continuant], [voice] and [sonorant] are affected.

These examples show the nature of the dependency relationship between higher and lower features. They also show that if the normal dependency relationship is violated, a less common or unusual process occurs. If higher nodes are affected and all specified lower nodes are also affected, then the substitution is a normal one. If a higher node is affected while lower nodes which are specified are not affected, then the substitution is not normal; it is either less common or unusual.

Less common and unusual processes often involve the root feature [sonorant], whereas normal processes never involve this feature. Thus, if a process affects [sonorant], it should be considered either less common or unusual. There is no easily discernible relationship between less common or unusual processes and the way that [sonorant] is affected. In both types of processes there are cases in which [sonorant] is specified in the target but not the substitute. $/ / / \rightarrow$ d] is an example of a less common process which fits this pattern, and $/ \mathrm{w} / \rightarrow[\mathrm{v}]$ is an example of an unusual process. There 
are also cases in which the target is not specified for [sonorant], but the substitute is, as in $/ \mathrm{s} / \rightarrow[1]$ for less common, and $/ \mathrm{f} / \rightarrow[\mathrm{w}]$ for unusual. There are two unusual processes in which [sonorant] is not specified in either target or substitute, frication of stops $/ \mathrm{b} / \rightarrow[\mathrm{v}]$, and backing $/ \mathrm{k} / \rightarrow[\mathrm{t}]$. There is no less common or unusual process in which [sonorant] is specified in both target and substitute. Thus, we can conclude that any process which affects [sonorant] is either less common or unusual. We can also say that there are no normal processes which show that [sonorant] is affected. Combining feature counting with affected [sonorant] feature may give a better picture in distinguishing less common from unusual substitutions.

It is possible to differentiate less common from unusual processes. Less common processes have equally specified targets and substitutes or a target which is more specified than the substitute. The root node [sonorant] is affected in all these substitutions, making them different from normal processes. To distinguish them from unusual processes, we can look at unusual and less common processes that are not accounted for by using only the feature counting method. If we have a less common substitution in which target and substitute are equally specified, and an unusual substitution in which target and substitute are equally specified, we can identify the less common one because only part of the root node is affected, not the entire root node (the root node is considered to be both [consonantal] and [sonorant]). Less common processes affect one of these features, but unusual processes seem to affect both. For example, in the less common process gliding of fricatives, /s/ and [1] are equally 
specified. Only [sonorant] is affected in the substitution. For the unusual process stopping glides $/ \mathrm{j} / \rightarrow[\mathrm{t}]$, both [consonantal] and [sonorant] are affected.

For substitutions that involved the same number of specified features in the target and the substitute, examining the root node for [sonorant] can distinguish between normal and less common or unusual processes. As we saw earlier $/ \theta / \rightarrow[\mathrm{f}]$ is a normal process in which the same number of features is specified in the target and the substitute. In this substitution, [sonorant] is not affected. There are two less common substitutions which show that the same number of features are specified in the target and substitute, $/ \mathrm{s} / \rightarrow[1]$ and $/ \mathrm{l} / \rightarrow[\mathrm{d}]$. In both of these substitutions, [sonorant] is affected. For the unusual process $/ j / \rightarrow[t]$, target and substitute are specified for only one feature, and [sonorant] is affected. Thus, looking at the status of the [sonorant] feature (the root node) can distinguish between normal and other processes when underspecification cannot make the distinction.

\subsection{Markedness}

Although normal processes involve lower nodes in general, and unusual or less common processes involve higher nodes, there are exceptions to this. The unusual process backing $/ \mathrm{t} / \mathrm{k}]$ involves only the lower level feature [dorsal], and the gliding substitution of $/ 1 / \rightarrow[j]$ affects only a root feature [consonantal]. The unusual process affects only a lower node, and the normal process affects only a higher node, contrary to expectation. If one looked only at the tree representation without considering markedness 
or number of specified features, it would not be clear that the backing process is unusual or that the gliding process is normal.

From underspecification we see that the target $/ t /$ is specified only for [consonantal], but the substitute is specified for [consonantal] and [dorsal]. In other words, the substitute is specified for more features than the target, and the specified features include a low level (more marked) feature, [dorsal]. In terms of markedness, the specification of [dorsal] is more marked than an unspecified place, which is [+coronal]. For the gliding process we see that the target and the substitute are both unspecified for place of articulation, so no lower level nodes are affected. This follows the pattern for normal substitutions identified from the feature geometry discussion. Also, $/ \mathrm{l} / \mathrm{is}$ a more specified segment than [j], and the specified features of [i] are a subset of the features specified in $/ 1 /$, which indicates a normal process. Since $/ 1 /$ is specified for more features than [j], and the features specified in [j] are also specified in $/ \mathrm{l}$, we can say that $/ 1 /$ is more marked than [j]. This example shows how normal substitutions involve more marked segments becoming less marked substitutes if only underspecification is considered, and if the root node consists of [sonorant] and [consonantal] located at the same level. Moving [sonorant] to a slightly higher level would also resolve this problem by identifying $/ 1 /$ as more marked than [j] on the basis of the hierarchy.

Markedness is most useful in differentiating which processes are normal or less common from those that are unusual. The general pattern for normal and less common substitutions is that more marked targets become less marked substitutes, even when target and substitute are equally specified. 
In the less common process stopping of $/ \mathrm{r} / \rightarrow[\mathrm{d}]$, feature counting indicates that $/ \mathrm{r} /$ is specified for more features than [d]. This shows that the less common process can also follow the same pattern for markedness as normal substitutions. The difference is that the substitution affects [sonorant], and this is not a trait of normal substitutions. Another less common process, $/ 1 / \rightarrow[\mathrm{d}]$, shows equally specified target and substitute. We cannot say that the segments are equally marked, however. $/ 1 /$ is specified for [consonantal] and [sonorant], whereas [d] is specified for [consonantal] and [voice]. Specification of [consonantal, sonorant] is more marked than [consonantal, voice]. Although it is not clear from feature counting or feature geometry analysis, markedness shows that this substitution also follows that pattern of normal processes with more marked segments becoming less marked. Another less common substitute $/ \mathrm{s} / \rightarrow[1]$ shows that although the segments are equally specified, [1] is specified for [sonorant] while $/ \mathrm{s} /$ is not. Thus, a less marked target is becoming a more marked substitute. Less common substitutions show cases of more marked targets becoming less marked substitutes, and more marked targets becoming less marked, though not less specified, substitutes.

Unusual processes show that less specified and less marked targets become more marked and more specified targets. In the case of an equally specified target and substitute, or a more specified target, markedness cannot be easily determined. For example, in the $/ \mathrm{j} / \rightarrow[\mathrm{t}]$ substitution, both segments are equally specified for one feature. However, $/ \mathrm{j} /$ is specified for [sonorant] and [t] is specified for [consonantal]. It is difficult to determine which is more marked in this case. The same situation occurs in 
another exception, $/ \mathrm{f} / \rightarrow[\mathrm{w}]$. If the segments are considered in isolation, [w] is less marked than /f7, yet this is an unusual process because [sonorant] is affected.

Although markedness cannot give a full account for normal and other substitutions, there are some general patterns that apply. Normal processes show more marked targets becoming less marked substitutes, and this is reflected through underśpecification and feature geometry models. Less common processes show more marked targets becoming less marked substitutes, even when the segments are equally specified. Unusual processes show less marked targets becoming more marked substitutes. By using both feature counting and a feature hierarchy to determine markedness, more accuracy in identifying less common and unusual processes is achieved.

\subsection{Developing a Metric}

It is the goal of this thesis to determine if a metric for distinguishing between normal and unusual substitutions can be developed using feature geometry and radical underspecification. By compiling the generalizations observed in the data analysis, I have developed a metric which accounts for the data studied in this thesis. Of course, it needs to be applied to many more substitutions to see if it is a valid form of assessment.

From the cases we have discussed above, we can make some generalizations which show that feature geometry and underspecification can account for normal, less common and unusual processes. A list of these generalizations can serve as a metric for analysis of substitutions. This metric serves mainly to distinguish between normal and unusual processes; however, less common processes can also be identified. 
1. If the target is specified for less features than the substitute, it is an unusual substitution and not a normal or less common substitution.

2. If the root node feature [sonorant] is affected, it is a less common or unusual substitution.

3. If the target is specified for more features than the substitute and the root node (manner) features specified in the substitute form a subset of the root node (manner) target features, it is a normal substitution, not less common or unusual.

4. If lower (place) and higher (manner) features are specified and both levels of features are affected, it is a normal substitution. If lower and higher features are specified, but only higher ones are affected, it is an unusual substitution.

5. If only lower level (place) features are affected in a geometry model, underspecification information must be considered. If a marked segment becomes less marked, it is a normal substitution. If a less marked or unmarked segment becomes more marked, it is an unusual substitution.

6. If feature counting does not reveal whether a substitution is less common or unusual, but [sonorant] is affected, then the feature geometry models can distinguish between unusual and less common. Unusual substitutions of this type (target more specified than or as specified as the substitute) show [sonorant] and [consonant] being affected; that is, the entire root node is affected, and less common substitutions show that only part of the root node, [sonorant] is affected. 


\subsection{Data from Normal Phonological Development}

In the literature review chapter, we saw that normally developing children employ phonological processes to simplify adult forms. Looking at these processes in the framework of feature geometry and underspecification may give further information about the location of features in the hierarchy and about the ability of underspecification and feature geometry to distinguish between processes which disappear early and those which persist later.

Stoel-Gammon and Grunwell both outline normal processes which persist longer than other normal processes (see tables 4 and 5). I will consider only some of the normal processes which have been examined here. These include processes disappearing by $3 ; 0$, velar fronting, and processes persisting after 3;0, gliding, stopping, and depalatalization. Grunwell (1987) makes a finer distinction among the types of processes. Stopping of $/ \delta / \rightarrow[\mathrm{d}]$ persists much longer than stopping of $/ \mathrm{s} /$. Gliding $/ \mathrm{r} / \rightarrow[\mathrm{w}]$ is a very late persisting process among many children. Velar fronting disappears relatively early, about the same time as stopping of $/ \mathrm{s} /$ is suppressed, but fronting of $/ \mathrm{J} /$ to $[\mathrm{s}]$ persists relatively late. In order to see if underspecification and feature geometry can help explain these phenomena, I will examine these processes in greater detail.

\section{Stopping:}

$/ \mathrm{s} / \rightarrow[\mathrm{t}]$ is specified for only two features in the target and one in the substitute. In neither the target nor the substitute is the place of articulation specified for. Only root features are specified in both the target and the substitute. 
$. / \delta / \rightarrow[d]$ This substitution involves a target which is specified for four features being reduced to a substitute with only two specified features. The place cor[+distributed] is specified for in the target. Root features and place node features are specified in the target, but only root features are specified in the substitute.

\section{Fronting:}

Velar Fronting: $/ \mathrm{k} / \rightarrow[\mathrm{t}]$ - The target is specified for two features and the substitute is specified for only one. The target is specified for place of articulation [dorsal], in addition to the root feature [consonantal]. The substitute is specified only for the root feature.

Depalatalization: $/ \delta / \rightarrow[\mathrm{s}]$ - The target is specified for three features, and the substitute is specified for two. The target is specified for a coronal place of articulation cor:[-anterior], and the substitute is not specified for place of articulation. The root features specified in the target and substitute are the same.

\section{Gliding:}

$/ \mathrm{l} / \rightarrow[\mathrm{j}]$ - The target is specified for two features and the substitute is specified for one. Neither the target nor the substitute is specified for place of articulation.

$/ \mathrm{r} / \rightarrow[\mathrm{w}]$ The target is specified for three features, and the substitute for two. Two root features are specified in $/ \mathrm{r} /$ ([sonorant, consonantal]), but only one [sonorant] is specified for [w]. Also, the target is specified for a coronal place of articulation, cor:[+distributed], and the substitute is specified for [labial] as place of articulation. 
In all three of these cases, it seems that processes which disappear earlier involve targets that are specified for fewer features overall than targets in processes which persist later. $/ \mathrm{s} / \rightarrow[\mathrm{t}], / \mathrm{k} \rightarrow[\mathrm{t}]$ and $/ \mathrm{V} \rightarrow[\mathrm{j}]$ all involve targets specified for two features being substituted by segments specified for one feature. Only fronting involves a target which is specified for place of articulation.

Persisting processes involve targets which are specified for more features than processes which disappear earlier. Targets of persisting processes are specified for three features as compared to the earlier processes in which targets were specified for two features. Persisting processes have targets which are specified for a place of articulation at the coronal node. This seems to be the factor that separates processes which disappear early from those which persist later. Substitutions involving targets which are either not specified for place, or targets which are specified for a non-coronal place disappear earlier than processes that involve a target that is specified for a coronal place. With reference to the feature geometry trees, persisting processes are those that involve more lower nodes.

From this information we can conclude that processes involving targets which are specified for a greater number of features will persist longer than processes in which fewer target features are specified. We can also conclude that processes involving targets which are specified for coronal place features will persist longer than processes with targets which are either unspecified for place or are specified for non-coronal place features. This shows us that place features that are specified for coronal are acquired later by children, and should therefore be placed lowest on the tree. The unspecified coronal 
node is acquired earlier than other place nodes, but specified coronal node [anterior] or [distributed] is acquired later than other place nodes ([labial] or [dorsal]). The feature geometry tree should have some method of indicating this special relationship.

\subsection{Relationship of Findings to Other Studies}

We saw in the literature review chapter that studies have been done to test feature geometry models for their ability to account for phonological development and disorders. Chin and Dinnsen (1991) found that feature geometry models accounted for unusual substitutions better than standard rules and processes. The findings of this study seem to support their conclusions. However, the model used by Chin and Dinnsen is not structured the same as the models I examined. In their model, proposed by Sagey, the root node does not contain the feature [sonorant]. I found that in ability to account for normal versus other processes, having [sonorant] as part of the root node gives explanatory power to the tree models. Chin and Dinnsen conclude from their study that large category descriptions (place, manner, voice) and distinctive features are reconciled in feature geometry models. My study agrees with their findings. Generalizations about place and manner of articulation are possible while discussing individual features.

Beers (1996) found that a feature geometry model could account for normal phonological development, and that abnormal development patterns were ones which could not be accounted for by the model. My finding is similar, that normal processes involve expected patterns, but unusual processes involve patterns which are different from the normal patterns. Normal processes involve targets which are specified for more, especially lower level, features being replaced by substitutes that are specified for less, 
and generally not higher level features. Unusual substitutions deviate from this pattern. Unlike Beers, I found that the feature geometry models alone could not fully account for normal, less common and unusual substitutions. The most useful guideline provided by the geometry models is that when [sonorant] is affected, the substitution is not normal. In this way, the tree serves to distinguish between normal and other processes.

Bernhardt (1992) and Bernhardt and Gilbert (1992) used hierarchies and underspecification to establish treatment plans for phonological intervention. A benefit of using a hierarchy was the ability of the model to incorporate markedness. The ability of the models to account for markedness was also an important factor in my study. If [sonorant] is a higher feature than [consonantal], as I propose earlier in the discussion, and lower features are more marked than higher ones, then this accounts for markedness in the unusual substitution, $/ \mathrm{j} / \rightarrow[\mathrm{t}]$. According to this model, $/ \mathrm{j} /$ would be less marked than [t]. The substitution of the more marked target for the less marked one follows the overall pattern for unusual substitutions. For the $/ f / \rightarrow[w]$ substitution, both target and substitute are specified for [labial], which is the lowest level, and thus the most marked. Both segments are equally marked for place, so the pattern of normal substitutions is violated.

The information of which processes persist longer in normal child language seemed to confirm Bernhardt and Gilbert's statement that lower features are learned later than higher node features. Additionally, from underspecification, the default features seem to be acquired earlier than other features. Combining information we can gather from underspecification, and thus, markedness, with feature geometry seems to be a 
productive method for at least assessing phonological problems. This idea is very much in line with the findings of Bernhardt (1992) and Bernhardt and Gilbert (1992).

In their tutorial (1994) on application of nonlinear phonology, Bernhardt and Stoel-Gammon propose that the hierarchical representation should be emphasized over rules and processes. From my study, I found that processes can be explained by feature geometry models and underspecification. By using feature geometries rather than rules and processes to explain substitution processes, a much more precise method of description and explanation is achieved.

It would be important to consider the Rice and Avery model for its ability to differentiate between normal and unusual processes. Ideally, one model of feature geometry would be able to account for general patterns of development, individual variation, and provide a tool for differentiating between normal patterns of development and patterns that represent disorders. According to Ingram (1996), the Rice and Avery model does account for individual variation and general patterns of development, so further testing with information from disordered phonologies is warranted.

Another model that requires future study is the Keyser and Stevens (1994) articulatory- and acoustically-oriented model of feature geometry. A model which accounts for articulatory-based and acoustically-based data is desirable since it incorporates the relationship between phonetics and phonology.

This assessment of the models seemed to support recent discussions and studies in application of feature geometry to phonological development and intervention. Further testing of the models should continue to develop the power of the models in explaining 
characteristics of normal and unusual phonological development. Feature geometry is a useful extension of syllable-based plans for remediation since the syllable and segment levels are related under autosegmental phonology. Underspecification provided the ability to make finer distinctions among processes in the analysis of the data I studied. Without information from underspecification, the geometry models would have been insufficient to account for the data.

Although no one model seemed to best capture the differences between normal, less common and unusual processes, I was able to draw certain conclusions about the organization of a model. In developing a definitive model of feature geometry, it is important to consider a wide range of data that reflects the gamut of normal and unusual patterns and substitutions. For example, substitutions resulting from contextual influences, e.g. assimilatory processes, should be evaluated against the feature geometry and underspecification models. Since feature geometry models are thought to be universal, cross-linguistic data from a variety of from both normally developing and phonologically disordered children would also have to be examined to see if the models are as accountable for other languages as they are for English. Phonological disorders which involve nonnative language sounds should also be examined against the models. Since radical underspecification treats only phonemes of a given language, a method of treating substitutions that involve an allophone needs to be developed. For example, alveolar stop/glottal stop alternations need to be examined to see if underspecification can treat them, and to see if the feature geometry models can classify the substitution. 


\subsection{Redefining the Tree Structure}

Since all less common and unusual substitutions involve [sonorant], I would give it a higher position in the root node than [consonantal]. Child language data also confirms this decision as sonorant sounds are more common among children than consonants. I would include [consonantal] at the root node, although in doing so, it means that the root node is affected even for a normal process, gliding. The ClementsHume root node may help solve this problem if only [sonorant] and [approximant] were included in the root, and [vocoid] were located at a lower node. Drawing from the relationships between lower and higher level features in normal processes, it is reasonable to say that a process which affects [continuant] is not necessarily unusual. For this reason, I would exclude [continuant] from the root node and follow the Clements and Hume model in which [continuant] is located at a lower node. The feature still needs to dominate lower level place features, however, to reflect the dependency relationship that exists between [continuant] and lower level features. I would also indicate the relationship that exists between features at the place node. Features under the coronal node [anterior] and [distributed] seem to be acquired later and more marked than other place features [labial] or [dorsal]. I would modify the tree structure to indicate this relationship by having [anterior] and [distributed] located below the other place features. Again, this would resemble the Clements-Hume model in which [labial] and [dorsal] are specified, but the lower features [round], [high], [low] and [back] are not, leaving [anterior] and [distributed] as the lowest place features. The Sagey model, though not analyzed here, also reflects the coronal features as lower than other place features. 


\section{Conclusion}

A feature geometry based tool for phonological assessment would be invaluable to speech therapists. Feature Geometry has already been found useful in remediation (Bernhardt 1992, Bernhardt \& Gilbert 1992), so it should be developed to provide an assessment tool. Accurate assessment of phonological problems with a feature geometry tool could lead to more principled remediation.

The geometry models of segment representation correspond to the other levels of nonlinear phonology, so incorporating this in clinical phonology would be a step toward linking information from the feature level all the way to the segmental, syllable and prosodic levels. Ingram (1996) suggests that influence of syllable position must be considered in the study of children's acquisition of features. There is also evidence that phonological accuracy is linked to prosody, e.g. that stressed syllables are produced more accurately than unstressed syllables. Thus, linking the segmental and prosodic tiers is useful, and could provide information on language development beyond the segmental level.

Further developing feature geometry models and identifying the exact nature of the root node and the hierarchy would account for normal patterns of development as well as for disordered patterns. Greater knowledge of the nature of normal development has implications for many areas of language, not only developmental disorders. Applications may exist for brain-injury patients and language learners. Insight into the nature of phonological development could also provide information on development of 
metalinguistic awareness and literacy skills. There is no shortage of applications for a reliable model of feature geometry.

Feature geometry and radical underspecification were found to be successful in differentiating among the normal, less common and unusual processes examined in this thesis, and as a result, I was able to develop a metric to account for the substitutions I studied. It would be necessary to continue to apply the metric to other examples of substitutions in order to see if the findings hold for all child substitutions. Future proposals should ideally account for data from languages other than English. Many of the substitutions I studied also occur in other languages such as Swedish, Turkish and Spanish (Yavas, in preparation); however, further testing would need to be done to see if the metric for differentiating between normal and disordered phonologies could apply cross-linguistically. Initially, at least, it seems that there is hope for finding a principled way to account for the differences between normal and disordered phonologies. 


\section{LIST OF REFERENCES}

Archangeli, D. 1988. "Aspects of Underspecification Theory." Phonology 5: 183207.

Beers, M. 1996. "Acquisition of Dutch Phonological Contrasts within the Framework of Feature Geometry Theory." In B. Bernhardt, J. Gilbert and D. Ingram, (eds) Proceedings of the UBC International Conference on Phonological Acquisition. Cascadilla Press.

Bernhardt, B. 1992. Application of Nonlinear Phonological Theory to Intervention with One Phonologically Disordered Child." Clinical Linguistics and Phonetics. Vol. 6, No. 4: 283-316.

Bernhardt, B. and Gilbert, J. 1992. "Applying Linguistic Theory to Speech-Language Pathology: the Case for Nonlinear Phonology." Journal of Speech and Hearing Research, Vol. 6, Nos 1 \& 2: 123-145.

Bernhardt, B. and Stoel-Gammon, C. 1994. "Nonlinear Phonology: Introduction and Clinical Application." Journal of Speech and Hearing Research, Vol. 37: 123143.

Chin, S. and Dinnsen, D. 1991. "Feature Geometry in Disordered Phonologies." Clinical Linguistics \& Phonetics, Vol. 5, No. 4: 329-337.

Chomsky, N. and Halle, M. 1968. The Sound Pattern of English. New York: Harper \& Row.

Clements, G.N. and Hume, E.V. 1995. "The Internal Organization of Speech Sounds." In J. Goldsmith (ed) The Handbook of Phonological Theory. London: Blackwell. 244-306.

Edwards, M. L. 1997. "Historical Overview of Clinical Phonology." In B. Hodson and M.L. Edwards (eds) Perspectives in Applied Phonology. Gaithersburg, MD: Aspen . 1-14.

Goldsmith, J. 1995. "Phonological Theory." In J. Goldsmith (ed) The Handbook of Phonological Theory. London: Blackwell. 1-23.

Grunwell, P. 1987. Clinical Phonology, $2^{\text {nd }}$ Ed. Baltimore: Williams and Wilkins.

Halle, M. 1992. "Phonological Features." In W. Bright (ed) International encyclopedia of linguistics. New York: Oxford university Press. 207-212. 
Ingram, D. 1997. "The Categorization of Phonological Impairment." In B. Hodson and M.L. Edwards (eds) Perspectives in Applied Phonology. Gaithersburg, MD: Aspen . 19-38.

Ingram, D. 1996. "Some Observations on Feature Assignment." In B. Bernhardt, J. Gilbert and D. Ingram (eds) Proceedings of the UBC International Conference on Phonological Acquisition. :Cascadilla Press. 53-61.

Ingram, D. 1989. First Language Acquisition. Cambridge: Cambridge University Press.

Jakobson, R., Fant, C.G.M. and Halle, M. 1952. "Preliminaries to speech analysis, the distinctive features and their correlates. MIT Acoustics Lab Technical Report 13. Reprinted 1967. Cambridge, Mass: MIT Press.

Katamba, F. 1989. An Introduction to Phonology. Essex, England: Longman Group UK Limited.

Kenstowicz, M. 1994. Phonology in Generative Grammar. Cambridge, Massachusetts: Blackwell. 451-537.

Keyser, S.J. and Stevens, K.N. 1994. "Feature Geometry and the Vocal Tract." Phonology 11: 207-236.

Madiesson, I. 1984. Patterns of Sounds. Cambridge: Cambridge University Press.

McCarthy, J. 1988. "Feature Geometry and Dependency: A Review." Phonetica 43: 84108.

Rice, K. and Avery, P. 1995. "Variability in a Deterministic Model of Language Acquisition: A Theory of Segmental Elaboration." In J. Archibald (ed) Phonological Acquisition and Phonological Theory. Hillsdale, NJ: Lawrence Erlbaum Associates. 23-42.

Roca, I. 1994. Generative Phonology. New York: Routledge.

Sagey, E. 1986. "The Representation of Features and Relations in Nonlinear Phonology." PhD Dissertation. MIT.

Sander, E. 1972. "When are Speech Sounds Learned?" Journal of Speech and Hearing Disorders 37: 55-63. 
Schwartz, R. 1992. "Clinical Applications of Recent Advances in Phonological Theory." Language, Speech and Hearing Services in Schools. Vol. 23. 269-276.

Spencer, A. 1996. Phonology. Oxford, UK: Blackwell.

Stampe, D. 1969. "The Acquisition of Phonetic Representation." Papers from the Fifth Regional Meeting of the Chicago Linguistic Society. Chicago: Chicago Linguistic Society. 433-444.

Stoel-Gammon, C. and Dunn, C. 1985. Normal and Disordered Phonology in Children. Austin, TX: Pro-Ed.

Templin, M. 1957. "Certain Language Skills in Children: Their Development and Interrelationships." Institute of Child Welfare Monographs, Vol. 26. Minneapolis: University of Minnesota Press.

Yavas, M. In preparation. An Introduction to Phonology. Singular Publishing. 